\title{
Recent developments in enantioselective photocatalysis
}

\author{
Callum Prentice ${ }^{1}$, James Morrisson ${ }^{2}$, Andrew D. Smith ${ }^{* 1}$ and Eli Zysman-Colman ${ }^{* 1}$
}

\author{
Review \\ Address: \\ ${ }^{1}$ Organic Semiconductor Centre, EaStCHEM, School of Chemistry, \\ University of St Andrews, North Haugh, Fife, Scotland, KY16 9ST, \\ United Kingdom and ${ }^{2}$ Pharmaceutical Sciences, IMED Biotech Unit, \\ AstraZeneca, Macclesfield SK102NA, United Kingdom \\ Email: \\ Andrew D. Smith ${ }^{*}$ - ads10@st-andrews.ac.uk; Eli Zysman-Colman ${ }^{*}$ - \\ eli_journals@zysman-colman.com \\ * Corresponding author \\ Keywords: \\ enantioenrichment; enantionselective catalysis; enantioselective \\ photocatalysis; photocatalysis; photochemistry
}

Beilstein J. Org. Chem. 2020, 16, 2363-2441.

https://doi.org/10.3762/bjoc.16.197

Received: 20 July 2020

Accepted: 09 September 2020

Published: 29 September 2020

This article is part of the thematic issue "Advances in photoredox catalysis".

Guest Editor: T. Noël

(C) 2020 Prentice et al.; licensee Beilstein-Institut.

License and terms: see end of document.

\begin{abstract}
Enantioselective photocatalysis has rapidly grown into a powerful tool for synthetic chemists. This review describes the various strategies for creating enantioenriched products through merging enantioselective catalysis and photocatalysis, with a focus on the most recent developments and a particular interest in the proposed mechanisms for each. With the aim of understanding the scope of each strategy, to help guide and inspire further innovation in this field.
\end{abstract}

\section{Introduction}

Enantioselective catalysis has become a central focus for organic synthetic chemistry, particularly since the Nobel prize was awarded to Sharpless, Knowles, and Noyori for their pioneering work in the field. In the last 15 years, photocatalysis has become a transformative synthetic strategy, including in enantioselective synthesis. From the pioneering work by MacMillan [1] and Bach [2], enantioselective photocatalysis has grown into a well-established field of its own. A large proportion of photocatalysis focuses on photoredox catalysis, which involves single electron transfer (SET) steps photoinitiated using visible light as the energy source, often leading to the generation of radicals and subsequent reaction of these radicals with the ground-state substrates [3]. Energy transfer catalysis is another significant branch of photocatalysis, in which photocat- alysts (PCs) generate excited state substrates that can then undergo reactions that would be impossible in the ground state [4]. A challenge for enantioselective catalysis is stifling the racemic background reaction, which is generally achieved through a lower activation energy for the catalysed process relative to the non-catalysed. However, this is particularly difficult for enantioselective photocatalysis as the intermediates generated are highly reactive and activation energies are typically already low [5]. Even so, there are now a large number of reactions that have been developed that address these issues, with many different strategies and types of photocatalysts employed.

This review aims to cover the seminal work within enantioselective photocatalysis but with a focus on the most recent devel- 
opments. There have been a number of reviews on or closely related to this topic, so this review will not contain an exhaustive list of all enantioselective photocatalytic reactions; however, this review does aim to cover the different strategies that have been developed [5-16]. There is a subset of reactions that achieve asymmetry via a stepwise photochemical process followed by a separate enantioselective catalysis step that will not be covered in this review [17-19]. Examples using cage complexes or other supramolecular reagents also lie outside the scope of this review. As all enantioselective photocatalysis requires a secondary mode of catalysis to induce enantioselectivity, the review will be organized according to these strategies. Mechanistic understanding is vital to furthering development of any field of organic chemistry, so the mechanisms proposed by the authors are included for many examples, although the level of mechanistic investigation that accompanies them is varied. The nature of the light source and its wavelength $\left(\lambda_{\mathrm{exc}}\right)$ can have significant effects on the outcome of the reaction; therefore, this information is indicated in the reaction schemes when it is disclosed by the authors. As with many reviews on enantioselective reactions, the percentage chemical yield and enantioselectivity (all values converted to nearest per cent enantiomeric ratio (er) for clarity) will be the common data for comparison; however, where possible the quantum yields of the photochemical reactions will also be provided as this latter metric provides the most accurate quantifier of the efficiency of a photochemical process. The quantum yield $(\Phi)$ of a reaction is often used as a mechanistic tool to probe whether a chain reaction is active $(\Phi>1)$ or not $(\Phi<1)$, although it should be noted that a reaction with $\Phi<1$ could also still include a radical chain process with an inefficient initiation step (i.e., $\Phi_{\text {initiation }}<<1$ ) (Equation 1). A less common use of quantum yields by organic synthetic chemists is as a measure of how efficiently the reaction uses the light source. Considering photocatalysis is often purported as a green chemistry because it uses light, a more efficient use of light would result in a greener reaction.
a) $\Phi=\frac{\text { product formed }}{\text { photons absorbed }}$
b) $\Phi=\Phi_{\text {initiation }} \times$ chain lenght

where (a) is the definition of quantum yield and (b) is the quantum yield of a radical chain reaction.

\section{Review}

\section{Enantioselective photocatalysis}

\section{Amine catalysis}

Much of the history of amine catalysis used in photochemical reactions can be found in a review published by Zou and Bach [12], so the following are selected examples and recent develop- ments of the field. Amine catalysis can be broadly split into enamine and iminium catalysis, both of which have been utilised in combination with photocatalysis. The first example of enamine catalysis in combination with photoredox catalysis was reported by Nicewicz and MacMillan [1] for the alpha alkylation of aldehydes 1 with various alkyl bromides bearing an electron-withdrawing substituent $\mathbf{2}$, which while seemingly trivial, was not possible with enamine catalysis alone (Scheme 1). The proposed mechanism suggests a closed catalytic cycle is in operation; however, subsequent investigations by Yoon [20] found this reaction has a quantum yield $>1(\Phi=18)$, which signifies a chain propagation process is dominant. Therefore, according to Yoon's proposed mechanism, the reaction proceeds with the condensation of $\mathbf{1}$ with amine catalyst $\mathbf{3}$ to give enamine intermediate 4 . The initiation step is proposed to be a reductive quench of the photocatalyst using $\mathbf{4}$ as a sacrificial reductant to give $[\mathrm{Ru}]^{\bullet-}$, which can then reduce $\mathbf{2}$ to give electrophilic radical $2^{\bullet}$. Addition of $\mathbf{2}^{\circ}$ to another molecule of $\mathbf{4}$ generates $\alpha$-amino radical $\mathbf{5}^{\circ}$, which (depending on the EWG) can either reduce another molecule of $\mathbf{2}$ via a SET process or via an atom transfer (AT) process and propagate the chain reaction [21]. The SET route directly generates $\mathbf{2}^{\circ}$ and iminium ion intermediate $\mathbf{6}$, but the AT goes through alkyl bromide 7 , before generating 6. Hydrolysis of 6 furnishes the desired $\alpha$-functionalised aldehydes $\mathbf{8}$ in excellent yields and enantioselectivities (12 examples, up to $>99: 1$ er). Further work on this system expanded the scope to ketones [22] instead of aldehydes and varied the electron-withdrawing group to include fluorinated alkyl groups [23], electron-deficient arenes [24], and nitriles [25]. Additionally, Cozzi recently applied a novel aluminiumbased photocatalyst 9 to this reaction, as an earth-abundant metal alternative albeit with slightly reduced enantioselectivities (8 examples, up to $96: 4$ er) [26]. Interestingly, as with some other photocatalysts used for this reaction, it is proposed the excited state of $\mathbf{9}$ is sufficiently reducing to initiate the chain mechanism through an oxidative quench.

Moving away from electronically activated halides, MacMillan et al. investigated a tricatalytic system, utilising enamine, photoredox, and HAT (hydrogen atom transfer) catalysis to allow the use of alkenes as the alkylating agent either in an intermolecular process using aldehydes $\mathbf{1 0}$ and alkenes $\mathbf{1 1}$ or intramolecularly using aldehydes 12 (Scheme 2) [27]. The proposed mechanism again proceeds via the formation of an enamine intermediate $\mathbf{1 3}$ that then reductively quenches the photocatalyst to form enaminyl radical $\mathbf{1 3}^{\mathbf{*}}$. However, in this reaction $\mathbf{1 3}^{\mathbf{*}}$ can then add to the alkene to give an alkyl radical $\mathbf{1 4}^{\mathbf{*}}$, followed by hydrogen atom abstraction from the thiol, acting as a HAT catalyst, to give iminium ion intermediate $\mathbf{1 5}$. Hydrolysis of $\mathbf{1 5}$ generates the desired $\alpha$-functionalised aldehydes $\mathbf{1 6}$ (14 examples up to 97:3 er) or cyclization products $\mathbf{1 7}$ 


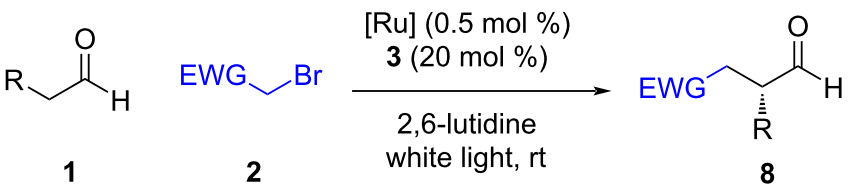

$$
\begin{aligned}
& \Phi=18
\end{aligned}
$$

EWG $=$ acyl (12 examples, up to $93 \%$ yield, $>99: 1 \mathrm{er}$ ) fluoro alkyl (19 examples up to $89 \%$ yield, $>99: 1 \mathrm{er}$ ) electron-poor aryl (16 examples, up to $91 \%$ yield, $97: 3 \mathrm{er}$ ) nitrile (18 examples, up to $97 \%$ yield, $99: 1 \mathrm{er}$ )

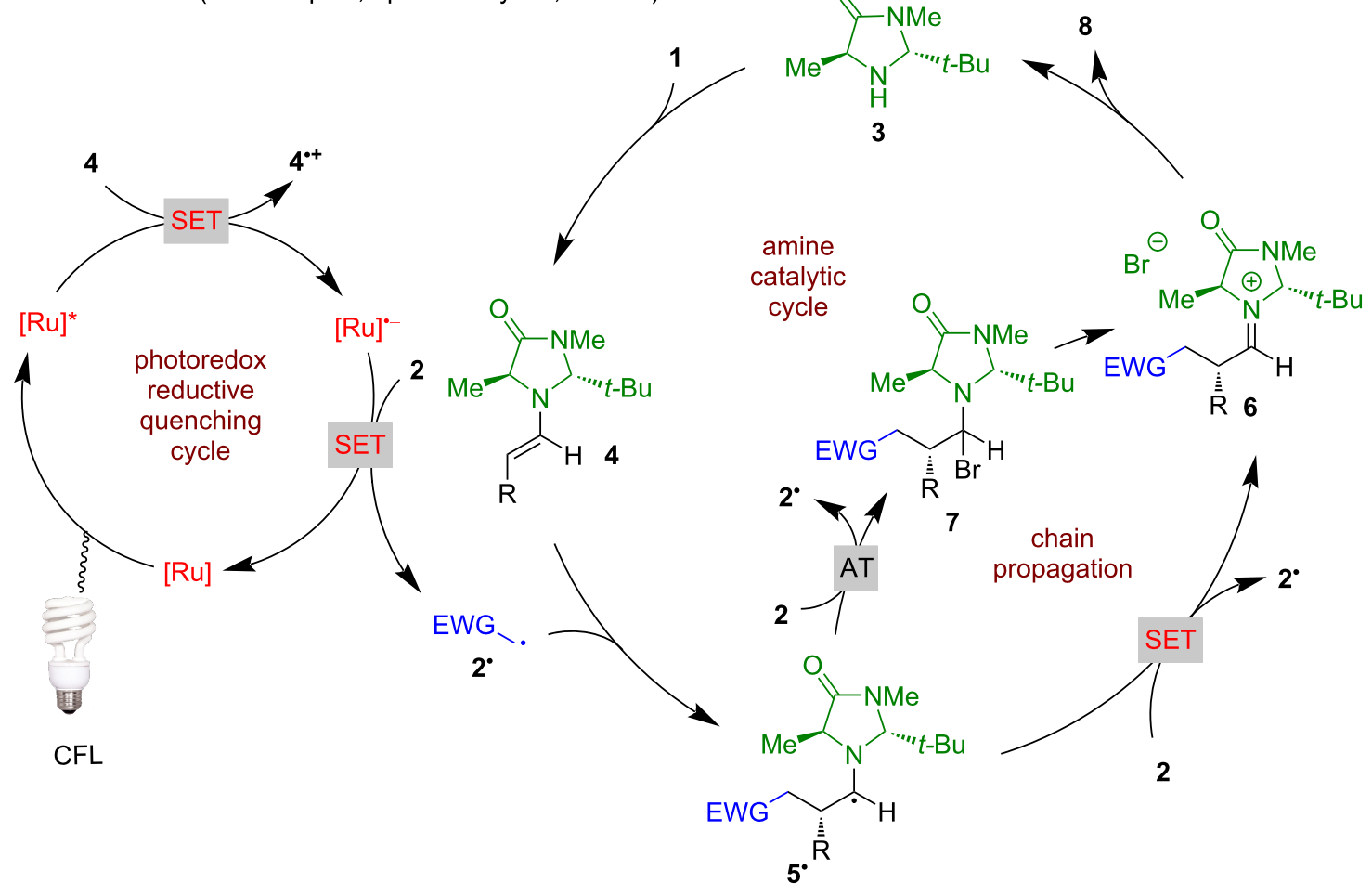

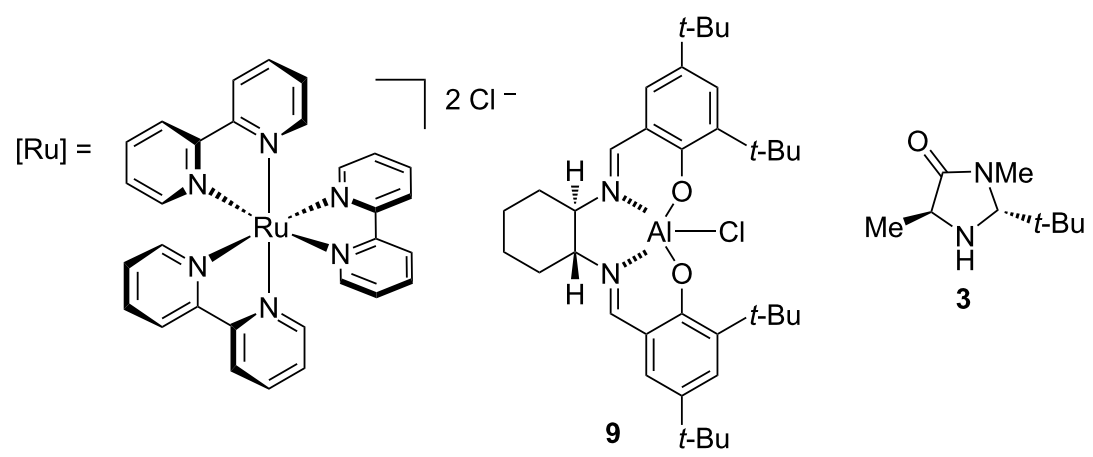

Scheme 1: Amine/photoredox-catalysed $\alpha$-alkylation of aldehydes with alkyl bromides bearing electron-withdrawing groups.

(15 examples up to 98:2 er) in excellent yields and enantioselectivities. A SET process between thiyl radical $\mathbf{1 8}^{\circ}$ and $[\mathrm{Ir}]^{\mathbf{0}^{-}}$is proposed to complete both catalytic cycles.

Another tricatalytic system developed by Tung et al. merged photoredox, cobalt, and amine catalysis towards the synthesis of $\alpha$-functionalised ketones $\mathbf{2 1}$ from tetrahydroisoquinolines
(THIQs) 22 and ketones 23 (Scheme 3) [28]. The proposed mechanism involves an oxidative quenching cycle using the $\left[\mathrm{Co}^{\mathrm{III}}\right]$ catalyst to generate $\left[\mathrm{Co}^{\mathrm{II}}\right]$ and $[\mathrm{Ru}]^{\circ+}$, with the latter oxidising 22 to give radical cation $\mathbf{2 2}^{\mathbf{*}}$ and turn over the photocatalytic cycle. The radical cation $\mathbf{2 2}^{\mathbf{}+}$ is then proposed to participate in a two-step electron and proton exchange process with $\left[\mathrm{Co}^{\mathrm{II}}\right]$ to give $\left[\mathrm{H}-\mathrm{Co}^{\mathrm{III}}\right]$ and iminium ion 24 , likely via a 


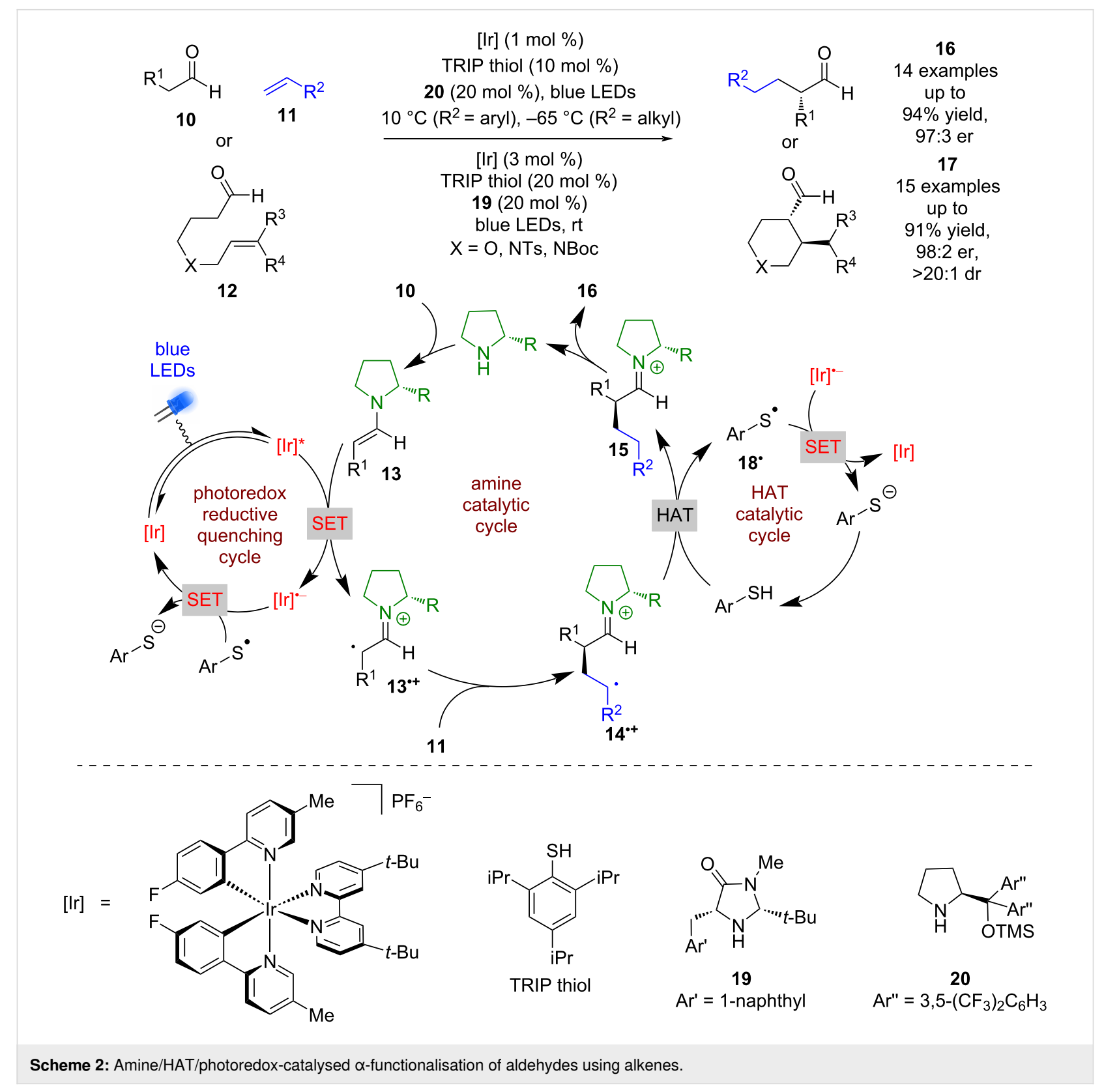

$\left[\mathrm{Co}^{\mathrm{I}}\right]$ intermediate. $\left[\mathrm{H}-\mathrm{Co}^{\mathrm{III}}\right]$ can then reduce 3 -nitrobenzoic acid to the corresponding aniline $\mathbf{2 5}$ to turn over the cobalt cycle. Simultaneously, $\mathbf{2 3}$ condenses with the chiral primary amine catalyst $\mathbf{2 6}$ to give enamine intermediate $\mathbf{2 7}$, which can be intercepted by $\mathbf{2 4}$ to generate imine intermediate $\mathbf{2 8}$, which is finally hydrolysed to turn over the amine catalytic cycle and releases the desired products $\mathbf{2 1}$ in excellent yields and enantioselectivities ( 35 examples, up to $>99: 1$ er). Notably, if $\mathbf{2 3}$ is acyclic the product enantioselectivities are poorer (2 examples up to $87: 13$ er).

A similar reaction was later reported by Guan et al. using ketones 29 with 2 -substituted indoles $\mathbf{3 0}$ as a precursor to imine 31, for the synthesis of indolin-3-ones 32 in good yields and excellent enantioselectivities (21 examples, up to $>99: 1$ er) (Scheme 4a) [29]. Zhang et al. recently added to the scope of this family of reactions with their use of aldehydes/ketones $\mathbf{3 3}$ with glycine derivatives $\mathbf{3 4}$ to synthesise the corresponding products 35 in good yields and excellent enantioselectivities (35 examples, up to 99:1 er) (Scheme 4b) [30].

The previous examples of enamine/photoredox catalysis have all required two or more separate catalysts. Currently, three different approaches have been developed that use a single catalyst. Alemán et al.'s approach combines the two catalytic motifs into a single bifunctional catalyst $\mathbf{3 8}$, using thioxanthone as the 

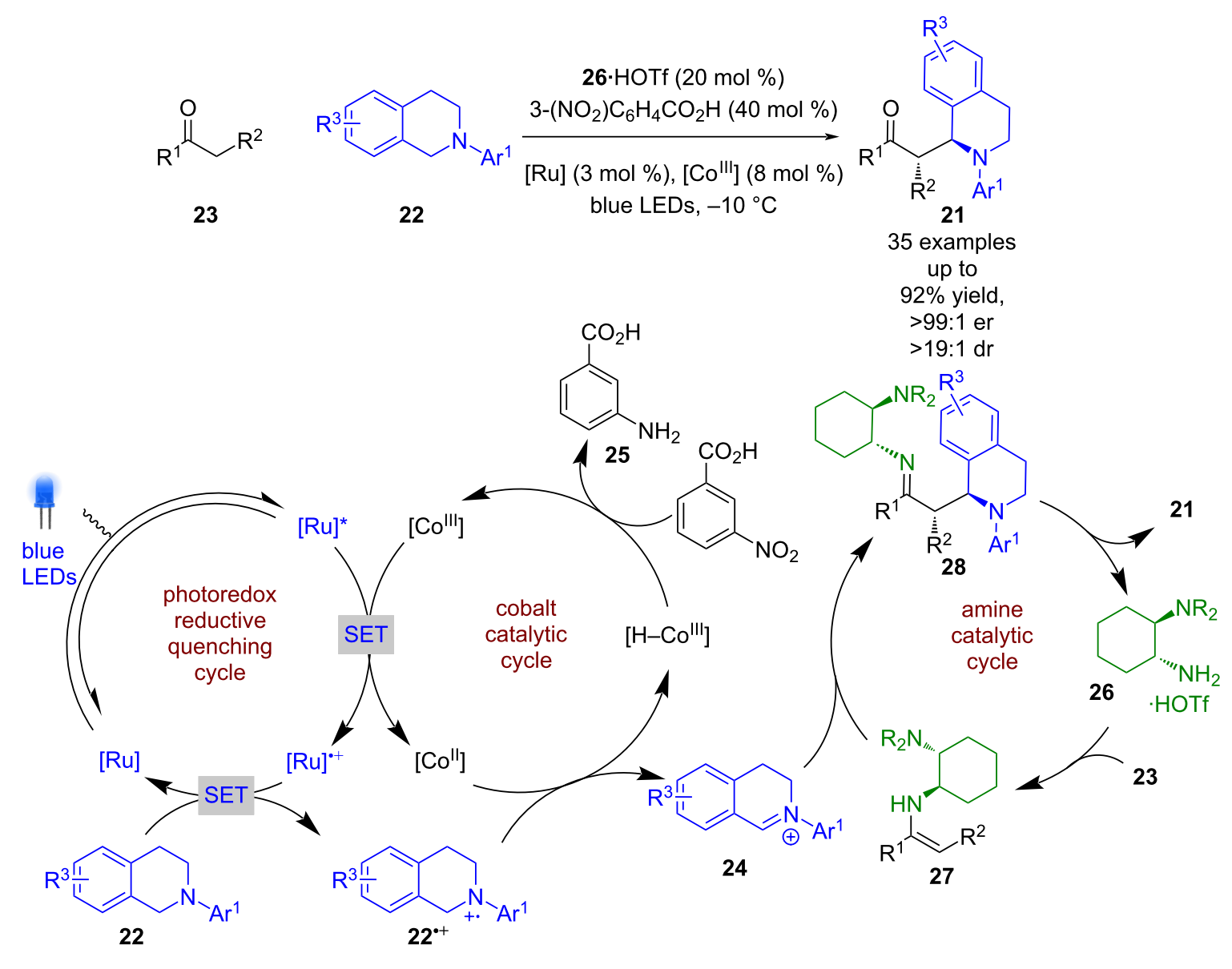

up to

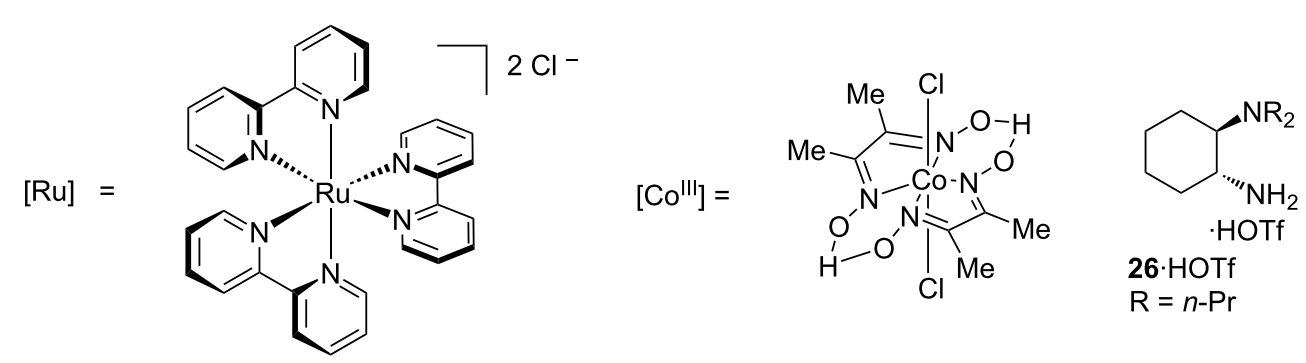

Scheme 3: Amine/cobalt/photoredox-catalysed $\alpha$-functionalisation of ketones and THIQs.

chromophore (Scheme 5) [31]. The catalyst $\mathbf{3 8}$ was then applied to known reactions such as the $\alpha$-functionalization of aldehydes and gave excellent yields and enantioselectivities (13 examples, up to $>99: 1$ er).

Another approach that used a single catalyst was developed by Melchiorre et al., where they discovered that a conventional photocatalyst was not necessary to achieve similar transformations (Scheme 6) [32,33]. When an alkylating agent containing an aryl ring 40 (e.g., phenacyl/benzyl bromides) is used, the enamine intermediate $\mathbf{4 1}$ forms a coloured electron-donor acceptor (EDA) complex that can absorb visible light via an intermolecu- lar charge-transfer state (EDA route) [14,34]. Mechanistic investigations [21] showed that after excitation of the EDA complex, the electrophilic radical $\mathbf{4 0}^{\circ}$ that is formed enters the same chain propagation cycle as in Scheme 1, whereas the radical cation $\mathbf{4 1}^{\circ+}$ is proposed to be unstable and decomposes. The third approach, also developed by Melchiorre et al., was based on their observation of similar reactivity when using bromomalonates $\mathbf{4 2}$ as substrates (direct excitation route) [35]. As no aryl ring is present, no EDA complex is formed, and thus direct excitation of the photoactive enamine intermediate affords an excited state enamine $41 *$ that can reduce $\mathbf{4 2}$ to initiate the chain reaction that produces the desired products 43 and 44 in 
a<smiles>[R]CC([R])=O</smiles>

29<smiles>[Al]c1cc2cc[nH+]cc2[nH]1</smiles>

30

b<smiles>[R]CC([R7])=O</smiles>

33
[Ru] (3 mol \%), 36 (40 mol \%) 2,6-lutidine (4.0 equiv)

$\mathrm{O}_{2}$, rt, blue LEDs<smiles></smiles>

[Ru] (2 mol \%), 37 (20 mol \%) $\mathrm{Cu}(\mathrm{OAc})_{2}(5 \mathrm{~mol} \%)$

air, rt, blue LEDs<smiles></smiles>

32

21 examples

up to

$86 \%$ yield,

$>99: 1 \mathrm{er}$

$>20: 1 \mathrm{dr}$

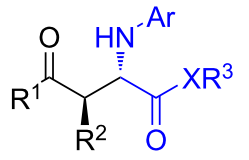

35

35 examples up to

$84 \%$ yield,

99:1 er

$>99: 1 \mathrm{dr}$

Scheme 4: Amine/photoredox-catalysed $\alpha$-functionalisation of aldehydes or ketones with imines. (a) Using ketones with 2-substituted indoles. (b) Using ketones or aldehydes with glycine derivatives.

$$
\overbrace{\mathrm{H}}^{\mathrm{O}} \mathrm{EWG} \mathrm{Br}
$$<smiles>[R]C(C=O)C([R])C[Na]</smiles>

39

13 examples

up to

$99 \%$ yield,

$>99: 1$ er

$t-\mathrm{Bu}$<smiles>CN1C(=O)[C@H](Cl)N[C@H]1c1ccc2sc3ccccc3c(=O)c2c1</smiles>

38

Scheme 5: Bifunctional amine/photoredox-catalysed enantioselective $\alpha$-functionalisation of aldehydes.

excellent yields and enantioselectivities (15 examples, up to 97:3 er and 12 examples, up to 97:3 er, respectively). Subsequent progress using this methodology expanded the scope to the use of $\alpha$-iodo sulfones $\mathbf{4 5}$, which is proposed to proceed via the excited-state enamine [36].
While there is an abundance of known photoredox reactions that generate iminium ions catalytically either as a side product [37], or for further transformations [38], the use of iminium ions generated by chiral amines in combination with photoredox catalysts has been less explored. The first example was de- 


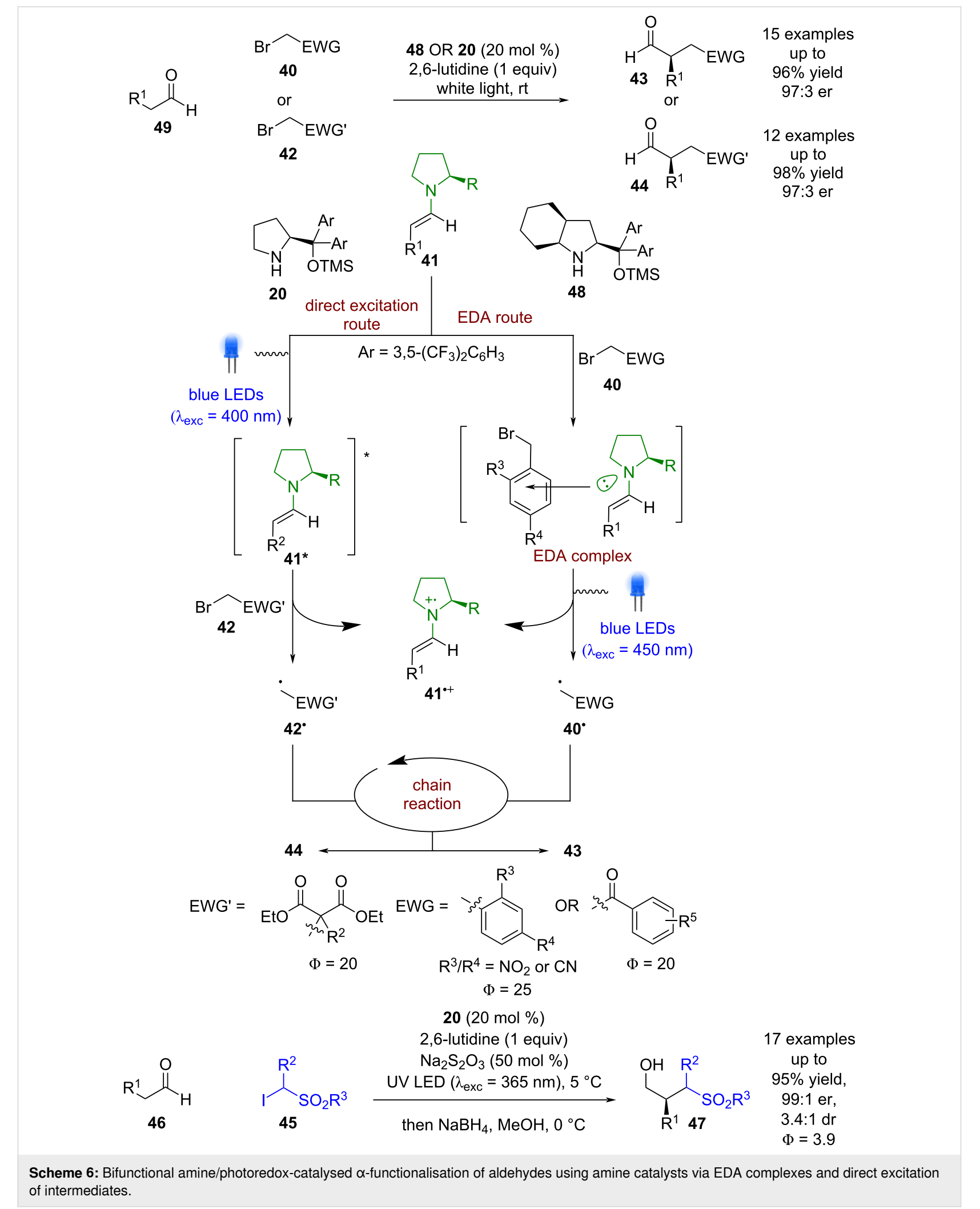

veloped by Melchiorre et al. using a unique secondary amine catalyst containing a carbazole group 49 in combination with either tetrabutylammonium decatungstate $($ TBADT $=[\mathrm{W}])$ or an iridium-based photocatalyst (Scheme 7a) [39]. The proposed mechanism begins with the condensation of $\mathbf{4 9}$ with enone $\mathbf{5 0}$ to form the iminium ion intermediate 51. Concomitantly, the 
a<smiles>[R]C1=CC(=O)CCN1</smiles>

50<smiles>[R]C1([R])Oc2ccccc2O1</smiles>
or $\mathrm{R}^{3}$<smiles>CNc1ccccc1</smiles>
UV LED $\left(\lambda_{\text {exc }}=365 \mathrm{~nm}\right)$, benzoic acid $(40 \mathrm{~mol} \%)$ $(n-\mathrm{Bu})_{4} \mathrm{NBF}_{4}\left(1.0\right.$ equiv), $35^{\circ} \mathrm{C}$

$49(20 \mathrm{~mol} \%), \mathrm{PC}=[\mathrm{Ir}](1 \mathrm{~mol} \%)$ white LEDs, benzoic acid ( $40 \mathrm{~mol} \%)$ $15{ }^{\circ} \mathrm{C}$

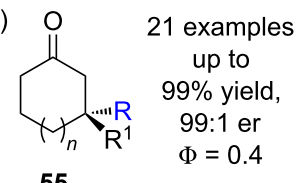

55

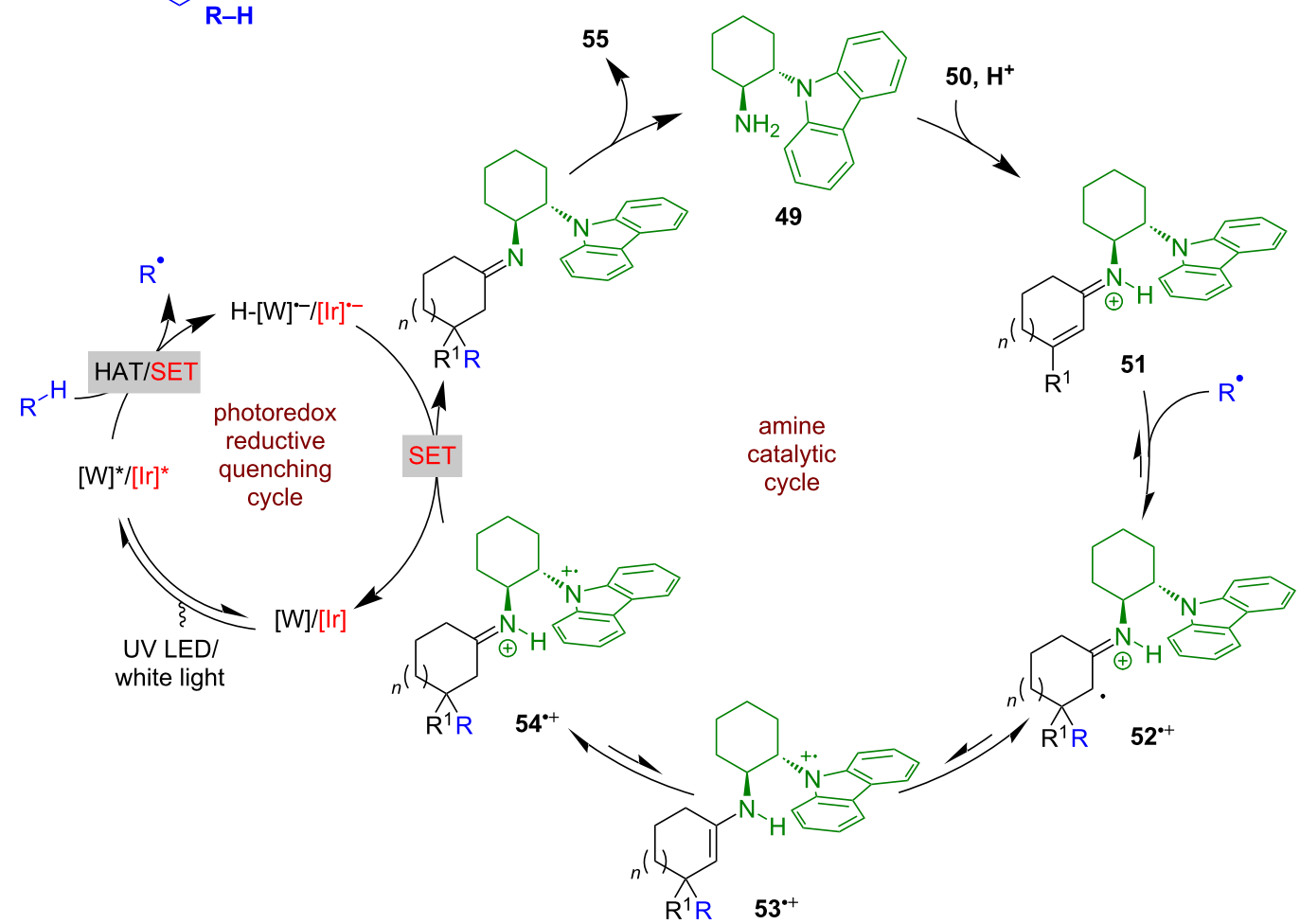

b

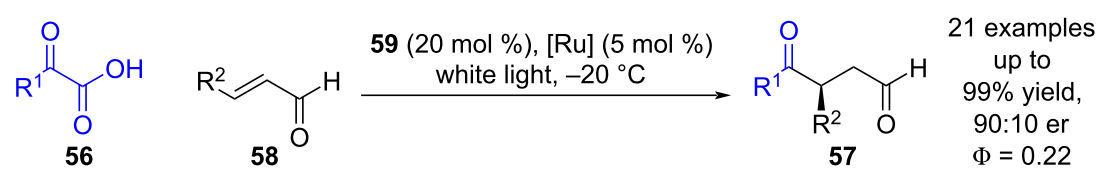

$[\operatorname{lr}]=$

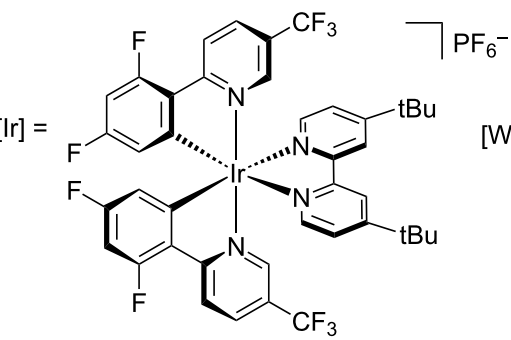

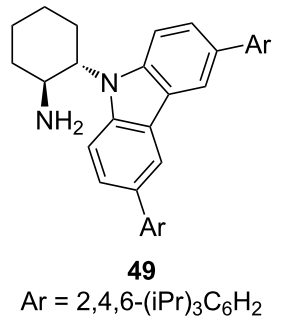

$[\mathrm{Ru}]=$

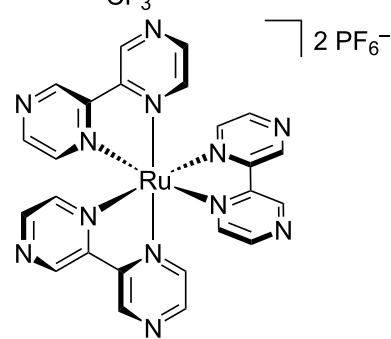

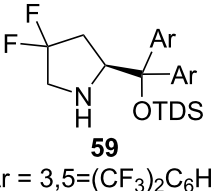<smiles>CC(C)C(C)(C)[Si](C)(C)[Mg]</smiles>

Scheme 7: Amine/photoredox-catalysed RCA of iminium ion intermediates. (a) Synthesis of quaternary stereocentres using benzodioxole derivatives or tertiary amines. (b) Synthesis of 1,4-dicarbonyls using carboxylic acids. 
excited-state photocatalyst generates an alkyl radical $\mathrm{R}^{\bullet}$ from $\mathrm{R}-\mathrm{H}$, either through HAT ([W] with a benzodioxole derivative) or SET ([Ir] with a tertiary amine). This radical then adds to the $\beta$-position of the iminium ion generating an unstable iminyl radical $\mathbf{5 2}^{\mathbf{}}$ that is quickly quenched by the nearby carbazole to form a more stable carbazole centred radical $\mathbf{5 3}^{\mathbf{*}}$. Rapid tautomerisation to imine $\mathbf{5 4}^{\mathbf{*}}$ precludes the undesired back electron transfer. Single electron reduction of $\mathbf{5 4}^{\mathbf{}}{ }^{+}$by $\mathrm{PC}^{\mathbf{*}}$ and hydrolysis provides the radical conjugate addition (RCA) products 55 with a quaternary stereocentre in excellent yields and enantioselectivities (21 examples, up to 99:1 er). The quantum yield was measured to be $<1(\Phi=0.4)$ for the iridium-catalysed reaction, suggesting that a radical chain process is not dominant. Subsequent investigations by $\mathrm{Yu}$ expanded the scope to acyl radicals generated from carboxylic acids 56, affording enantioenriched 1,4-carbonyls 57 in excellent yields and good enantioselectivities (21 examples, up to 90:10 er) (Scheme 7b) [40]. The quantum yield was also measured to be $<1(\Phi=0.22)$, so a chain mechanism is likewise unlikely.

Interestingly, Melchiorre later found that with $\alpha$-amino silanes 60, no photocatalyst was required (Scheme 8) [41]. This was proposed to be due to the formation of an intramolecular EDA complex, which upon excitation can form cation $\mathbf{6 1}^{+}$that can subsequently oxidise $\mathbf{6 0}$ to give a nucleophilic radical $\mathrm{R}^{\bullet}$ that enters a similar RCA cycle as for Scheme 7. However, in the absence of an external photocatalyst, radical cation intermediate $62^{\circ+}$ is reduced by another molecule of 60 , thus propagating a radical chain mechanism that leads to the formation of ketones $\mathbf{6 3}$ in good yields and excellent enantioselectivities<smiles>[SiH2]Cn1c2ccccc2c2ccccc21</smiles>

60 $\mathrm{R}-$ Si<smiles>[R]C1=CC(=O)CC[Y]1O</smiles>
65<smiles>[R1]c1ccc2c(c1)c1ccccc1n2CC1([R2])CC(=O)CC[Y]1([H])OC#N</smiles>

63

27 examples

up to

$95 \%$ yield

98:2 er

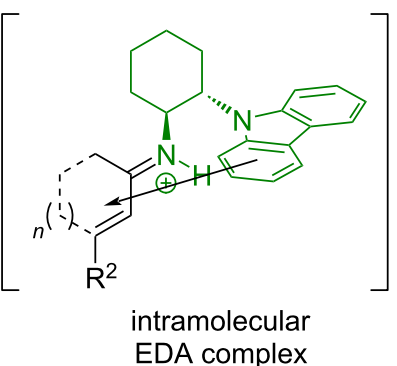

EDA complex
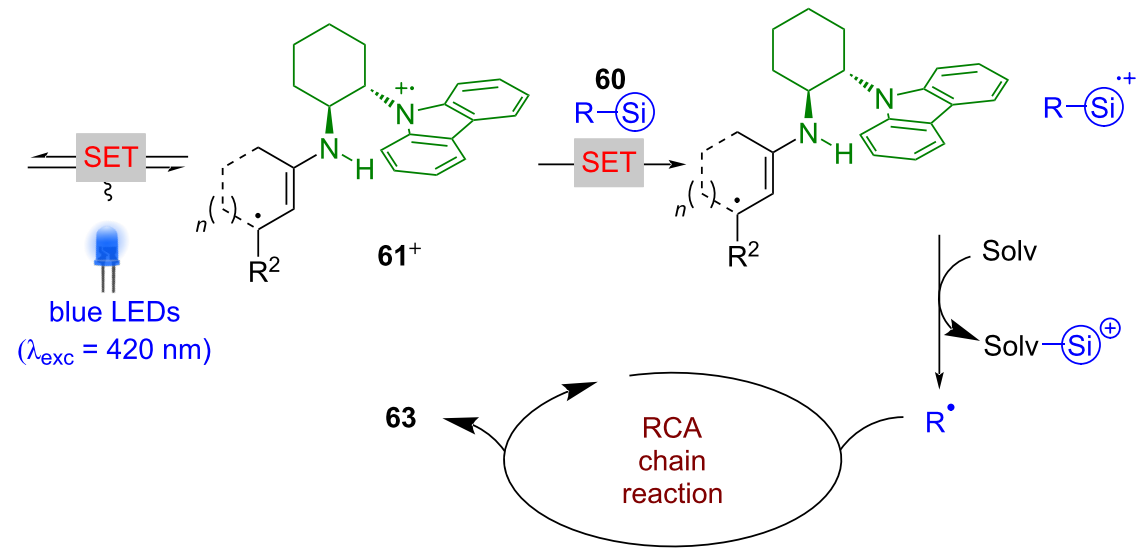

63<smiles>CCC(C)CC</smiles>

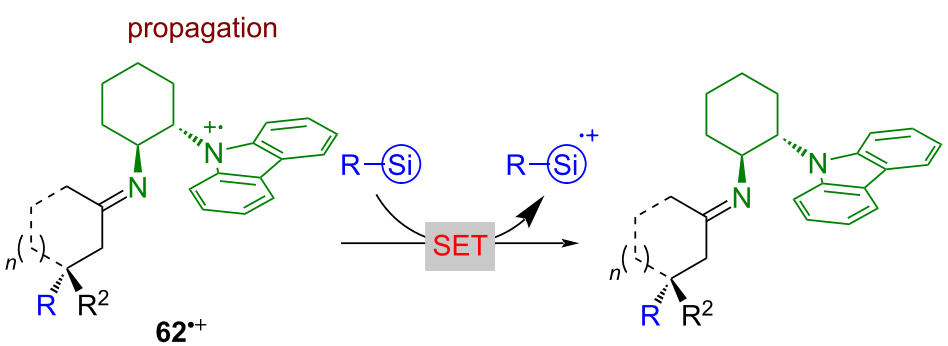

$62^{\circ+}$

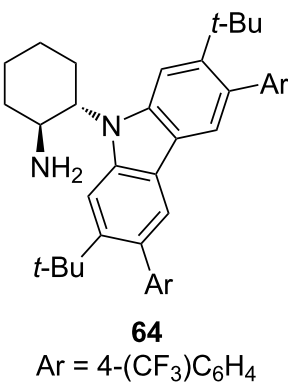

Scheme 8: Bifunctional amine/photoredox-catalysed RCA of enones in a radical chain reaction initiated by an intramolecular EDA complex. 
(27 examples, up to $98: 2$ er). The authors were unable to measure the quantum yield in this case due to difficulties with the high-power LED that is typically required.
As with the enamine intermediates, Melchiorre et al. also demonstrated that iminium ions $\mathbf{6 6}$ can be excited directly without formation of an EDA complex (Scheme 9a) [42]. The a<smiles>O=CC=CC=[18O]</smiles>

74<smiles></smiles>

67

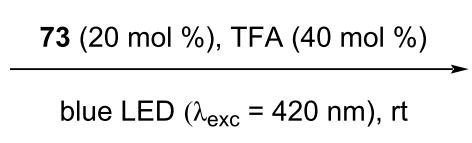

blue LED $\left(\lambda_{\mathrm{exc}}=420 \mathrm{~nm}\right)$, rt

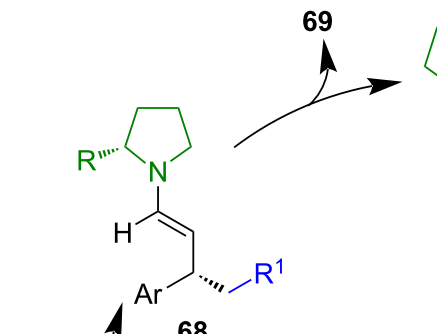

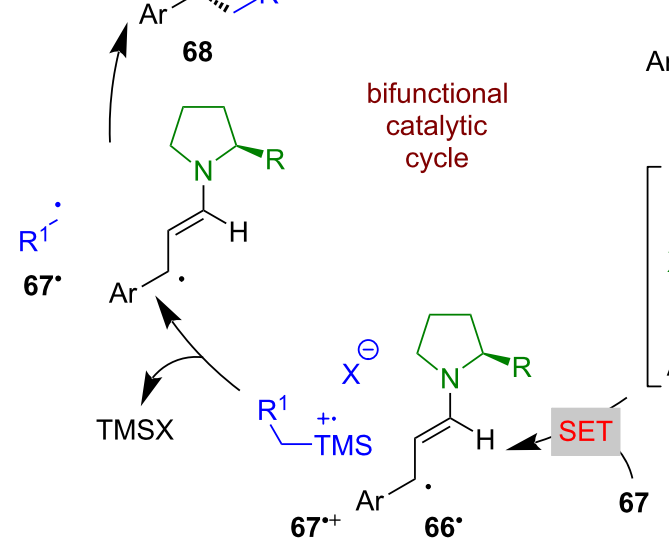

\section{7 examples up to $93 \%$ yield 97:3 er $\Phi=0.05$}

b<smiles>O=C/C=C/Br</smiles>

74<smiles>[R]C([R])C</smiles>

70
$59(20 \mathrm{~mol} \%), \mathrm{Zn}(\mathrm{OTf})_{2}(40 \mathrm{~mol} \%)$ blue LED $\left(\lambda_{\text {exc }}=420 \mathrm{~nm}\right), 35^{\circ} \mathrm{C}$<smiles>[R]C([Al])[C@H]([Al])CC(=O)[O-]</smiles>

71 c<smiles>[13CH2]/C=C/C=O</smiles>

74<smiles>[Y]CCOC(=O)C1=C(C)CC(C)=C(C(=O)OCC)C1[R1]</smiles>

72

$R^{2}=$ alkyl, $X=420, Y=10$

$=$ acyl, $X=460, Y=15$

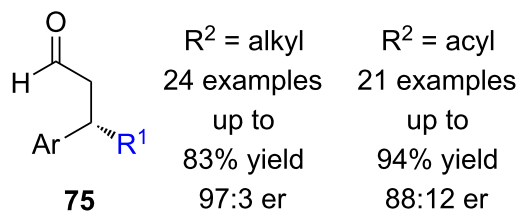

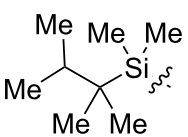

TDS<smiles>[O+2]OC(c1cc(C(F)(F)F)cc(C(F)(F)F)c1)(c1cc(C(F)(F)F)cc(C(F)(F)F)c1)[C@H]1CC(F)(F)CN1</smiles>

59<smiles>[X]c1cc([X])cc(C([O+])(c2cc([X])cc([X])c2)C2CC(F)(F)CN2)c1</smiles><smiles>[X]C(F)(F)C(F)(F)F</smiles>

Scheme 9: Bifunctional amine/photoredox-catalysed RCA reactions of iminium ions with different radical precursors. (a) Silanes. (b) Toluene derivatives. (c) Alkyl and acyl DHP derivatives. 
excited state iminium ion 66* can oxidise silanes 67 via a SET process to give radical cation $67^{\circ+}$ and alkyl radical $66^{\circ}$. Loss of the TMS group generates alkyl radicals $67^{\circ}$ that can couple with $\mathbf{6 6}^{\circ}$ enantioselectively to give enamine intermediate $\mathbf{6 8}$, which after hydrolysis completes the catalytic cycle and releases the desired RCA products 69 in good yields and enantioselectivities (27 examples, up to 97:3 er). The quantum yield was determined to be $<1(\Phi=0.05)$ so a chain reaction is unlikely to be dominant. This reactivity was later extended to the use of toluene derivatives $\mathbf{7 0}$ to generate the corresponding RCA products 71 in good yields and enantioselectivities (31 examples, up to 96:4 er) (Scheme 9b) [43]. Melchiorre et al. also discovered that dihydropyridine (DHP) derivatives $\mathbf{7 2}$ could act as efficient radical precursors in this system, allowing for both alkyl [44] and acyl [45] RCA reactions. In the case of acyl DHPs, they propose that direct excitation of the DHP leads to radical generation rather than the iminium intermediate (Scheme 9c).

The same system was used for the radical cascade reaction between carboxylic acid/alcohol $\mathbf{7 6}$ and enal 77 (Scheme 10a) [46]. Analogously to the mechanism outlined in Scheme 9, it was proposed that formation of excited state iminium ion $66^{*}$ is used to oxidise 76 to give radical cation $\mathbf{7 6}^{\circ+}$ and alkyl radical $\mathbf{6 6}^{\circ}$. Nucleophilic addition from the carboxylic acid or alcohol gives neutral radical $\mathbf{7 6}^{\circ}$, which couples enantioselectively with $\mathbf{6 6}^{\circ}$ to give enamine intermediate 78 . Subsequent condensation releases the photocatalyst and the desired products $\mathbf{7 9}$ in good yields and excellent enantioselectivities (16 examples, up to 99:1 er). Recently, this process was extended to allenes $\mathbf{8 0}$ to give complex bicyclic products $\mathbf{8 1}$ in moderate yields and good enantioselectivities (20 examples, up to 92:8 er) (Scheme 9b) [47].

The Bach group recently developed an enantioselective synthesis of cyclobutane 82 from enal 83 and diene 84 (Scheme 11a) [48]. Most of the examples proceed via a stepwise approach with preformation of the corresponding iminium ion $\mathbf{8 5}$. The only catalytic example achieves the same transformation by generating 85 in situ but has reduced yields and enantioselectivities (82:18 er vs 92:8 er for stepwise). Alemán et al. reported that a similar reaction could proceed catalytically and with a broad scope using amine catalyst $\mathbf{8 6}$ with enones 87 and alkenes $\mathbf{8 8}$ without the need for an external photocatalyst (Scheme 11b) [49]. The mechanism proposed by Alemán begins with the condensation of $\mathbf{8 6}$ with $\mathbf{8 7}$ to generate iminium ion $\mathbf{8 9}$, which has a suitably low energy charge transfer state that can be photoexcited to generate singlet intermediate 89*. Subsequent enantioselective photocycloaddition with $\mathbf{8 8}$ via diradical $\mathbf{9 0}$ gives iminium ion intermediate $\mathbf{9 1}$, which after hydrolysis affords the desired cyclobutane products $\mathbf{9 2}$ in excellent yields and good enantioselectivities (17 examples, up to 91:9 er). Bach proposes for their reaction that an external ruthenium photocatalyst generates the triplet excited state iminium ion through an energy transfer process, which is also observed by Alemán when using an external transition metal-based sensitiser.

Tertiary amine catalysts such as $\beta$-isocupreidine ( $\beta$-ICD) have found limited use in combination with photoredox catalysis, likely due to their tendency to oxidise to form iminium ions. However, Jiang et al. have developed a process using acrolein (94) in the presence of tetrahydro- $\beta$-carbolines (THCs) 95 or THIQs 96 and a dicyanopyrazine-derived (DPZ) photocatalyst (Scheme 12) [50]. They propose that addition of $\beta$-ICD to acrolein is assisted by $\mathrm{NaBArF}$ to give a zwitterionic intermediate $\mathbf{9 7}$, which is then intercepted by the photocatalytically generated iminium ion $\mathbf{9 8}$, followed by loss of $\beta$-ICD to give enantioenriched products $\mathbf{9 9}$ or $\mathbf{1 0 0}$ in good yields and enantioselectivities (21 examples for THCs, up to 98:2 er and 10 examples for THIQs, up to 98:2 er).

\section{$\mathrm{N}$-Heterocyclic carbene catalysis}

$\mathrm{N}-\mathrm{Heterocyclic}$ carbene (NHC) catalysis was first used in combination with photoredox catalysis by Rovis in 2012. They showed that iminium ions $\mathbf{1 0 1}$ could be generated in an oxidative quenching cycle from THIQs 102 using a ruthenium-based photocatalyst and 1,3-dinitrobenzene (DNB) as a sacrificial oxidant (Scheme 13) [51]. These iminium ions could then be intercepted by a Breslow intermediate $\mathbf{1 0 3}$, formed between aldehydes 104 and the NHC catalyst 105, to generate intermediate 106, which can then turn over the NHC and release the desired acylated products $\mathbf{1 0 7}$ in good yields and enantioselectivities (13 examples, up to $96: 4$ er).

There has been little development of enantioselective reactions using NHCs in photocatalysis since this work. Another example was reported by Rovis in 2013 using enal 108 in the presence of chiral NHC 109 to form extended Breslow intermediate 110 (Scheme 14) [52]. Photoisomerisation of $\mathbf{1 1 0}$ is then required for the following spirocyclisation reaction to intermediate $\mathbf{1 1 1}$ to proceed, which then releases the NHC catalyst and intermediate $\mathbf{1 1 2}$ for the synthesis of (-)-cephalimysin A in moderate yield and excellent enantioselectivity (98:2 er). Interestingly, there have been multiple reports of racemic reactions that combine photoredox and NHC catalysis [53-56], but few enantioselective examples, suggesting there is much progress yet to be made.

\section{Brønsted acid catalysis}

Using chiral amines and NHCs as catalysts to generate asymmetry relies upon the formation of covalently bonded intermediates such as enamines, iminium ions or Breslow intermediates within the catalytic cycle. The first example of merging non- 
<smiles>CC=CC=O</smiles>

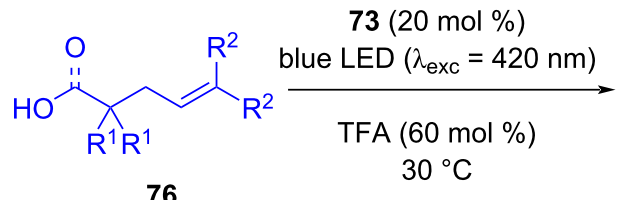

76<smiles>[R]CC1CC([R17]([R])([H])[H])[C@H]([R])O1</smiles><smiles>[R]C1CCCN1</smiles><smiles>CC1CC1C</smiles><smiles>CCC1CCCN1</smiles>
$77, \mathrm{H}^{+}$<smiles>C1CCCCC1</smiles><smiles>[Y][CH][CH]</smiles>

77

b<smiles>[R1]C([R])=CC([R])C([R])C(=O)O</smiles>

80

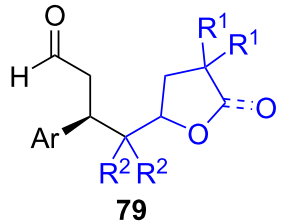

79 16 examples up to $75 \%$ yield 99:1 er 1.3:1 dr

$59(20 \mathrm{~mol} \%)$ blue LED $\left(\lambda_{\text {exc }}=420 \mathrm{~nm}\right)$

$\mathrm{Zn}(\mathrm{OTf})_{2}(25 \mathrm{~mol} \%)$ $35^{\circ} \mathrm{C}$

then

$\mathrm{BF}_{3} \cdot \mathrm{OEt}_{2}$ (2.5 equiv)

2,6-lutidine

(if $\mathrm{R}^{3} \neq \mathrm{H}$ )

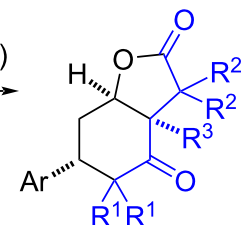

81

20 examples up to $59 \%$ yield 92:8 er $>19: 1 \mathrm{dr}$<smiles>[X]c1cc([X])cc(C(O[Na])(c2cc([X])cc([X])c2)C2CC(F)(F)CN2)c1</smiles>

73<smiles>[13CH3]OC(c1cc(C(F)(F)F)cc(C(F)(F)F)c1)(c1cc(C(F)(F)F)cc(C(F)(F)F)c1)[C@H]1CC(F)(F)CN1</smiles>

59

$$
\mathrm{X}={\stackrel{\mathrm{F}}{3}-\mathrm{F}_{3} \mathrm{C}}_{\mathrm{CF}_{3}}^{\mathrm{F}}
$$


a<smiles>O=C/C=C/c1ccccc1</smiles>

83<smiles>C=C(C)C(=O)OCC</smiles>

84

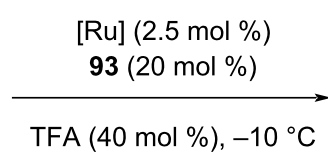

blue light $\left(\lambda_{\text {exc }}=458 \mathrm{~nm}\right)$

blue light $\left(\lambda_{\text {exc }}=458\right.$ nm $)$

via b

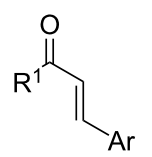

87<smiles>[R]C(=C)CCCC</smiles>

88

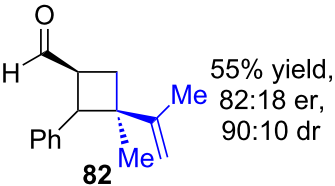

82

82:18 er,
$90: 10 \mathrm{dr}$

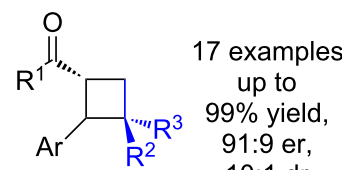

92

blue $\operatorname{LED}\left(\lambda_{\text {exc }}=450 \mathrm{~nm}\right)$<smiles>Clc1cccc2ccccc12</smiles><smiles>CCc1cccc2ccccc12</smiles>

$\mathrm{X}^{\ominus} \stackrel{\oplus}{\mathrm{HN}} \stackrel{\mathrm{NH}}{3}^{\ominus} \mathrm{x}^{\ominus}$ blue LEDs
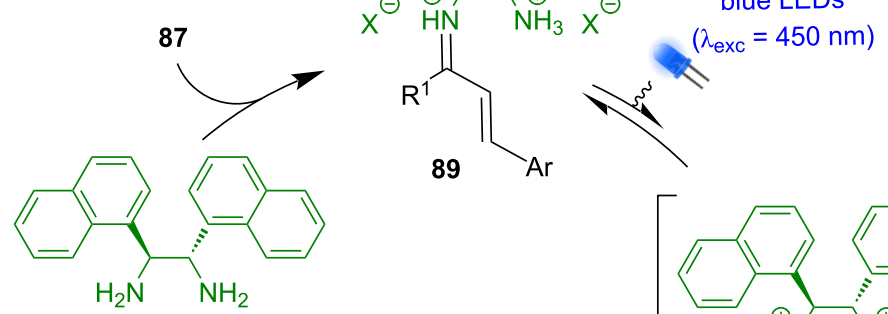

89

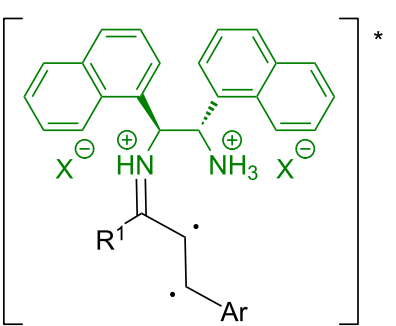

924

bifunctional

amine

catalytic

cycle

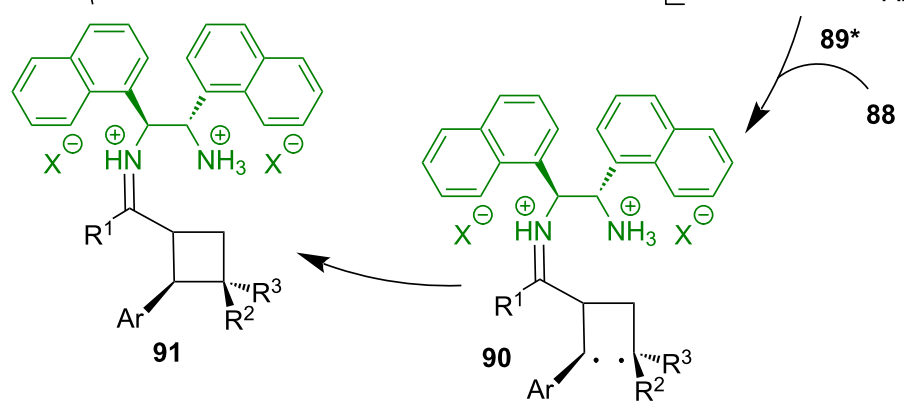

$[\mathrm{Ru}]=$
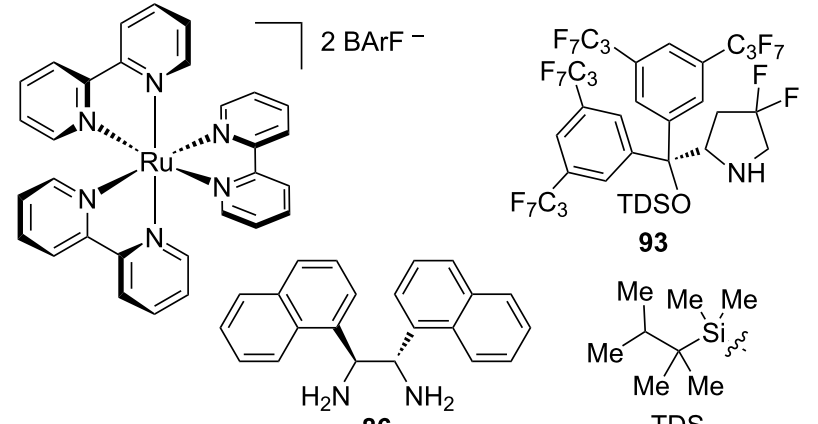

93

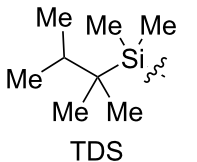

Scheme 11: Amine/photocatalysed photocycloadditions of iminium ion intermediates. (a) External photocatalyst used as triplet sensitiser with enals and dienes. (b) Bifunctional amine catalyst used with enones and alkenes. 


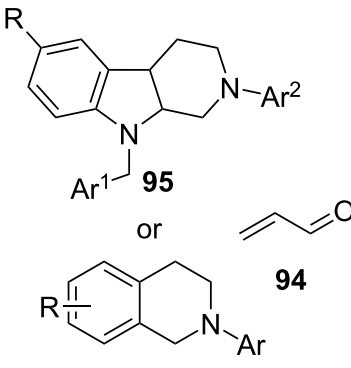

96

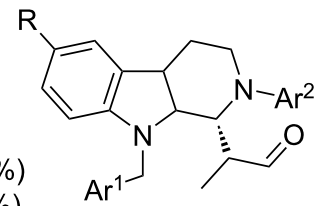

or<smiles></smiles>

99

21 examples up to $85 \%$ yield 98:2 er

100

10 examples

up to

$90 \%$ yield

98:2 er

$\operatorname{BArF}=\left[\left\{3,5-\left(\mathrm{CF}_{3}\right)_{2} \mathrm{C}_{6} \mathrm{H}_{3}\right\}_{4} \mathrm{~B}\right]^{-}$
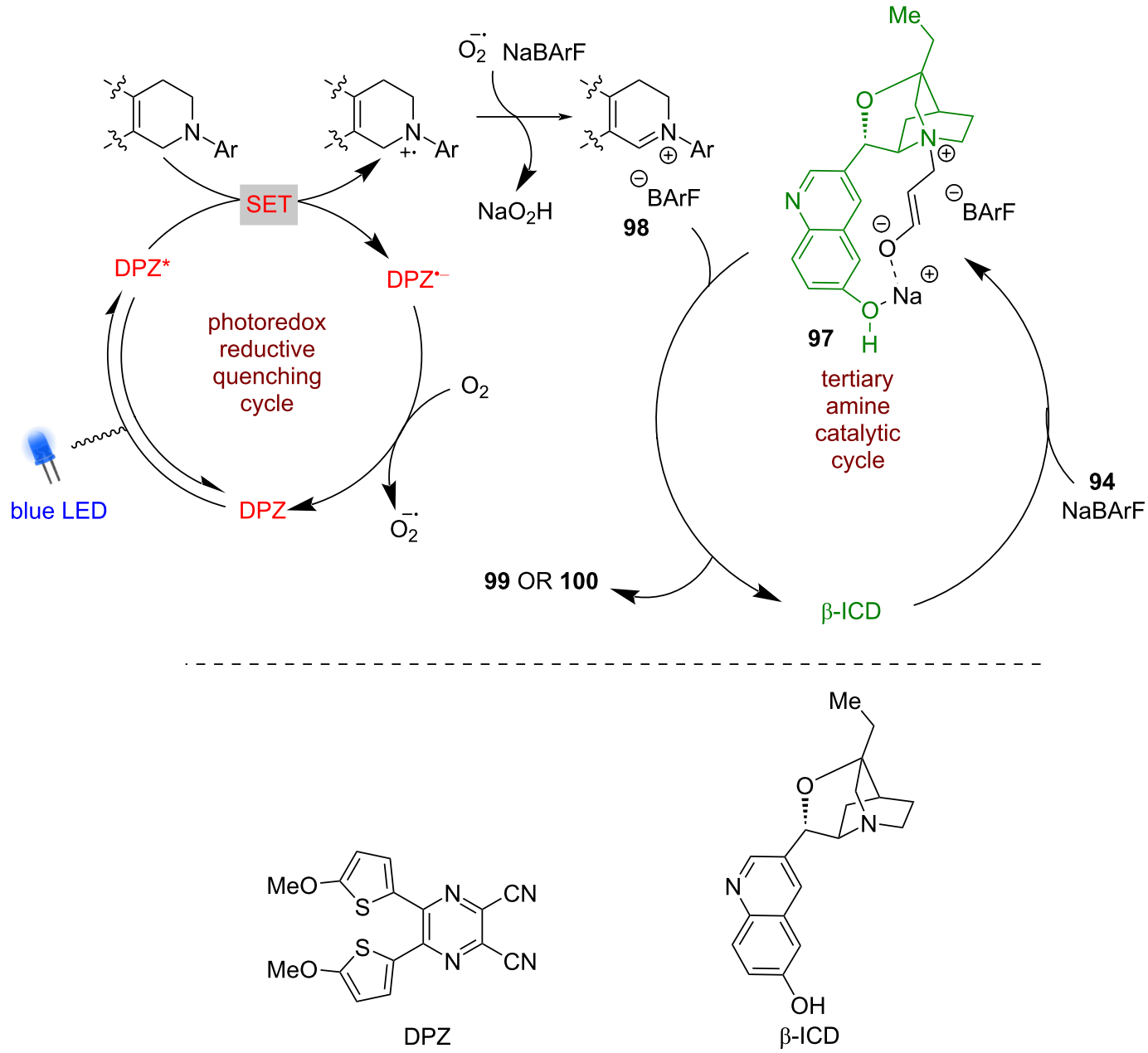

Scheme 12: Amine/photoredox-catalysed addition of acrolein (94) to iminium ions.

covalent catalysis with photoredox catalysis was reported by Rono and Knowles in 2013 (Scheme 15) [57]. They showed that using a chiral phosphoric acid (CPA), a photoredox catalyst and Hantzsch ester (HEH) as a HAT reagent, a concerted proton-coupled electron transfer (PCET) process is promoted to form ketyl radicals $\mathbf{1 1 3}^{\circ}$, which, in the presence of a hydrazone, cyclises to give $N$-centred radical $\mathbf{1 1 4}^{\circ}$. Subsequent HAT from HEH furnishes aza-pinacol product 115 in good yields and excellent enantioselectivities (14 examples, up to 98:2 er).

Since this initial report, a variety of processes have been developed using CPAs in combination with photoredox catalysis [58]. A significant contribution came from the Phipps group 

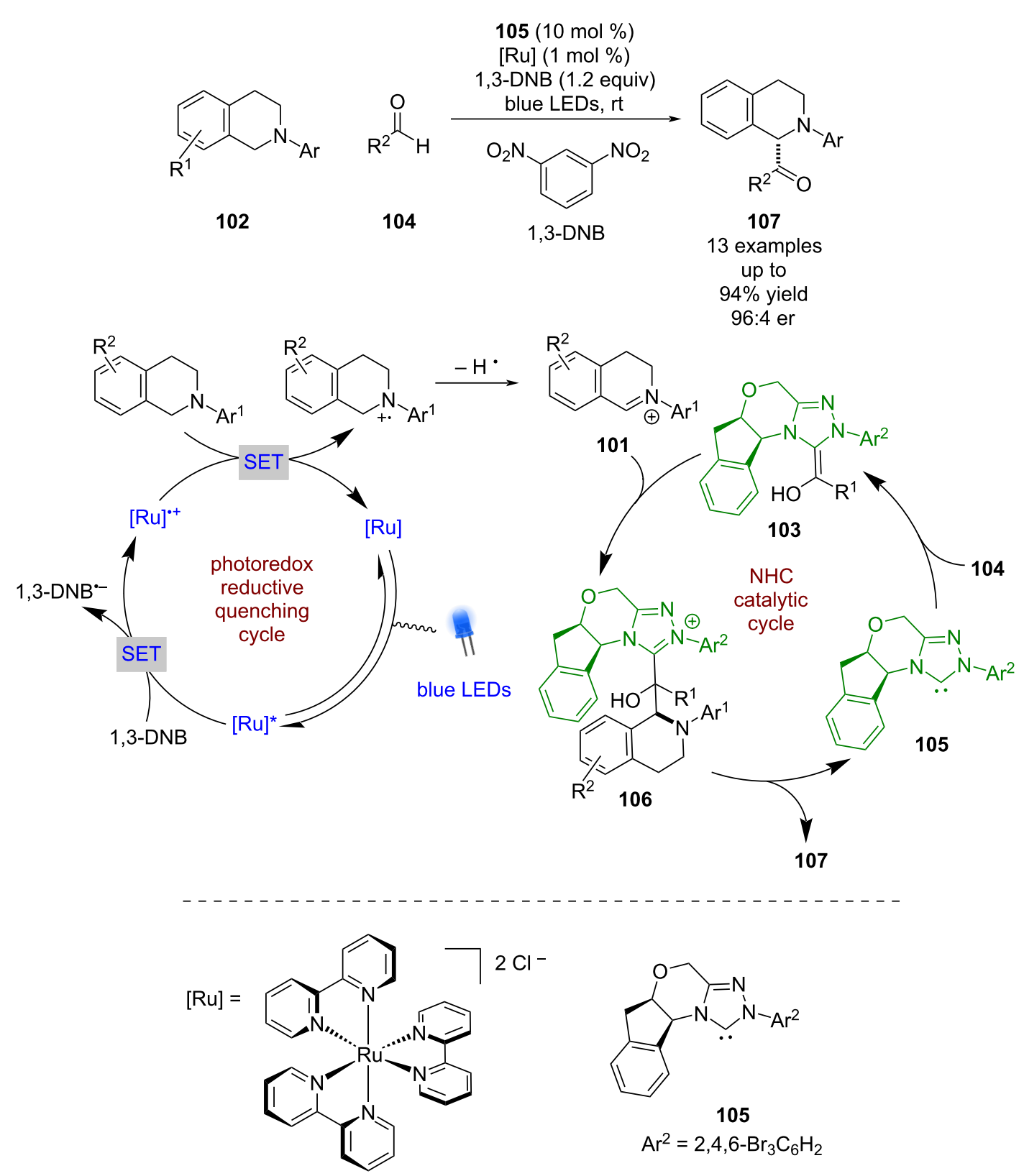

Scheme 13: Dual NHC/photoredox-catalysed acylation of THIQs.

with their work on enantioselective Minisci-type reactions (Scheme 16) [59]. Here, the CPA acts as a sacrificial reductant, with the photocatalyst proceeding through a reductive quenching cycle, generating $[\mathrm{Ir}]^{--}$, which reduces the phthalimide ester 117 to give $\alpha$-amino radicals $117^{\circ}$ after decarboxylation. The CPA then activates the azaarene $\mathbf{1 1 8}$ through protonation and brings the two reactive species together in a hydrogen bonded complex 119, which facilitates radical addition. After deprotonation and oxidation via SET, both catalysts are regenerated and Minisci-type products $\mathbf{1 2 0}$ are released in excellent yields and enantioselectivities (30 examples, up to 99:1 er).
Pyridyl substrates are tolerated, but generally required the presence of electron-withdrawing groups for the reaction to proceed.

Jiang et al. developed a similar system for the enantioselective radical addition into 2-vinylazaarenes 122 using DPZ and either $\alpha$-amino radicals [60] or ketyl radicals [61], with pyridines being well tolerated as substrates in this latter case (Scheme 17a). The same group also separately developed a Minisci-type reaction using phthalimide esters 123; however, their system did not extend past isoquinoline substrates $\mathbf{1 2 4}$ 


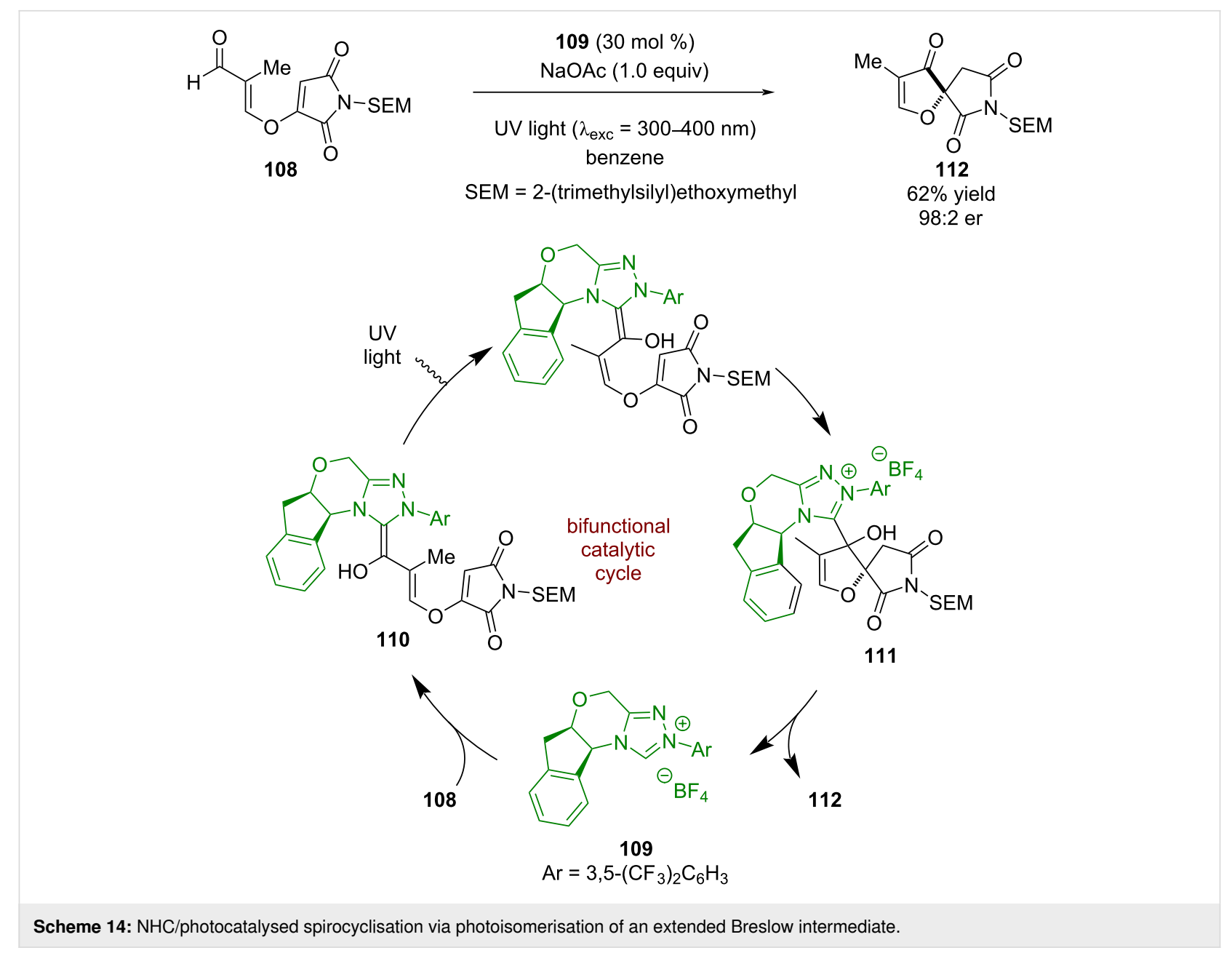

(Scheme 17b) [62]. Zheng and Studer expanded the scope of this type of reactivity to a three-component cascade reaction with alkyl bromides 125 and enamides 126 (Scheme 17c) [63]. Interestingly, they found some of their examples required the more strongly reducing photocatalyst $\operatorname{Ir}(\mathrm{ppy})_{3}$ to achieve high yields, although the reason for this is unclear.

Jiang et al. continued to explore the reactivity landscape of CPAs and azaarenes, demonstrating that ketone 128 could be reduced enantioselectively (Scheme 18a) [64]. The proposed mechanism in this case also follows a reductive quenching cycle using DPZ, but this time includes a tertiary amine $\mathbf{1 2 9}$ as a sacrificial reductant to generate $\mathrm{DPZ}^{--}$. As in the previous examples, the azaarene nitrogen is proposed to be protonated by the CPA to form chiral ion pair $\mathbf{1 3 0}$, which is then reduced by $\mathrm{DPZ}^{\boldsymbol{0}^{-}}$to give ketyl radical $\mathbf{1 3 0}^{\circ}$. The radical $\mathbf{1 3 0}^{\circ}$ is then reduced further to the carbanion $\mathbf{1 3 0}^{-}$, which is protonated enantioselectively to give alcohols $\mathbf{1 3 1}$ in excellent yields and enantioselectivities (38 examples, up to $98: 2$ er). It is notable that pyridyl ketones do not perform well in this reaction (1 example, 70:30 er). A further extension of this methodology includes the deuteration of $\mathbf{1 2 8}$ and alkyl halides 132 using $\mathrm{D}_{2} \mathrm{O}$ to afford 133 (18 examples, up to $>99: 1$ er) and 134 (34 examples, up to 98:2 er), respectively (Scheme 18b) [65].

Jiang et al. also reported a series of radical coupling reactions using different CPAs 135a-g and DPZ, with the first examples using $\alpha$-bromoketones $\mathbf{1 3 6}$ and $\alpha$-amino acids $\mathbf{1 3 7}$ as radical precursors (Scheme 19a) [66]. The proposed mechanism proceeds through a reductive quenching cycle to generate $\alpha$-amino radical $137^{\circ}$ and $\mathrm{DPZ}^{\circ}$, which can reduce 136 to give $\alpha$-carbonyl radical $136^{\circ}$. The CPA is then proposed to form a ternary hydrogen-bonded complex $\mathbf{1 3 8}$ to mediate enantioselective radical coupling that furnishes the desired products $\mathbf{1 3 9}$ in good yields and excellent enantioselectivities (48 examples, up to $99: 1$ er). This methodology was later expanded to 2-oxindoles 140 [67] and 1,2-diketones 141 [68] to form the corresponding radical coupling products 142 (43 examples, up to 98:2 er) and 143 (30 examples, up to 99:1 er), respectively, in comparable yields and enantioselectivities to those of $\mathbf{1 3 9}$ (Scheme 19b). 


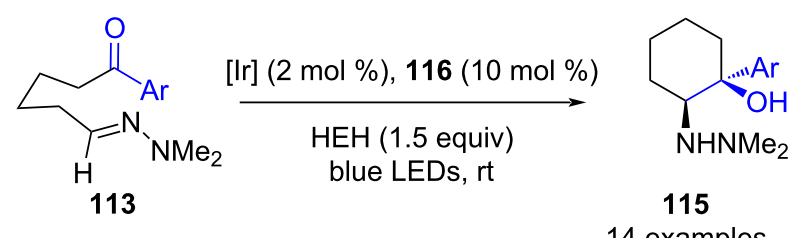

examples

up to

$86 \%$ yield

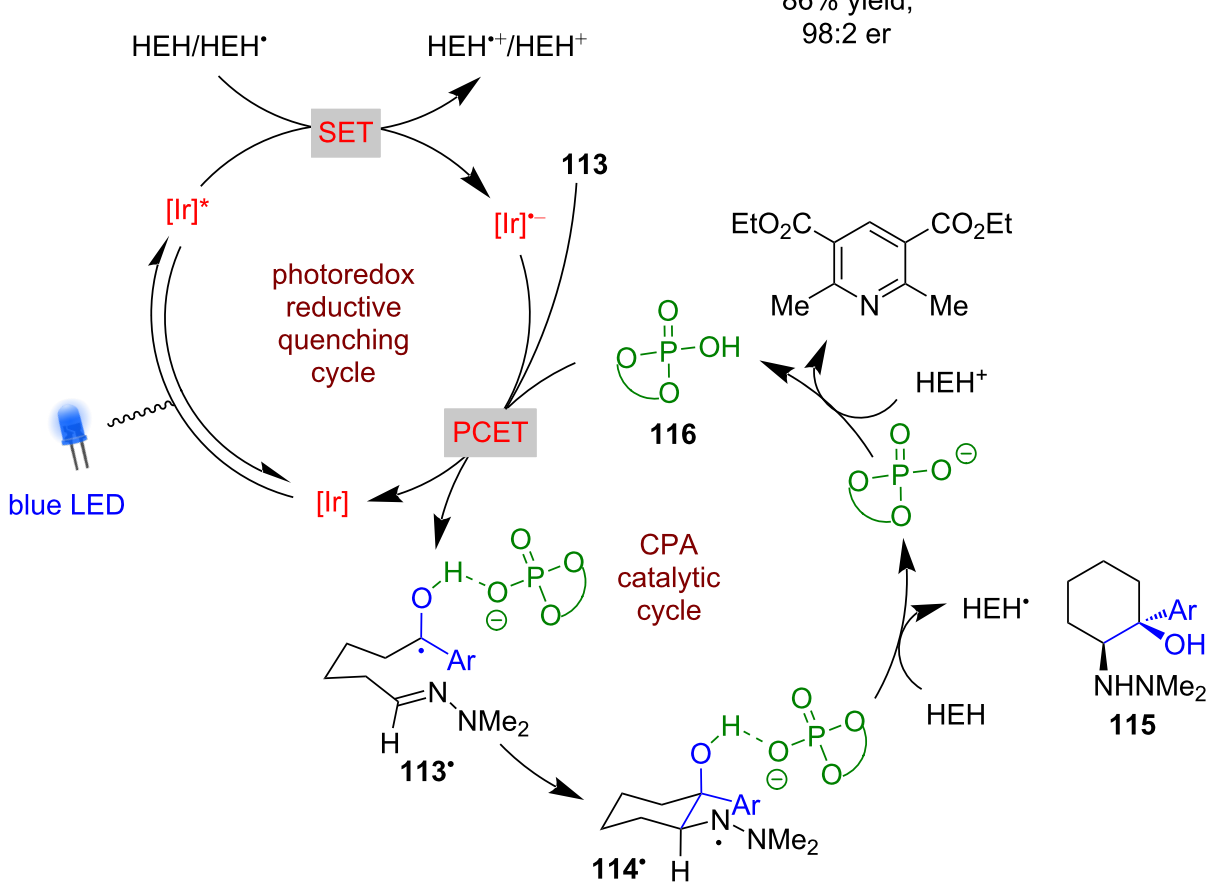

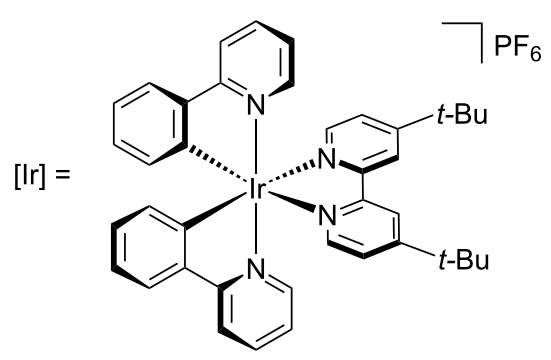

$\mathrm{HEH}=$<smiles>CCOC(=O)C1=C(C)C(C(=O)OCC)NC1[N+](=O)[O-]</smiles>

Scheme 15: CPA/photoredox-catalysed aza-pinacol cyclisation.

As previously mentioned, photoredox catalysis has been widely used for the generation of imines. The Jiang group applied this to the synthesis of substituted tetrahydroquinolines (THQs) 144 from $\alpha$-amino acids $\mathbf{1 4 5}$ to give racemic products in good yields and found that the addition of a CPA provided good enantioselectivity (Scheme 20) [69]. The putative mechanism proceeds via a reductive quenching cycle to give $\alpha$-amino radical $145^{\circ}$ after decarboxylation, which is then oxidised further to the imine 146 in the presence of oxygen. Imine 146 is in equilibrium with the enamine tautomer 147 , and the CPA-catalysed
Povarov reaction between them gives the enantioenriched THQ 144 in good yields and enantioselectivities (4 examples, up to 97:3 er).

This reactivity has been extended to enamides $\mathbf{1 4 8}$, with the imine generated from the $\alpha$-amino acid 149 now reacting with 148 in a CPA-catalysed Povarov reaction rather than with its own tautomer (Scheme 21a) [70]. Zhang and You developed a catalytic dearomatisation reaction of indoles $\mathbf{1 5 0}$ using similar chemistry, where the generated imine $\mathbf{1 5 1}$ now reacts intramo- 

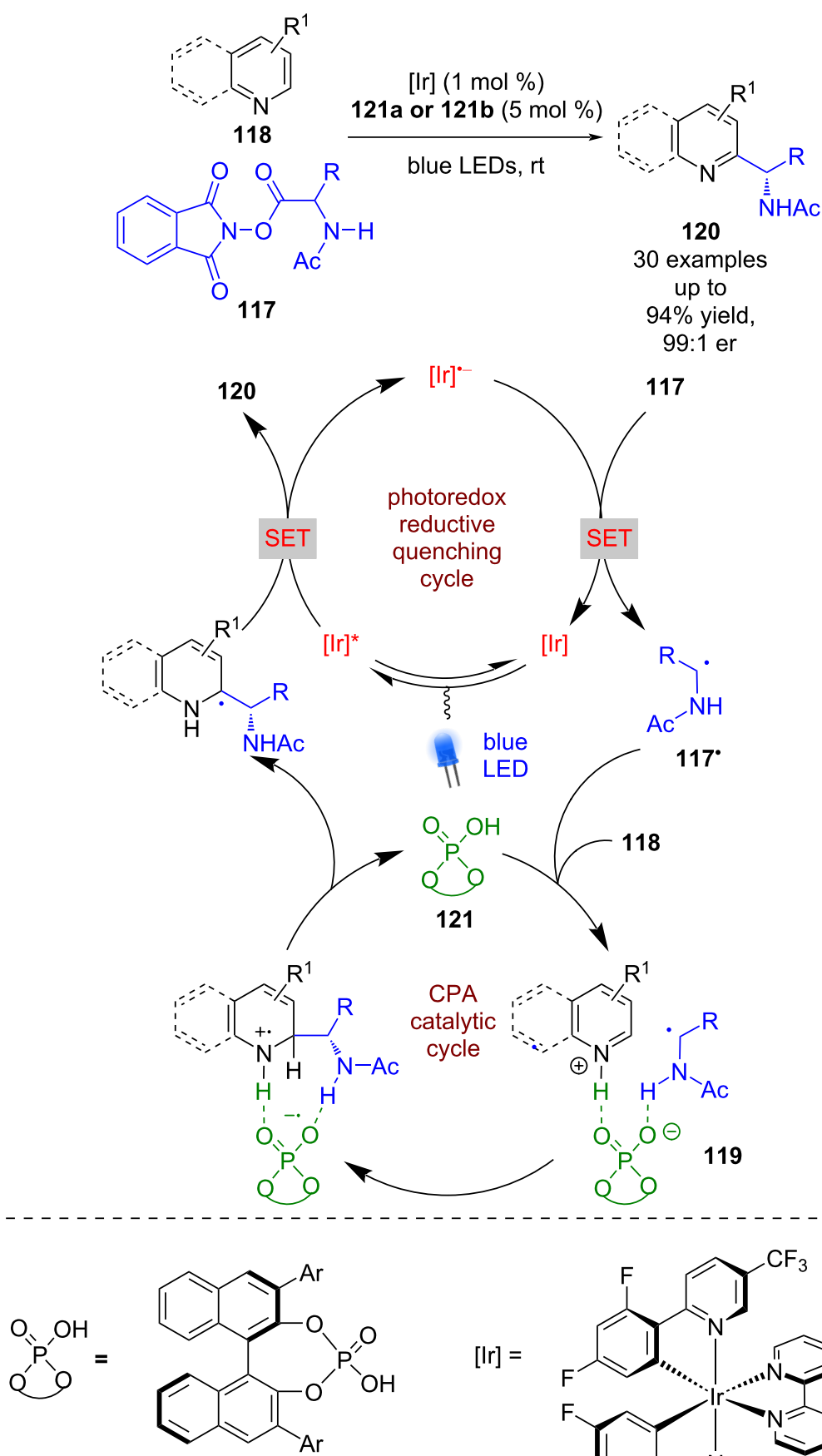

$\mathrm{Ar}=2,4,6-(\mathrm{iPr})_{3} \mathrm{C}_{6} \mathrm{H}_{2}, 121 \mathrm{a}$

$=2,4,6-(\mathrm{Cy}){ }_{3} \mathrm{C}_{6} \mathrm{H}_{2}, 121 \mathrm{~b}$

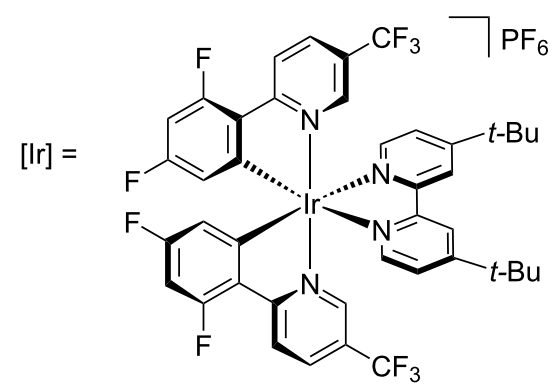

Scheme 16: CPA/photoredox-catalysed Minisci-type reaction between azaarenes and $\alpha$-amino radicals.

lecularly with a pendant nucleophile and is further oxidised to a carbocation that is trapped intermolecularly by $N$-hydroxycarbamates 152 (Scheme 21b) [71].

Bach et al. has recently reported a bifunctional catalyst $\mathbf{1 5 4}$, which contains both a photoactive thioxanthone unit and a CPA
(Scheme 22) [72]. They have applied this photocatalyst to the $[2+2]$ photocycloaddition of carboxylic acids 155 with alkenes 156. A low yielding benzylation reaction was required for determination of enantioselectivities and a large excess of alkene was required for the reaction. The reaction is proposed to proceed via hydrogen-bonded complex $\mathbf{1 5 7}$, that lowers the 


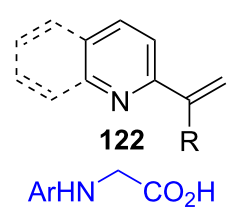

a

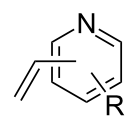<smiles>[R]C([R])=[X]</smiles>$$
\mathrm{X}=\mathrm{O}, \mathrm{NAr}
$$

b<smiles>[R][X]1ccc2ccncc2c1</smiles><smiles>[14CH3]</smiles><smiles>[R]CC(NC(=O)OCC)C(=O)ON1C(=O)c2ccccc2C1=O</smiles>

c

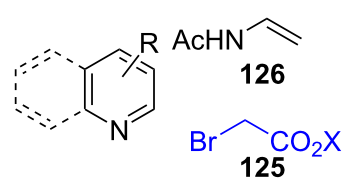

DPZ $(0.2 \mathrm{~mol} \%)$

127 a or $127 \mathrm{~b}(15 \mathrm{~mol} \%)$ $\mathrm{LiPF}_{6}(40 \mathrm{~mol} \%)$

blue LED, rt<smiles></smiles>

29 examples up to

$98 \%$ yield,

99:1 er 135d or $135 f(8-20 \mathrm{~mol} \%)$ $\mathrm{HEH}$ (1.5-2.5 equiv) blue LED, -5 or $-50^{\circ} \mathrm{C}$<smiles>[R]c1cccnc1CCC([R])([R])[Y1]</smiles>

51 examples up to $99 \%$ yield, $>99: 1$ er<smiles>[R]c1ccc2ccnc([C@H](CP)NC(=O)OCC)c2c1</smiles>

[Ir] $(1.5 \mathrm{~mol} \%)$

121a (10 mol \%)

$\mathrm{K}_{3} \mathrm{PO}_{4}$ (1.0 equiv) blue LED, $-10^{\circ} \mathrm{C}$

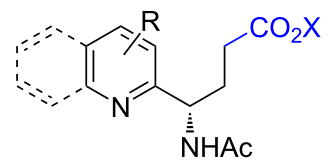

29 examples up to $95 \%$ yield, 98:2 er<smiles>CCC(C)(C)C(F)(F)F</smiles>

or<smiles></smiles><smiles>COc1ccc(-c2nc(C#N)c(C#N)nc2-c2ccc(OC)s2)s1</smiles>

DPZ<smiles>O=P1(O)Oc2c(Br)ccc3c2C2(CC3)CCc3ccc(Br)c(c32)O1</smiles>

$\mathrm{Ar}=$ 2-naphthyl, 127a $=2-\left(\mathrm{CF}_{3}\right) \mathrm{C}_{6} \mathrm{H}_{4}, 127 \mathrm{~b}$

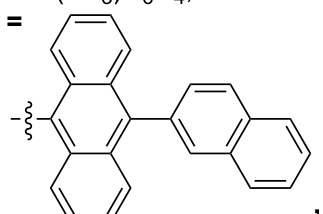

, 127c

Scheme 17: CPA/photoredox-catalysed radical additions to azaarenes. (a) $\alpha$-Amino radical or ketyl radical addition to 2-vinylazaarenes. (b) Miniscitype reaction using redox-active esters and isoquinolines. (c) Radical cascade reaction using $\alpha$-carbonyl radicals with enamides. 
a

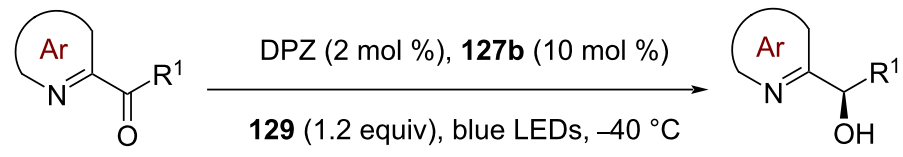

128

131

38 examples<smiles>CC(C)(C)C</smiles>

up to

$99 \%$ yield,

98:2 er

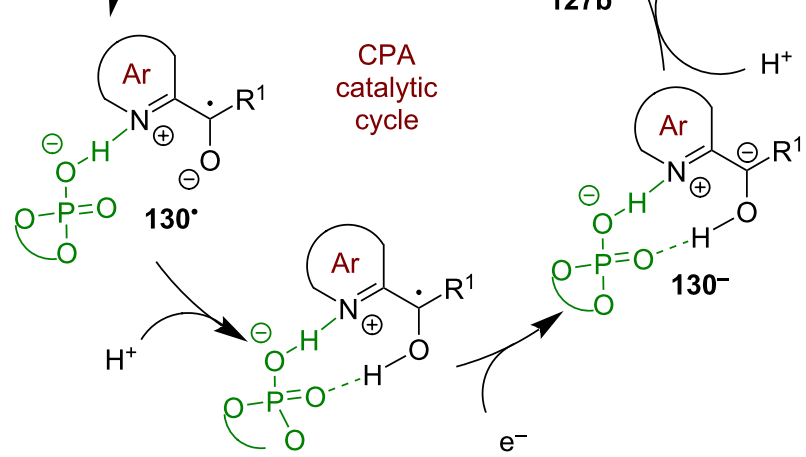

b
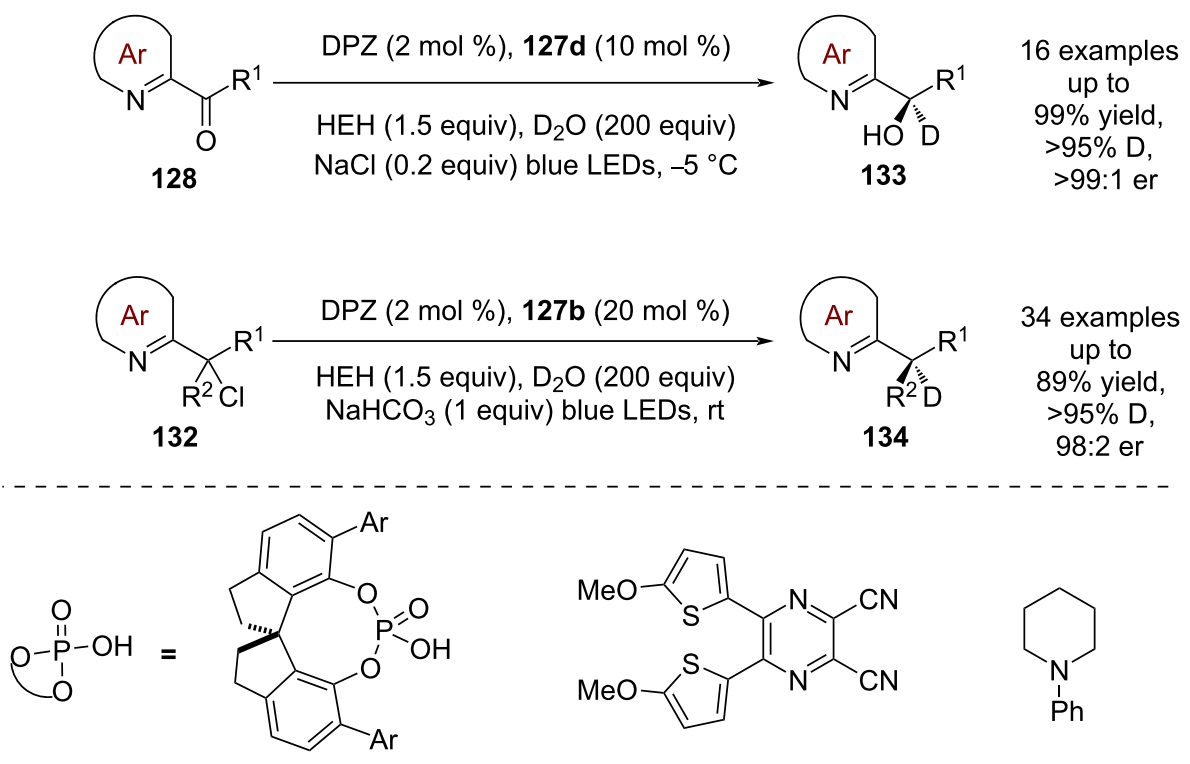

$\mathrm{Ar}=2-\left(\mathrm{CF}_{3}\right) \mathrm{C}_{6} \mathrm{H}_{4}, 127 \mathrm{~b}$

$=2-(t-\mathrm{Bu}) \mathrm{C}_{6} \mathrm{H}_{4}, 127 \mathrm{~d}$<smiles>COc1ccc(-c2nc(C#N)c(C#N)nc2-c2ccc(OC)s2)s1</smiles><smiles>c1ccc(N2CCCCC2)cc1</smiles>

DPZ 
a<smiles>[R]C(=O)C([R])Br</smiles>
136

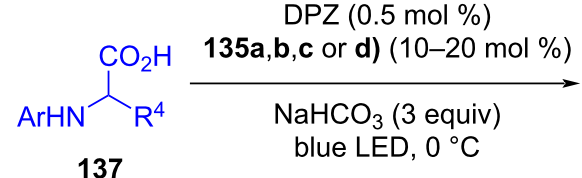

137

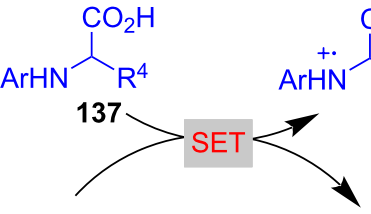

$\mathrm{DPZ} *$<smiles>C=CC(C=C)C=C</smiles>

blue LEDs

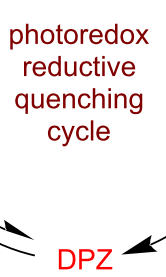

DPZ
DPZ*-

$\mathrm{CO}_{2} \mathrm{H}$

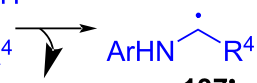

$\mathrm{CO}_{2}$
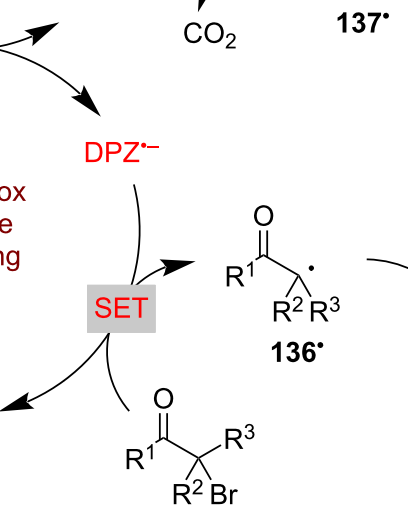

136

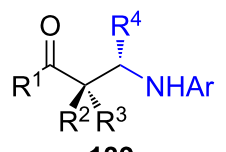

139

48 examples

up to

$86 \%$ yield

99:1 er, >20:1 dr

b
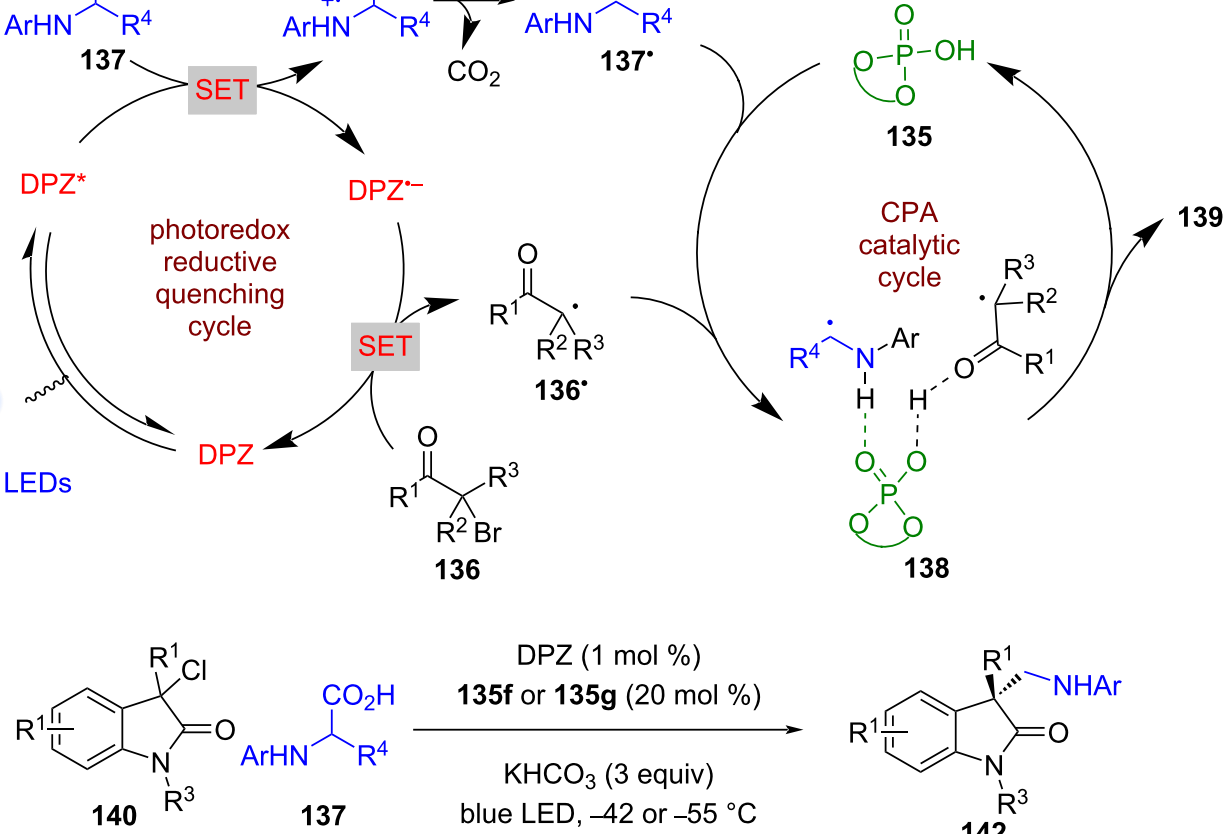<smiles>[R10]N1C(=O)C([R1])(N[AlH2])c2cc[R1]cc21</smiles>

43 examples

$$
\text { up to }
$$

$97 \%$ yield

98:2 er<smiles>[R]C(=O)[C@@](O)([Al])CN[14CH3]</smiles>

143

30 examples

up to

91\% yield,

99:1 er

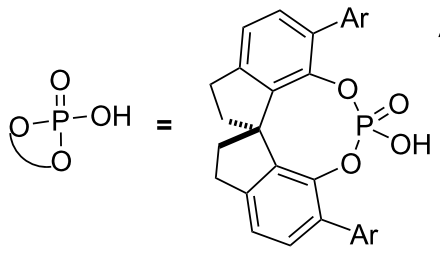

$\mathrm{Ar}=3,5-(t-\mathrm{Bu}) \mathrm{C}_{6} \mathrm{H}_{3}, 135 \mathrm{a}$

$=3,5-\left(\mathrm{CF}_{3}\right) \mathrm{C}_{6} \mathrm{H}_{3}, 135 \mathrm{~b}$

$=3,5-(t-\mathrm{Bu})_{2}-4-(\mathrm{MeO}) \mathrm{C}_{6} \mathrm{H}_{3}, 135 \mathrm{c}$

$=2,4,6-(\mathrm{iPr})_{3} \mathrm{C}_{6} \mathrm{H}_{2}, 135 \mathrm{~d}$

$=2,6-(\mathrm{Me})_{2}-4-(t-\mathrm{Bu}) \mathrm{C}_{6} \mathrm{H}_{2}, 135 \mathrm{e}$

$=$ 9-anthryl, $135 f$

(1)

, $135 \mathrm{~g}$

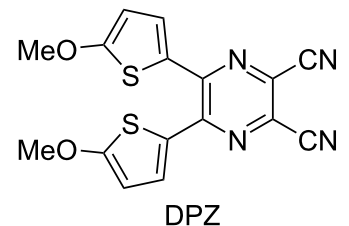

DPZ

Scheme 19: CPA/photoredox-catalysed radical coupling reactions of $\alpha$-amino radicals with $\alpha$-carbonyl radicals. (a) Using $\alpha$-bromoketones. (b) Using $\alpha$-chloro-2-oxindoles or 1,2-diketones. 


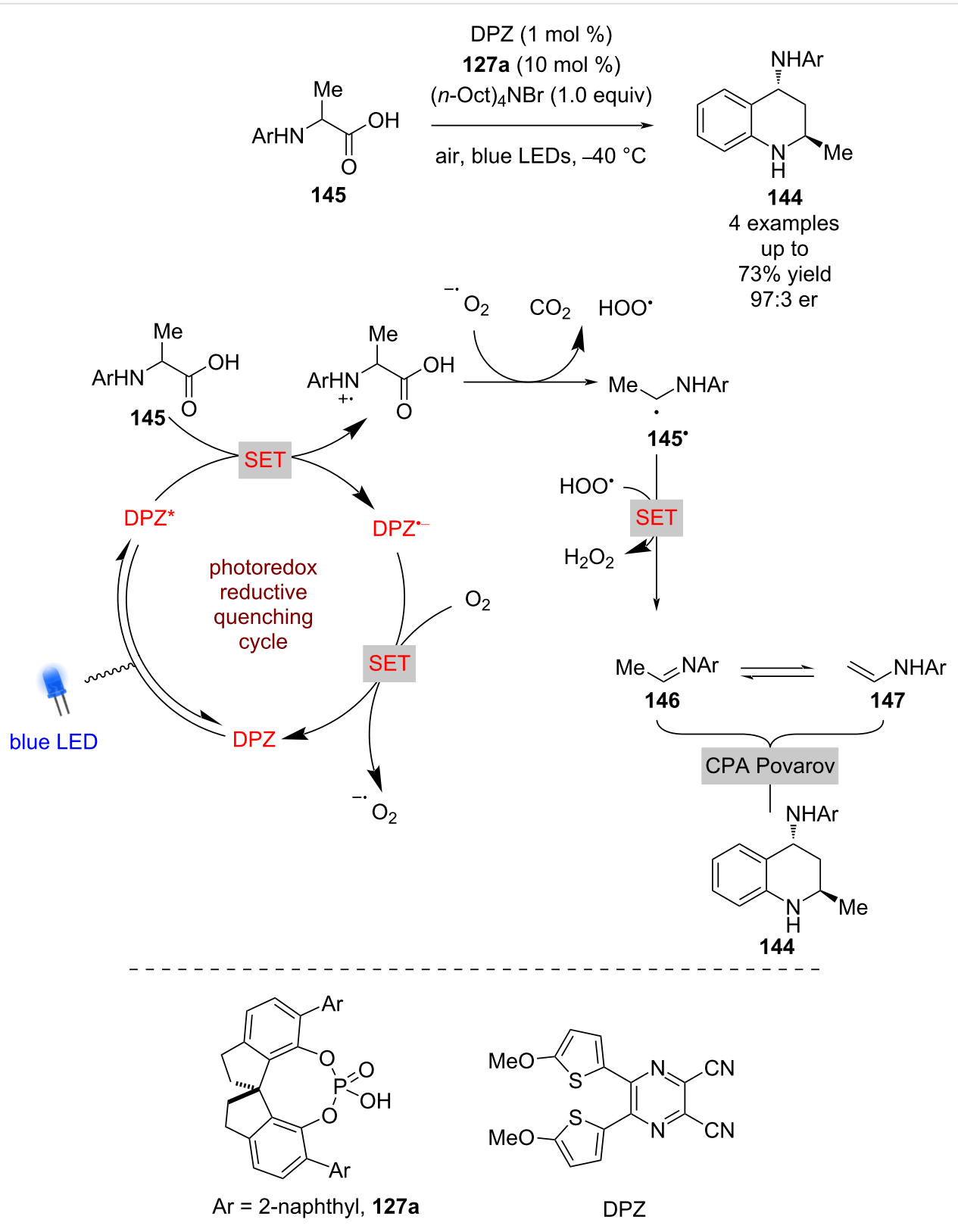

Scheme 20: CPA/photoredox-catalysed Povarov reaction.

triplet energy of the carboxylic acid so that a Dexter energy transfer process is possible from the photocatalyst to the substrate to promote $\mathbf{1 5 5}$ into its triplet state, which can then cyclise with 156 to give enantioenriched cycloaddition products $\mathbf{1 5 8}$. The selectivity of this reaction is generally low (6 examples, up to 93:7 er, 67:33 rr) but this example does demonstrate an interesting proof of concept with potential for the development of processes using alternative bifunctional catalysts.

\section{Phase-transfer catalysis}

Phase-transfer catalysis (PTC) is another non-covalent mode of catalysis that has been combined with photocatalysis. The first example of PTC being used in combination with photocatalysis was developed by Gao towards the oxygenation of 1-indanone derived $\beta$-keto esters 159 (Scheme 23) [73]. Gao proposes tetraphenylporphyrin (TPP) acting as a sensitiser to form ${ }^{1} \mathrm{O}_{2}$ via photoinduced energy transfer, which is then trapped by enolate 160 in a chiral environment, provided by the PTC, to form a $\alpha$-hydroperoxyl intermediate 161. Subsequent deoxygenation by another molecule of $\mathbf{1 6 0}$ forms two molecules of the $\alpha$-hydroxylated products 162 in excellent yields and moderate enantioselectivities (11 examples, up to 88:12 er). The selectivity has been improved further with the development of new PTCs [7476], although the scope of the reaction remains limited. 
a<smiles>[R16]C1=C2C=[R1]=[C+]C=C2C(=O)N1</smiles><smiles>[R]C(N)C(=O)O</smiles>

$\mathrm{NaHCO}_{3}$ (1.5 equiv) air, blue LED, $0^{\circ} \mathrm{C}$

149

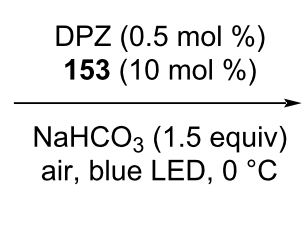

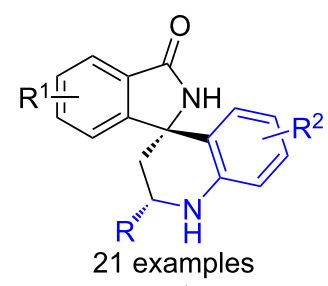

up to

$83 \%$ yield,

99:1 er, >20:1 dr

b<smiles>[Y]CCCc1c[nH]c2ccccc12</smiles>

150

\section{[Ir] $(0.2 \mathrm{~mol} \%)$ $116(10 \mathrm{~mol} \%)$ \\ $\mathrm{R}^{2} \mathrm{NHOH}$ \\ $\mathrm{NaHCO}_{3}$ ( 1.5 equiv) air, blue LED, rt then $\mathrm{Boc}_{2} \mathrm{O}$}

via<smiles>[Y]CCCc1c[nH]c2ccccc12</smiles><smiles>[R2]NC1(O)CCCCCC12Nc1ccccc1C2([Y])[R]</smiles>

31 examples up to, $98 \%$ yield, 96:4 er $[\mathrm{lr}]=$<smiles></smiles><smiles>O=P1(O)Oc2c(Br)ccc3c2C2(CC3)CCc3ccc(Br)c(c32)O1</smiles>

153 $\mathrm{Ar}=4$-pyrenyl<smiles>CCCCC[SnH2]c1cc(-c2c(OP(=O)(O)O)c([AsH-])cc3ccccc23)c2ccccc2c1</smiles>

Scheme 21: CPA/photoredox-catalysed reactions with imines. (a) Decarboxylative imine generation followed by Povarov reaction with an enamide. (b) Imine trapped by intramolecular nucleophile and intermolecular nucleophile.

Building on these initial reports, Melchiorre et al. developed a perfluoroalkylation reaction of the same starting materials $\mathbf{1 5 9}$ using alkyl iodides 163 (Scheme 24) [77]. Interestingly, this takes place without the need for an external photocatalyst and is proposed to proceed via an intermediate EDA complex 164, which, upon excitation, forms perfluoroalkyl radicals $1 \mathbf{1 6 3}^{\circ}$ that add to the enolate substrate that is coordinated to a chiral counterion $\mathbf{1 6 5}$ to give ketyl radical anion $\mathbf{1 6 6}^{\mathbf{-}}$. The latter interme- diate $166^{--}$can then abstract an iodine atom from another molecule of $\mathbf{1 6 3}$ to propagate the chain reaction and generate alkyl iodide 167, which collapses to give the desired enantioenriched alkylation products 168 in moderate yields and excellent enantioselectivities (14 examples, up to 98:2 er). The quantum yield of the enantioselective reaction could not be ascertained due to the reaction being heterogenous, but the quantum yield for the racemic variant using an achiral base was $>1(\Phi=1.2)$, support- 
<smiles>[Y]C=[Y16]C1=C(C(=O)O)CC(=O)CC1[R1]</smiles><smiles>[R]C([R])=C([R])[R5]</smiles>

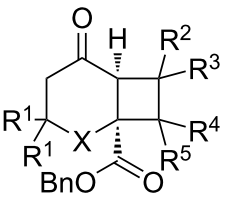

$\mathrm{R}^{1} \mathrm{X}$

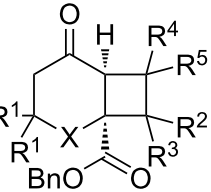

158

6 examples

up to

$55 \%$ yield,

93:7 er, $75: 25 \mathrm{dr}$

$67: 33 \mathrm{rr}$

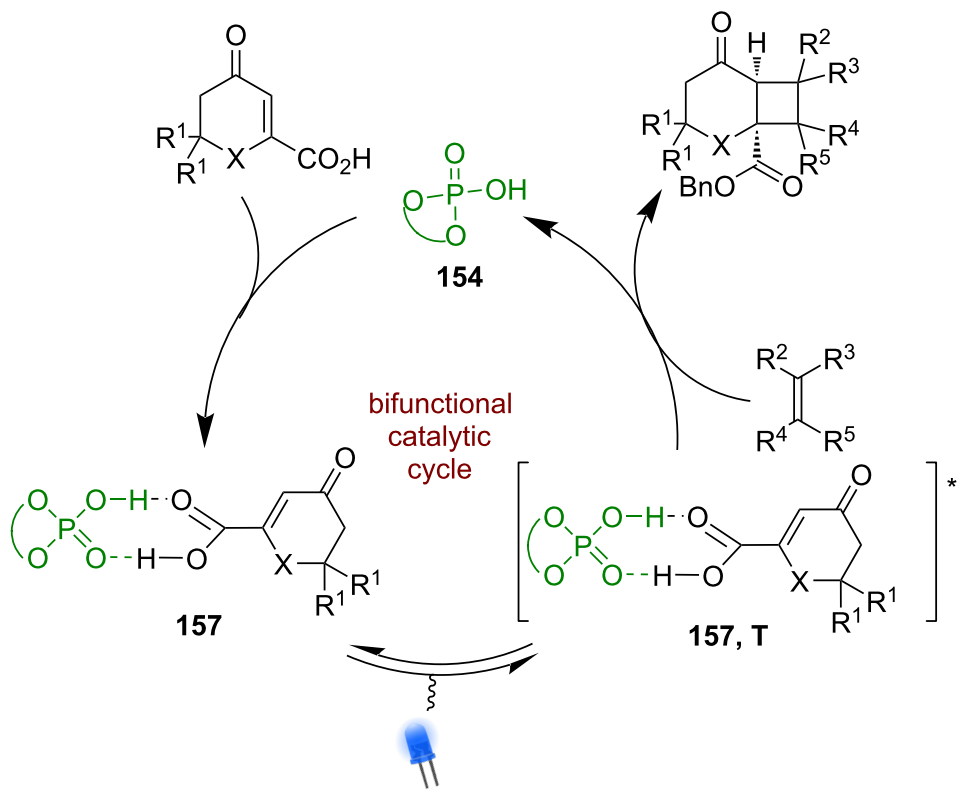

blue LED

$\lambda_{\text {exc }}=437 \mathrm{~nm}$

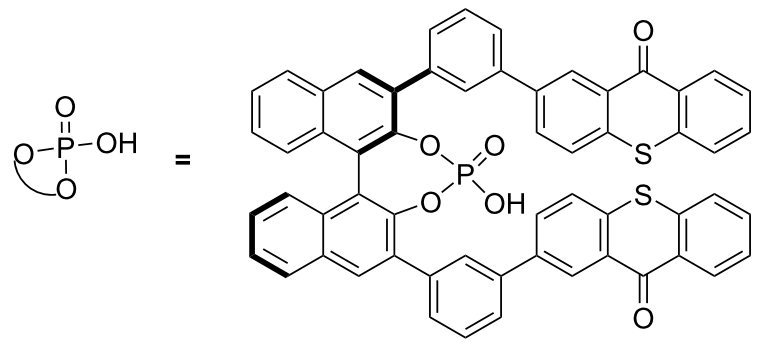

154

Scheme 22: Bifunctional CPA/photocatalysed [2 + 2] photocycloadditions.

ing the proposed radical chain process. While these results are promising for this mode of catalysis, more work is required to address the limited substrate scope.

\section{Hydrogen bonding}

Krische et al. were the first to develop a bifunctional hydrogen bonding photocatalyst 169 (Scheme 25) [78] that was used in an intramolecular enantioselective $[2+2]$ photocycloaddition of quinolone 170. The proposed mechanism proceeds via hydrogen-bonded complex 171, which is sensitised by the pendant benzophenone to its triplet excited state 171*. The following cycloaddition completes the cycle and generates the desired cyclobutane product 173 in excellent conversion but poor enantioselectivity (60:40 er). While the enantioselectivity was low, this reaction represented an interesting proof of concept that would be later expanded by others. 
<smiles>[R]OC(=O)C1Cc2c[R1]#ccc2C1=O</smiles>

159<smiles>[R]OC(=O)C1=C([O-])c2c[R17]ccc2C1</smiles>

160<smiles>CC(C)O[Na]</smiles><smiles>[R]O[C@]1(OO)Cc2cc[R17]cc2C1=O</smiles>

161
PTC $(5 \mathrm{~mol} \%)$

TPP (1 mol \%), white light

toluene/ $\mathrm{K}_{2} \mathrm{HPO}_{4}(\mathrm{aq})$

in air, $-18^{\circ} \mathrm{C}$<smiles>[R]OC1(O)Cc2c[R17]cc2C1=O</smiles>

162

11 examples

up to

$93 \%$ yield

88:12 er

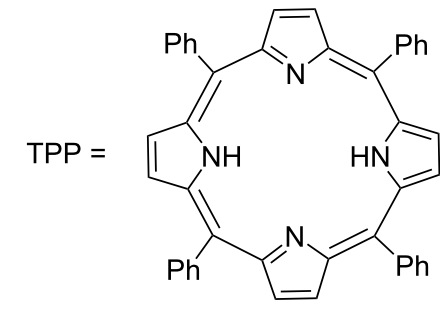<smiles>C=CC1CN(Cc2cc(C(F)(F)F)cc(C(F)(F)F)c2)C([C@H](O)c2ccnc3ccccc23)CC1Br</smiles>

Scheme 23: PTC/photocatalysed oxygenation of 1 -indanone-derived $\beta$-keto esters.

Later, Bach et al. developed a similar bifunctional hydrogen bonding photocatalyst 174. Reactions using catalysts of this type are well covered in Bach's recent review on the subject [13]. Photocatalyst 174 was first used in a cyclisation reaction where the putative mechanism involves a hydrogen bonding complex 175 between the catalyst and quinolone substrate $\mathbf{1 7 6}$ (Scheme 26) [2]. Subsequent photoexcitation promotes a photoinduced electron transfer to generate diradical $\mathbf{1 7 7}$ that then adds to the alkene to form diradical 178. A SET between the ketyl radical and the $\alpha$-carbonyl radical generates enolate intermediate 179, which after proton transfer regenerates the catalyst and releases the desired cyclisation product $\mathbf{1 8 0}$ in a moderate yield and enantioselectivity (85:15 er).

Photocatalyst 174 was next applied to the formal [2+2] photocycloaddition of quinolones $\mathbf{1 8 1}$, which is analogous to the reaction developed by Krische et al. in Scheme 25. Similarly, the mechanism that is proposed proceeds through complex 182 that can be photosensitised into its triplet excited state 182* (Scheme 27) $[79,80]$. However, the enantioselectivities for this reaction were poor (70:30 er), which prompted further catalyst design by changing the photosensitising group from benzophenone to xanthone $\mathbf{1 8 3}$ to improve enantioselectivity [79]. Xanthone has a higher triplet energy than benzophenone $(3.2 \mathrm{eV}$ vs $3.0 \mathrm{eV})$ and the authors attribute this difference to the increased efficiency; however, the efficiency of energy transfer is governed by spectral overlap between donor and acceptor. The much higher enantioselectivities observed (95:5 er) are attributed to a reduced amount of background reaction and the more rigid xanthone structure acting as a superior stereo-directing group.

Further variation to a thioxanthone unit $\mathbf{1 8 5}$, which has a lower triplet energy $\left(E_{\mathrm{T}}=2.7 \mathrm{eV}\right)$, was used to investigate a similar 

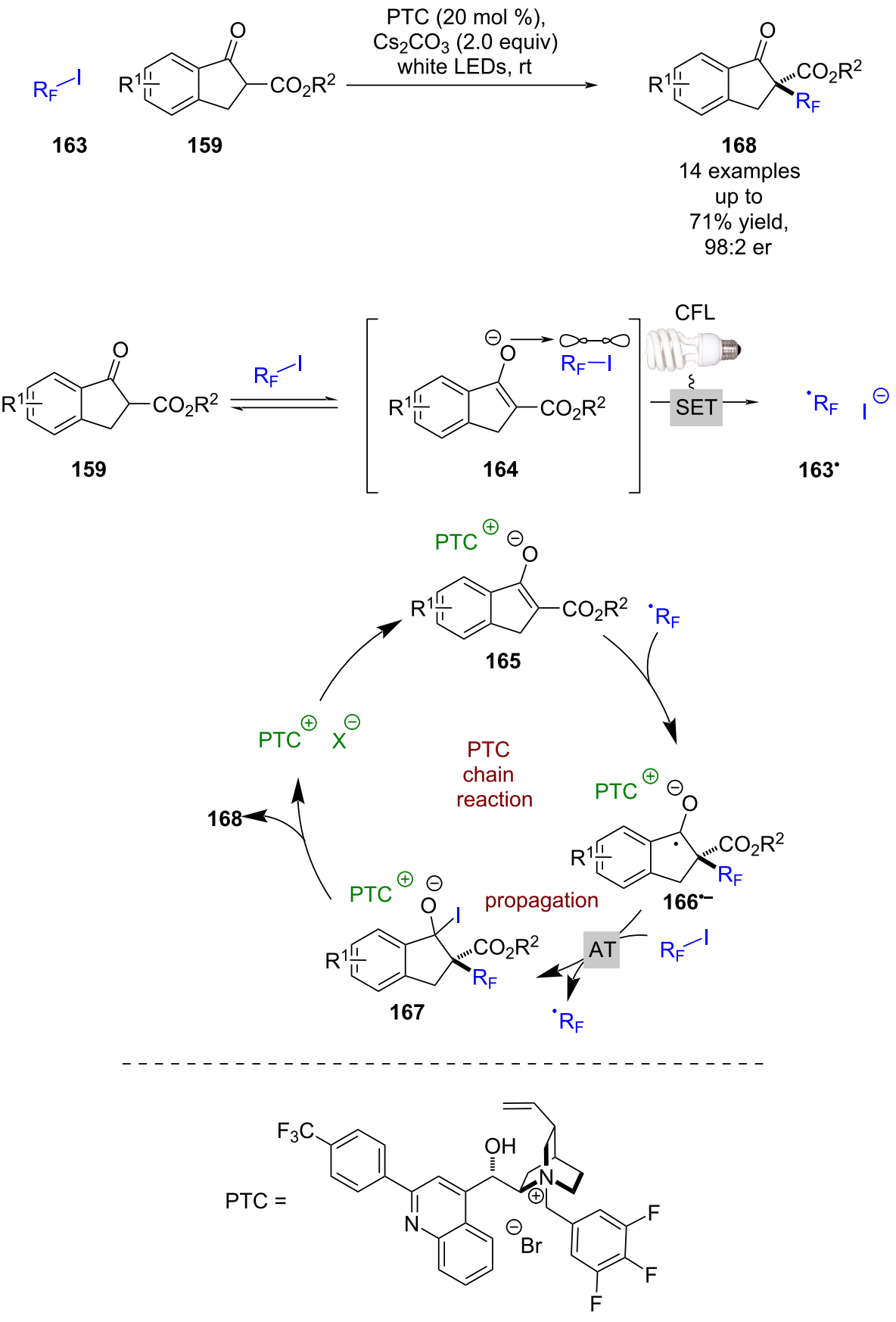

Scheme 24: PTC/photoredox-catalysed perfluoroalkylation of 1 -indanone-derived $\beta$-keto esters via a radical chain reaction initiated by an EDA complex.

$[2+2]$ photocycloaddition, giving comparable yields and enantioselectivities (7 examples, up to 97:3 er) (Scheme 28a) [81]. A lower energy wavelength irradiation was able to be used, which limited the amount of background reaction as the absorption spectra of photocatalyst and substrate were more clearly resolved. The first intermolecular process using these catalysts was the $[2+2]$ photocycloaddition of 2-pyridones 186 and acetylenedicarboxylates $\mathbf{1 8 7}$ catalysed by ent-183 to give cyclobutenes 188 (Scheme 28b) [82]. Another intermolecular reaction was later developed, this time using catalyst $\mathbf{1 8 5}$ for the $[2+2]$ photocycloaddition of quinolones $\mathbf{1 8 9}$ and electron-deficient alkenes 190 to synthesise cyclobutanes 191 (Scheme 28c) [83]. Recently, Bach et al. also employed this methodology for the intramolecular [2+2] cycloaddition of quinolones 192 con- 
<smiles>C=CCCOc1cc(=O)[nH]c2ccccc12</smiles>

170

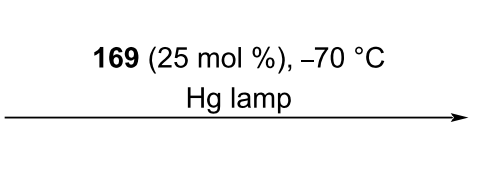

60:40 er

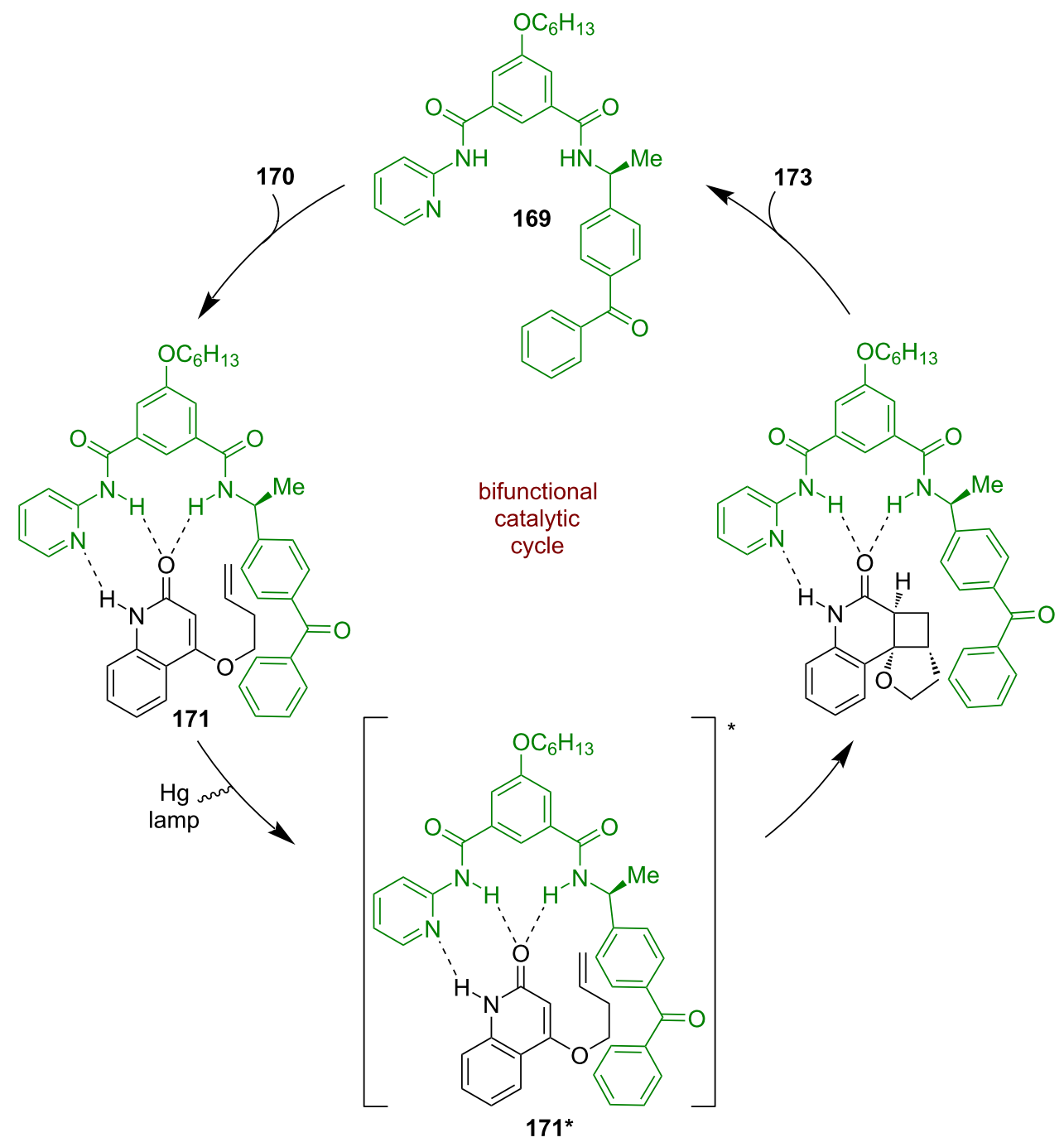

Scheme 25: Bifunctional hydrogen bonding/photocatalysed intramolecular [2 + 2] photocycloadditions of quinolones.

taining either a pendant alkene or allene to obtain cyclobutanes 193 (Scheme 28d) [84].

Recently, ent-185 was applied by Bach to the deracemisation of allenes rac-194 (Scheme 29) [85]. The proposed mechanism proceeds through configurationally isomeric hydrogen bonding complexes 195 and 195', with subsequent photoexcitation of the thioxanthone chromophore leading to racemisation of the allene through a triplet state intermediate 196. In 195 there is additional steric repulsion between the large $\mathrm{R}$ group and the thioxanthone that is not present in 195', which results in a smaller association constant and a larger calculated separation between the allene and the chromophore in $195(\mathrm{r}=510 \mathrm{pm})$ relative to 195' $(\mathrm{r}=363 \mathrm{pm})$. As the efficiency of Dexter energy transfer decreases exponentially with distance, the larger gap results in lower sensitisation rates for 190. This, in combi- 
<smiles>O=c1cc(CCN2CCCC2)c2ccccc2[nH]1</smiles>

$174(30 \mathrm{~mol} \%)$

$-60{ }^{\circ} \mathrm{C}$, UV lamp $\left(\lambda_{\text {exc }}>300 \mathrm{~nm}\right)$

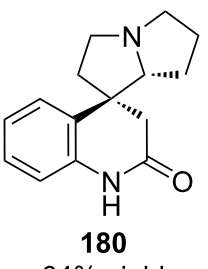

$64 \%$ yield

$85: 15$ er

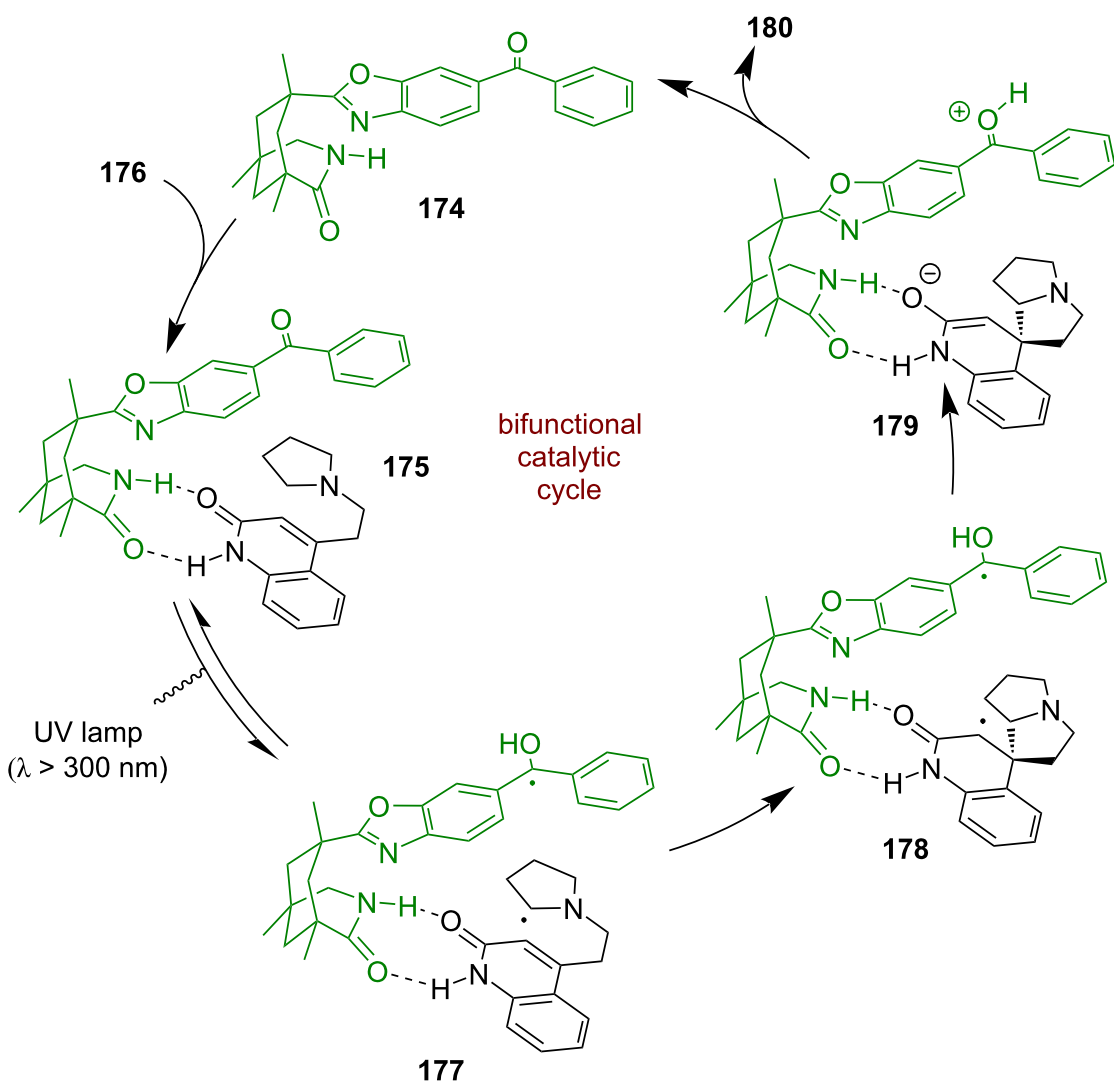

Scheme 26: Bifunctional hydrogen bonding/photocatalysed intramolecular RCA cyclisation of a quinolone.

nation with the difference in association constants, leads to greater racemisation of ent-194 and, therefore, a deracemisation with excellent enantioselectivities and yields (17 examples, up to $99: 1$ er). Interestingly, the quantum yield for the reaction was measured to be 0.52 , which the authors assert is quantitative based on the complete deracemisation in the reaction. Bach et al. recently extended this reactivity further to include 5-membered rings [86].

A similar mechanism is proposed for the deracemisation of sulfoxides rac-197; however, the enantioselectivities are lower (5 examples, up to 78:22 er), which the authors attribute to the catalyst differentiating between the sterics of an oxygen atom and a lone pair of electrons (Scheme 30a) [87]. Bach et al. also found that alkenes 198 can undergo a light-induced rearrangement to cyclopropane 199 in the presence of 185 (Scheme 30b) [88]. They discovered that $\mathbf{1 9 9}$ is configurationally unstable under the reaction conditions and propose that a similar deracemisation mechanism is responsible for the enantioselectivity via triplet state intermediate $\mathbf{2 0 0}$, rather than proceeding via an enantioselective rearrangement.

Bifunctional hydrogen bonding photocatalysts have been developed by other groups as well. Sivaguru developed an atropisomeric thiourea-based catalyst $\mathbf{2 0 1}$ and used it for the intramolecular photocycloaddition of coumarins 202 (Scheme 31) [89]. The proposed mechanism for this reaction is similar to that proposed by Bach and Krische, proceeding via a key hydrogen 


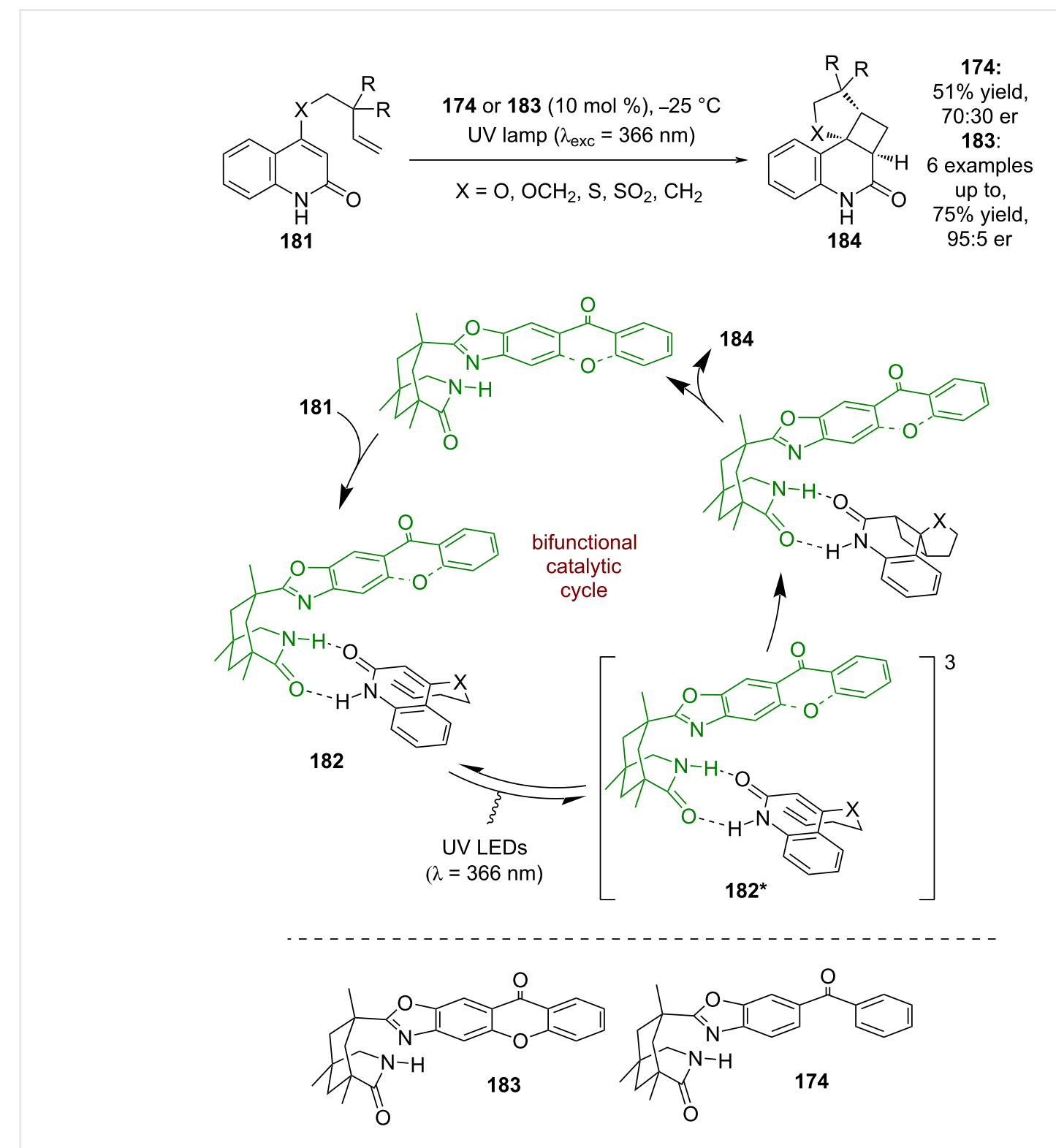

Scheme 27: Bifunctional hydrogen bonding/photocatalysed intramolecular [2 +2 ] photocycloadditions of quinolones.

bonding complex 203. Interestingly, this catalyst allowed for reactivity with lactones, whereas Bach's catalysts are limited to lactams.

Yoon et al. developed an iridium-based bifunctional hydrogen bonding photocatalyst $\mathbf{2 0 5}$. To demonstrate the effectiveness of this photocatalyst system, they tested the intramolecular photocycloaddition of quinolones 206 (Scheme 32a) [90]. The proposed mechanism again proceeds via a triplet sensitisation of the substrate within a hydrogen bonding complex 207 that provides the desired products $\mathbf{2 0 8}$ in excellent yields and good enantioselectivities (13 examples, up to $96: 4$ er) and a quantum yield of 0.31 [91]. As with Bach's catalysts, the scope is limited to lactams. Yoon et al. then applied a similar catalyst to an intermolecular photocycloaddition between quinolone 209 and maleimide 210 (Scheme 32b) [92]. After extensive mechanistic investigations, the proposed mechanism for this reaction is markedly different to the intramolecular example in Scheme 32a. Firstly, the hydrogen-bonded complex 211 that forms is proposed to involve the alkoxy group rather than the $\mathrm{N}-\mathrm{H}$ bond that is usually invoked. Then, upon photoexcitation, Dexter energy transfer to the maleimide is dominant to generate ${ }^{3}$ maleimide rather than energy transfer to the quinolone. While some maleimide dimerisation is observed, which supports the presence of triplet maleimide, a rapid cycloaddition occurs with the now ground-state hydrogen-bonded quinolone-iridium com- 
a<smiles>[Y]Cc1cc(=O)[nH]c2ccccc12</smiles>

$185(10 \mathrm{~mol} \%),-25^{\circ} \mathrm{C}$

white lamp $\left(\lambda_{\text {exc }}=400-700 \mathrm{~nm}\right)$

$\mathrm{X}=\mathrm{CH}_{2}, \mathrm{O}$ or NTs<smiles>[Y]C[C@H]1C([R])([R])[C@]23C(=O)Nc4ccccc4[C@]12[C@@H]3[Y]</smiles>

7 examples

up to

$97 \%$ yield,

97:3 er

b<smiles>[R20]OC(=O)C#CC([R20])=O</smiles>

c<smiles>[R]c1cc(=O)[nH]c2c([R])cccc12</smiles>

189<smiles>[R]C([R])=C([R])[R]</smiles>

190

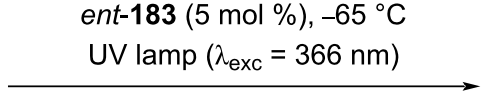<smiles></smiles>

188

11 examples up to $79 \%$ yield, 96:4 er

d<smiles>[R]/C=C\CCOc1c([R])c(=O)[nH]c2cc[R1]([R])cc12</smiles>

$185(0.5-10 \mathrm{~mol} \%),-25^{\circ} \mathrm{C}$ blue lamp $\left(\lambda_{\text {exc }}=420 \mathrm{~nm}\right)$

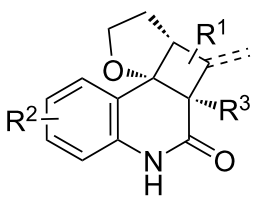

193

16 examples up to $99 \%$ yield, $>99: 1$ er

Scheme 28: Bifunctional hydrogen bonding/photocatalysed [2 + 2] photocycloaddition reactions. (a) First use of the thioxanthone-based bifunctional catalyst for an intramolecular cycloaddition. (b) Intermolecular cycloaddition of pyridines and acetylenedicarboxylates using a xanthone-based photocatalyst. (c) Intermolecular cycloaddition of quinolones with electron-deficient alkenes using a thioxanthone-based photocatalyst. (d) Intramolecular cycloaddition of quinolones with attached alkenes or allenes using a thioxanthone-based photocatalyst.

plex within the solvent cage pair 212 to give complex 213. Subsequent displacement by another substrate molecule releases the desired products 214 in excellent yields and enantioselectivities (20 examples, up to $>99: 1$ er), with a quantum yield of 0.013 .

While there has been significant progress using bifunctional catalysts, dual catalytic systems can offer other modes of reac- tivity. For instance, Jiang et al. developed a urea-catalysed formal arylation of benzofuranones 215, using naphthoquinones 216 to afford enantioenriched benzofuranones 217 (Scheme 33) [93]. They then expanded the scope of the naphthoquinone by coupling this reaction with a photocatalysed oxidation of naphthols 218 to generate 216 in situ. While no detailed mechanism has been proposed, based on prior work of Hawkins et al. [94] it is suggested that this reaction uses ${ }^{1} \mathrm{O}_{2}$ 

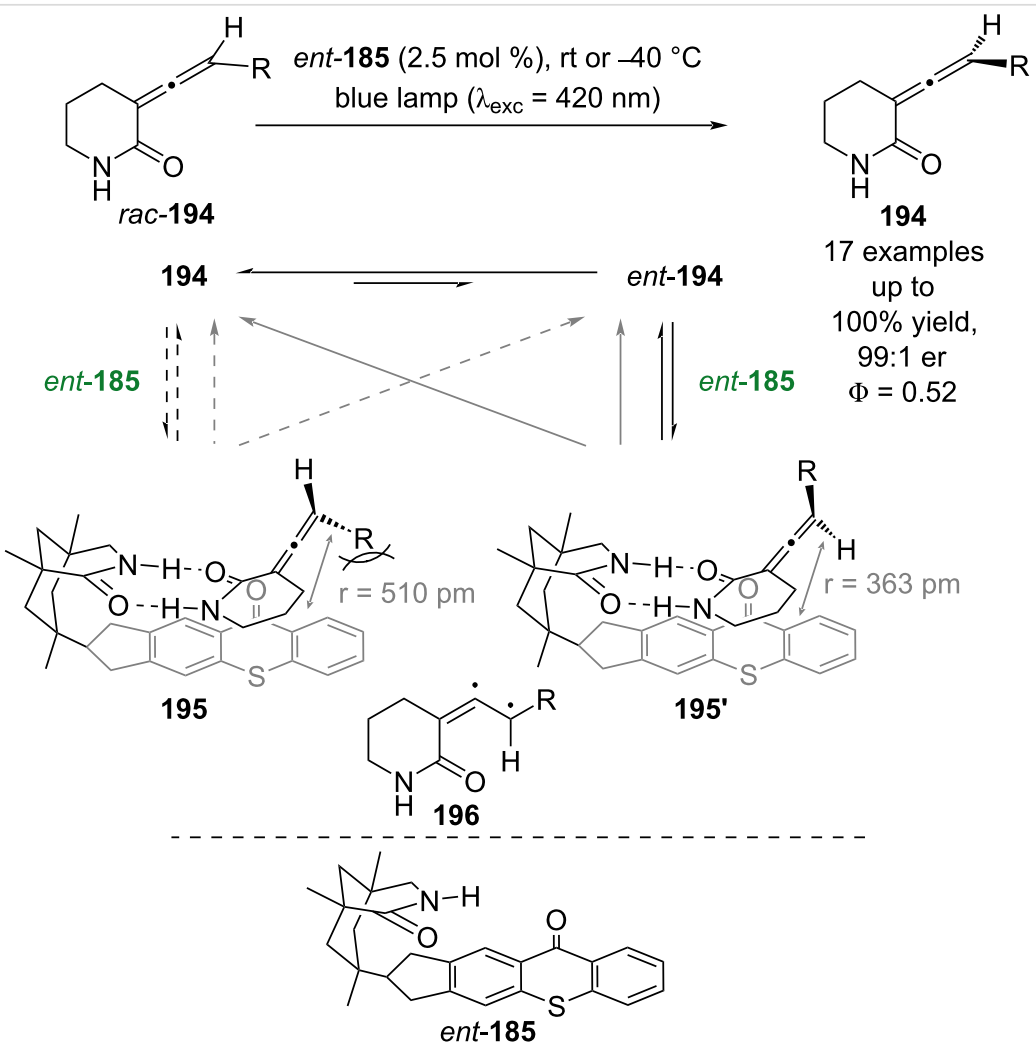

Scheme 29: Bifunctional hydrogen bonding/photocatalysed deracemisation of allenes.<smiles>[R]C1([R])C(=O)Nc2cc[R17]cc2S1=O</smiles>

$183(5 \mathrm{~mol} \%)$, rt UV lamp $\left(\lambda_{\text {exc }}=366 \mathrm{~nm}\right)$

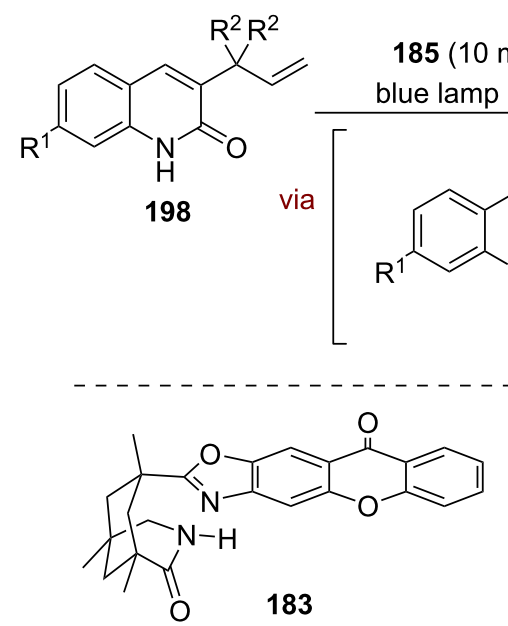<smiles>[R]C1([R])C(=O)Nc2c[R17]ccc2S1(O)O</smiles>

up to

$95 \%$ yield

78:22 er ment followed by photocatalysed deracemisation of the resulting cyclopropane products. 


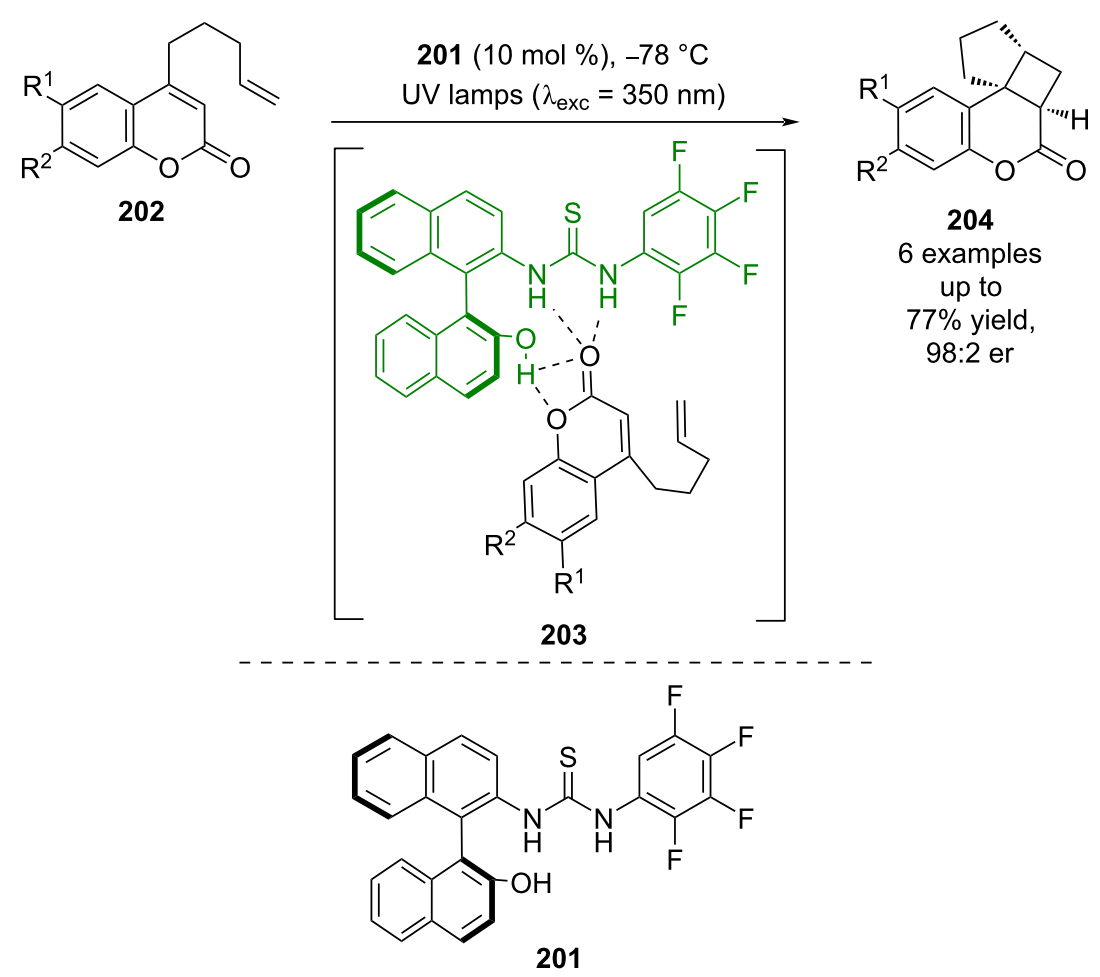

Scheme 31: Bifunctional hydrogen bonding/photocatalysed intramolecular [2 + 2] photocycloaddition of coumarins.

for the oxidation, and proceeds through transition state $219^{\ddagger}$ for the hydrogen-bonded catalysed nucleophilic addition step.

Jiang et al. recently applied a similar dual catalytic system to the dehalogenative protonation of $\alpha, \alpha$-chlorofluoro ketones 222 (Scheme 34) [95]. A reductive quenching cycle is proposed using tetrahydroquinoxaline $\mathbf{2 2 3}$ as a sacrificial reductant to generate $\mathrm{DPZ}^{--}$, which then reduces the organocatalyst-bound substrate 224 to give $\alpha$-carbonyl radical $\mathbf{2 2 4}^{\circ}$. Further reduction to the corresponding enolate and enantioselective protonation furnished the desired enantioenriched $\alpha$-fluoroketones $\mathbf{2 2 5}$ in excellent yields and enantioselectivities (33 examples, up to $>99: 1$ er).

Jiang et al. used a related system for the enantioselective reduction of 1,2-diketones 227 (Scheme 35a) [96]. In this case the catalyst $\mathbf{2 2 8}$ is proposed to form hydrogen-bonded complex 229. THIQ 230 is used as a sacrificial reductant to generate $\mathrm{DPZ}^{--}$, which reduces $\mathbf{2 2 9}$ to give radical anion intermediate $\mathbf{2 2 9}^{\circ-}$. Further reduction by 230 results in carbanion $\mathbf{2 2 9}^{-}$ which is protonated enantioselectively to give the desired $\alpha$-hydroxy ketones $\mathbf{2 3 1}$ in excellent yields and enantioselectivities (16 examples, up to 99:1 er). Within the same publication Jiang et al. expands this reactivity to activated imines $\mathbf{2 3 2}$, using slightly modified conditions to obtain $\alpha$-amino ketones 233 in excellent yields and good enantioselectivities (10 exam- ples, up to $95: 5$ er) (Scheme 35b). It is also worth noting that this reaction works in the absence of DPZ (albeit with lower enantioselectivities for some examples), which is proposed to be due to the formation of an EDA complex between $\mathbf{2 3 0}$ and 229.

CPAs were shown to be excellent partners for dual photoredox catalysis in the section "Brønsted acid catalysis", yet interestingly their conjugate bases can also be used as efficient hydrogen bonding catalysts. Knowles et al. showed that a tricatalytic system using chiral phosphate $\mathbf{2 3 5}$ can mediate the deracemisation of cyclic urea rac-236 (Scheme 36) [97]. The proposed mechanism involves a reversible reductive quenching step to give two enantiomeric radical cations $\mathbf{2 3 6}^{\mathbf{*}}$ and ent-236 ${ }^{\mathbf{*}}$. The acidified adjacent proton can then be abstracted by a base to give the racemic radical $\mathbf{2 3 6}^{\circ}$, which then undergoes HAT with a thiol HAT catalyst to complete the racemisation. If an appropriate chiral base is used, then ent-236 ${ }^{-+}$can be deprotonated, and therefore racemised faster than $\mathbf{2 3 6}^{\mathbf{}}$, leading to a build-up of one enantiomer. This process initially achieved an er of 86:14, but with the inclusion of a complementary chiral HAT catalyst 237 and a radical scavenger $\left(\mathrm{Ph}_{3} \mathrm{CH}\right)$, the er could be improved to $96: 4$.

Recently, Knowles et al. used a similar tricatalytic system for the enantioselective cyclisation of sulfonamides $\mathbf{2 3 8}$ 
a<smiles>[R]C/C=C\COc1cc2cc[R]cc2[nH]c1=O</smiles>

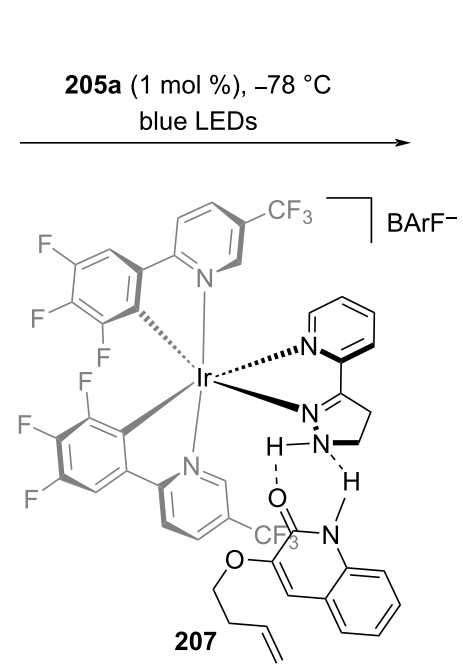

b<smiles>[R20]C1C=CC(=O)N1[R1]</smiles>

205b $(1.5 \mathrm{~mol} \%),-78^{\circ} \mathrm{C}$ blue LEDs

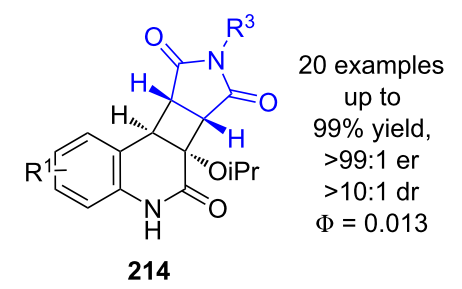

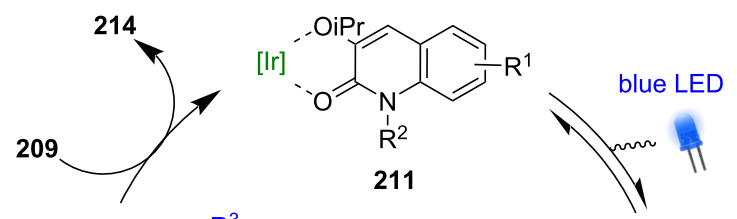

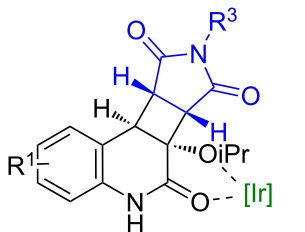

bifunctional catalytic cycle

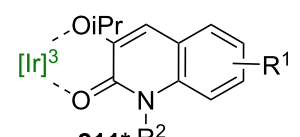

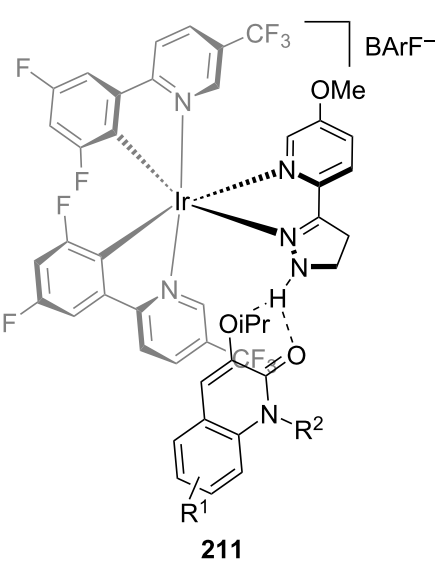

$\mathrm{R}^{2}$

212

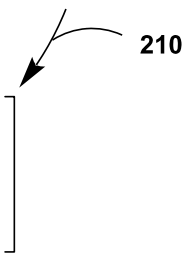<smiles></smiles>

213

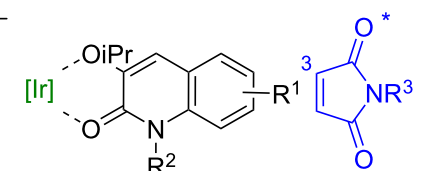

211

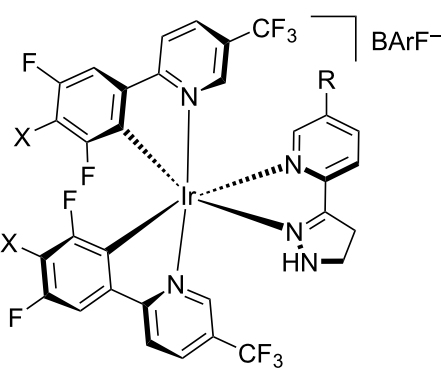

$X=F, R=H, 205 a$

$\mathrm{X}=\mathrm{H}, \mathrm{R}=\mathrm{OMe}, \mathbf{2 0 5 b}$

Scheme 32: Bifunctional hydrogen bonding/photocatalysed [2 + 2] photocycloadditions of quinolones. (a) Intramolecular cycloaddition of quinolones. (b) Intermolecular cycloaddition of quinolones and maleimides. 
<smiles>O=C1Oc2ccccc2C1Br</smiles>

215<smiles>O=C1Oc2ccccc2C1Br</smiles>

215<smiles>O=C1C=CC(=O)c2ccccc21</smiles>

216
$385(10 \mathrm{~mol} \%)$ $-40^{\circ} \mathrm{C}$

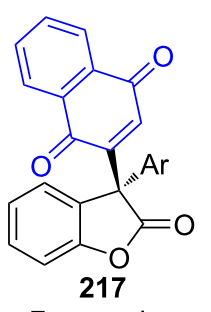

7 examples

up to $90 \%$ yield 96:4 er<smiles>O=C1C=C([C@@]2([Al])C(=O)Oc3ccccc32)C(=O)c2ccccc21</smiles>

217

10 examples up to

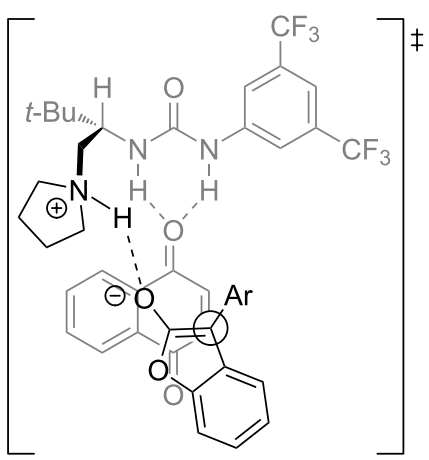

yield 98:2 er<smiles>CC(C)(C)C(CN1CCCC1)NC(=O)NNC1CCCCC1</smiles>

220<smiles>O=c1c(N[Ga])c(NC2CCCCC2N2CCCCC2)c1=O</smiles>

221

$\mathrm{Ar}=3,5-\left(\mathrm{CF}_{3}\right)_{2} \mathrm{C}_{6} \mathrm{H}_{3}$

Scheme 33: Hydrogen bonding/photocatalysed formal arylation of benzofuranones.

(Scheme 37) [98]. In this case, the proposed mechanism involves a PCET step to give an $N$-centred radical that then cyclises enantioselectively to give the alkyl radical intermediate $\mathbf{2 3 9}^{\circ}$, which abstracts a hydrogen atom from TRIP-thiol to produce enantioenriched cyclic sulfonamides 239 in excellent yields and enantioselectivities (28 examples, up to 98:2 er).

Chiral phosphates have also been used to catalyse the enantioselective nucleophilic addition of indoles $\mathbf{2 4 1}$ to imines, which are 
33 examples

up to

$96 \%$ yield,

$>99: 1$ er
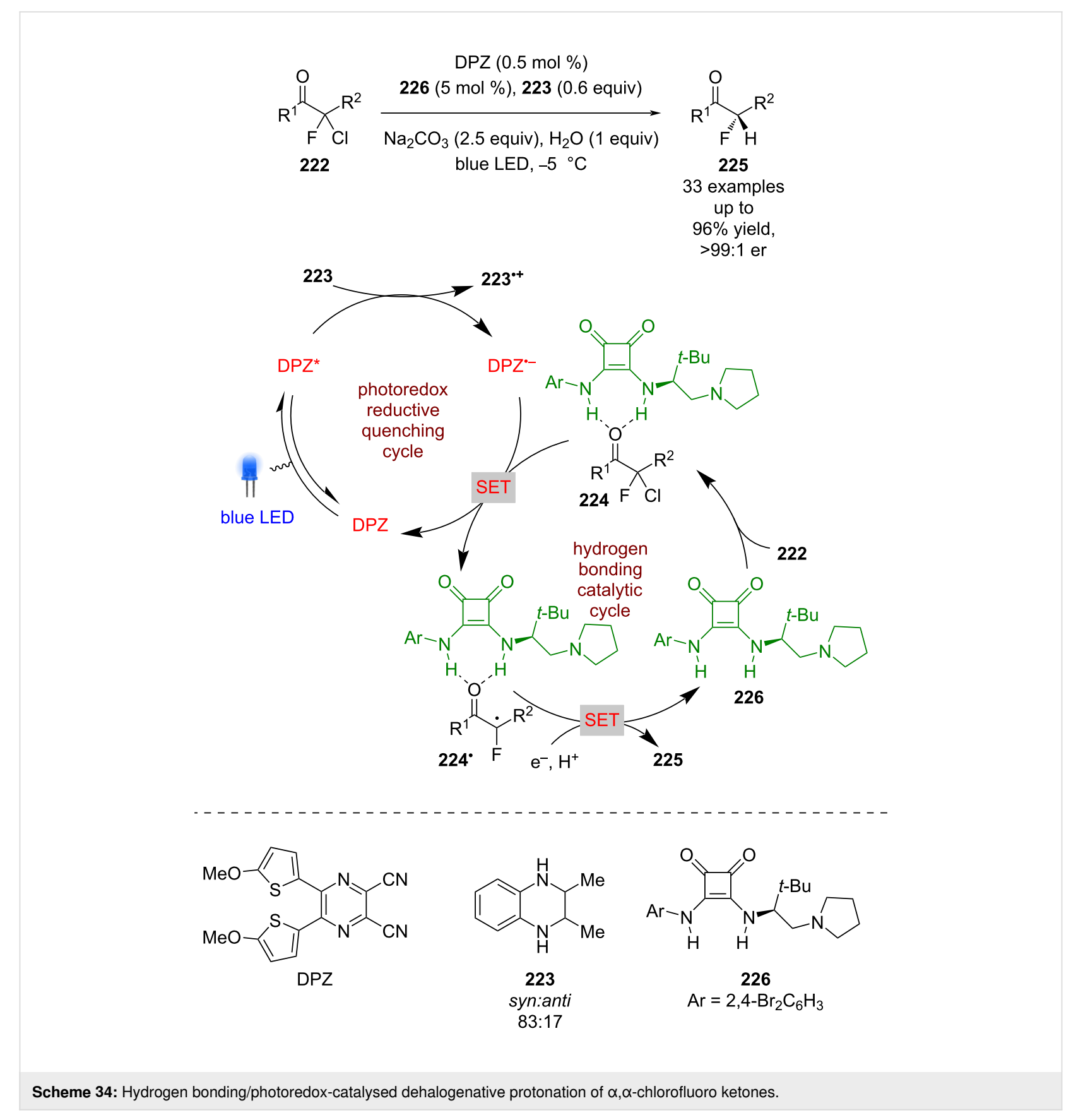

83:17

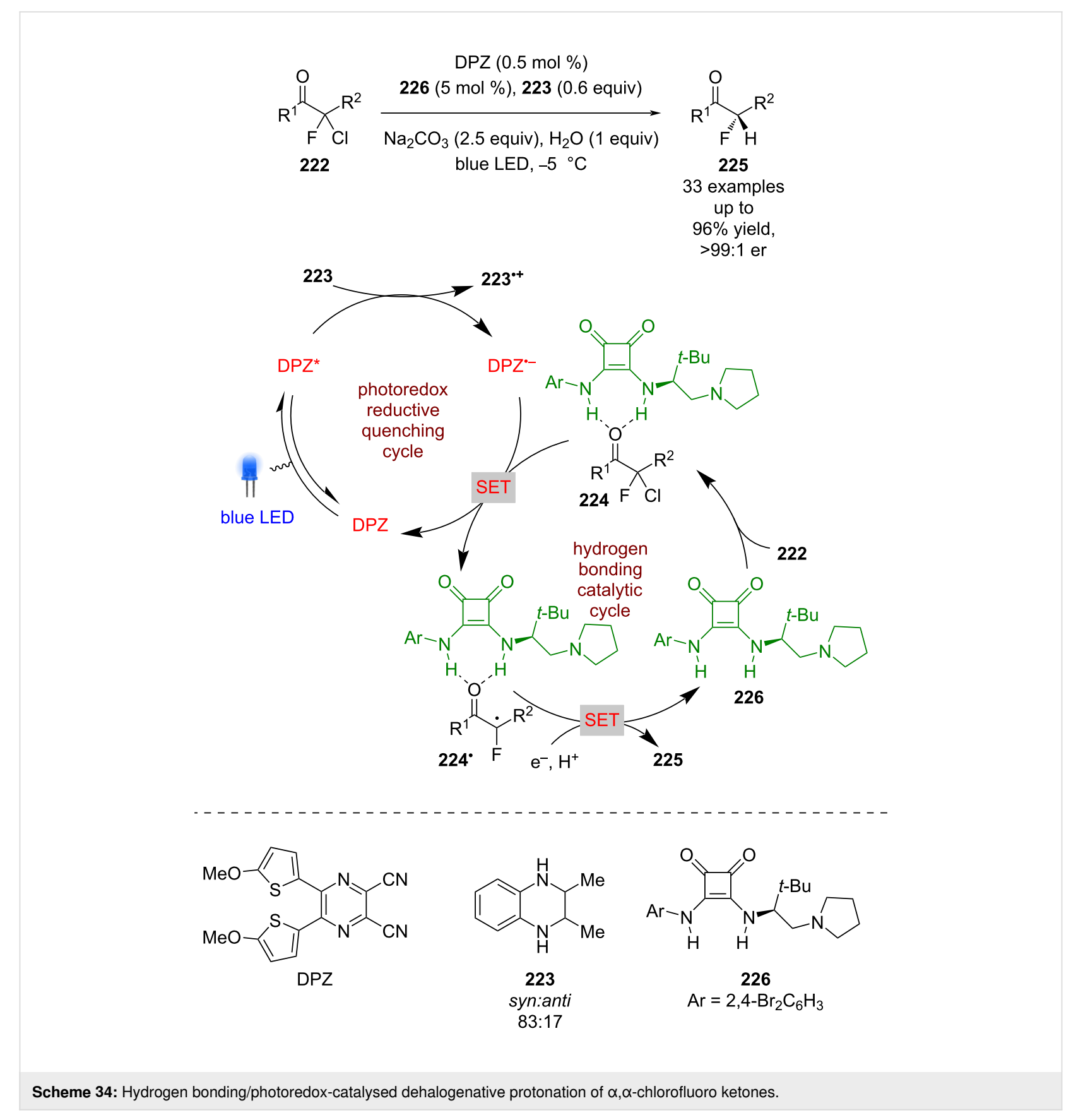

225

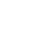

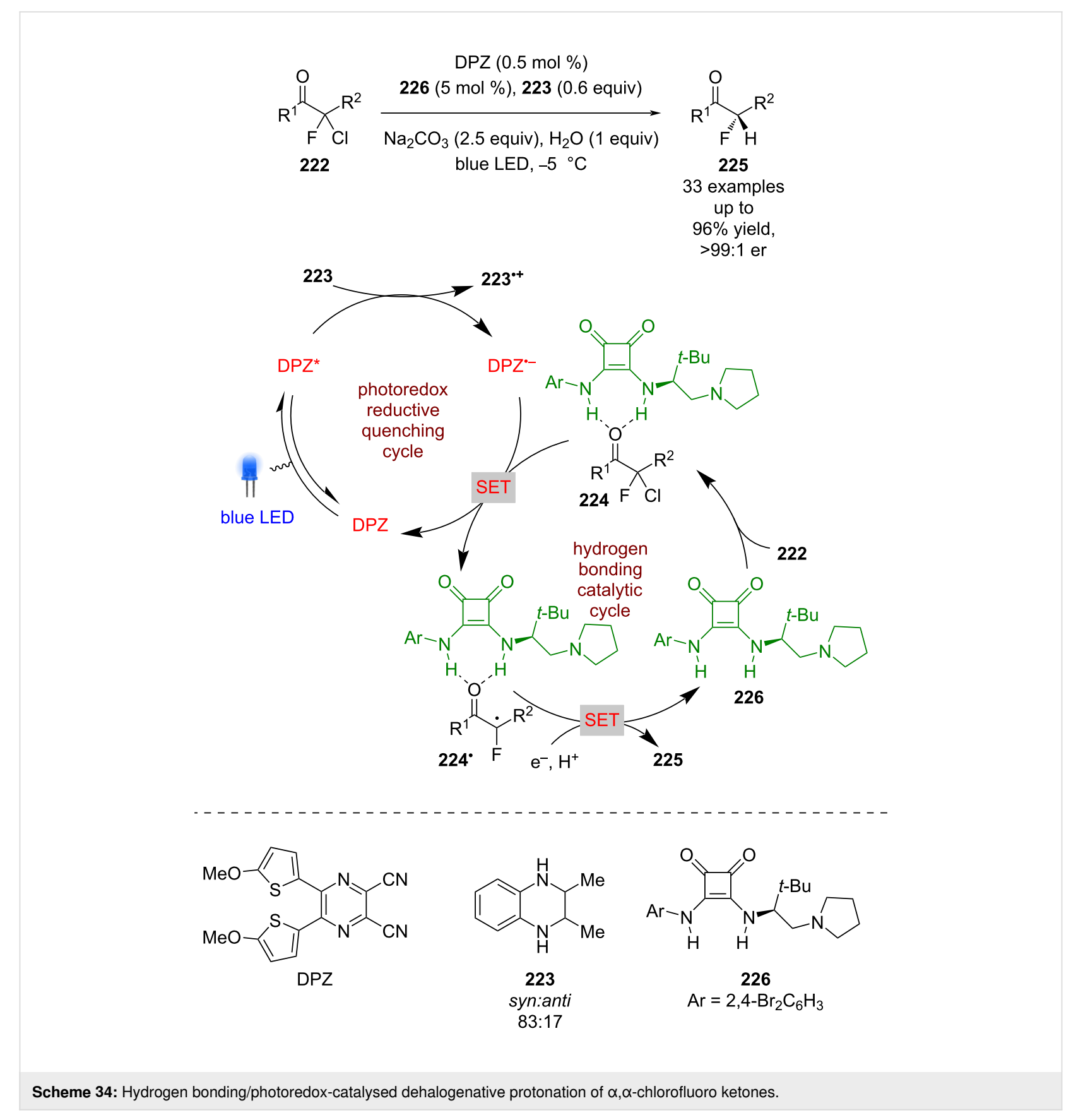

photocatalytically generated in situ from redox-active esters $\mathbf{2 4 2}$ (Scheme 38) [99]. The mechanism advanced by Wang et al. proposes that $\mathbf{2 4 1}$ acts as a sacrificial reductant to generate the reduced photocatalyst, which can then reduce $\mathbf{2 4 2}$ in a second SET step to give $\alpha$-amino radical $\mathbf{2 4 2}^{\circ}$ after decarboxylation. The excited photocatalyst is reductively quenched by $\mathbf{2 4 2}^{\circ}$ to give the imine intermediate $\mathbf{2 4 3}$. Indoles 241 and $\mathbf{2 4 3}$ are then brought together by the chiral phosphate catalyst 244 and the lithium counterion in a hydrogen-bonded complex 245 to give the desired enantioenriched products 246 in excellent yields and enantioselectivities (30 examples, up to 99:1 er).

\section{Ion pair}

Ion pair catalysis has interesting potential in combination with photoredox catalysis considering that the catalytic intermediates are often radical cations or anions. Despite this, there are relatively few examples of this dual catalytic mode. Ooi et al. reported an enantioselective synthesis of 1,2 diamines $\mathbf{2 4 7}$ from tertiary amines 248 and aldimines 249 (Scheme 39) [100]. The proposed mechanism involves a reductive quenching pathway with 248 to produce radical cations $\mathbf{2 4 8}^{\circ+}$, which following deprotonation and a [1,2]-radical shift generates $\alpha$-amino radicals 248. Simultaneously, 249 is reduced by the reduced photocata- 
a

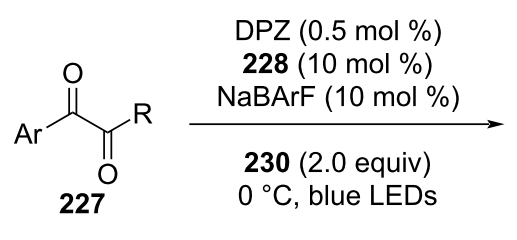<smiles>[R]C(=O)[C@H]([13CH3])O</smiles>

16 examples

up to

$99 \%$ yield

99:1 er

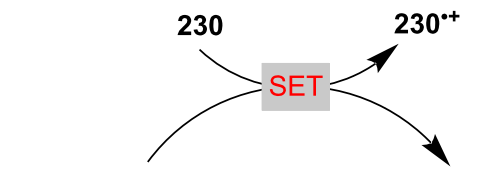

$\mathrm{DPZ}^{*} \quad$ photoredox

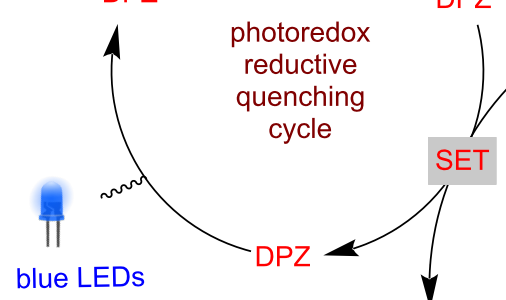

blue LEDs
DPZ

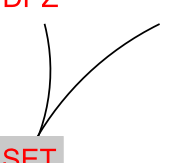

SET

r

$\stackrel{\ominus}{\mathrm{BArF}}$<smiles>c1cc2nc(c1)CCCCCC2</smiles><smiles></smiles>

๑o'

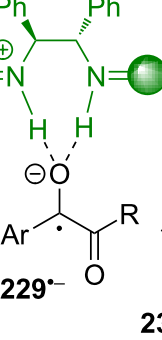

229

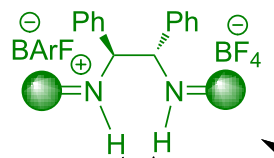<smiles>[R]C(=O)C(=O)OC</smiles><smiles>[3H]CC[12CH3]</smiles>

chiral counterion catalytic

cycle

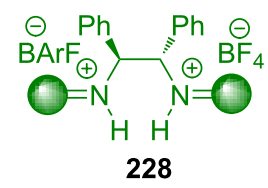

228

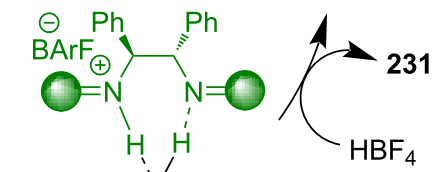<smiles>[AlH2]</smiles>

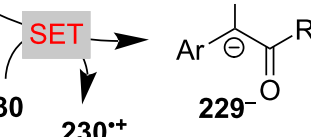

b<smiles>[R]C(=O)/C([Al])=N\c1ccc(OC)cc1Br</smiles><smiles>[R]C(=O)C([AlH2])Nc1ccc(OC)cc1Br</smiles>

10 examples

$$
\text { up to }
$$

$95 \%$ yield

95:5 er

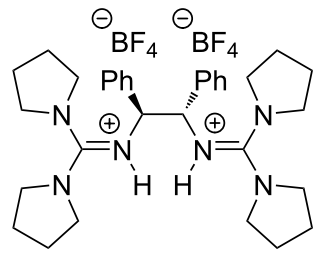

228<smiles>c1ccc2c(c1)CCN(c1ccc3ccccc3c1)C2</smiles>

230<smiles>COc1ccc(-c2nc(C#N)c(C#N)nc2-c2ccc(OC)s2)s1</smiles>

DPZ<smiles>O=C(Nc1cc(C(F)(F)F)cc(C(F)(F)F)c1)NC1CCCCC1N1CCCCC1</smiles>

234 

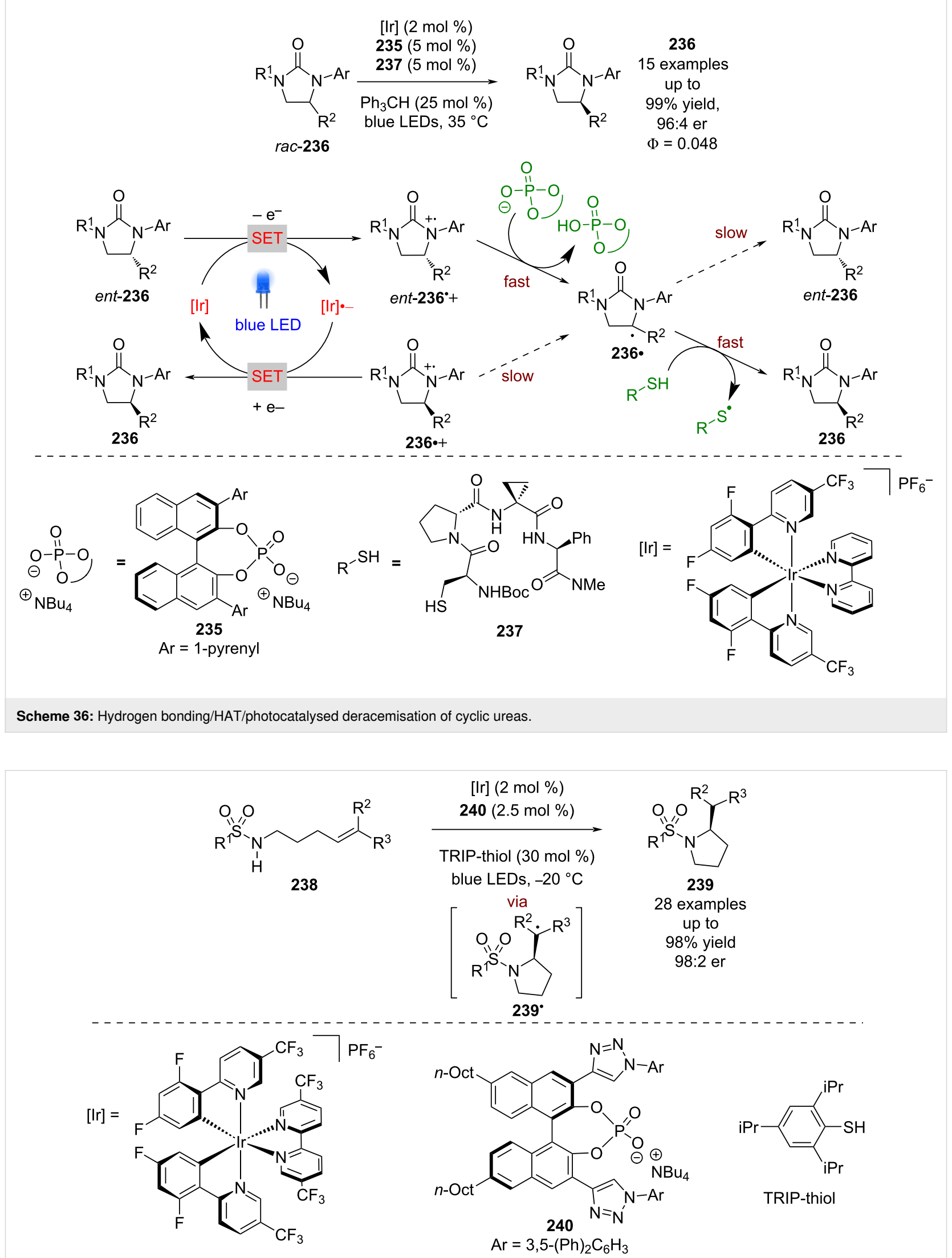

TRIP-thiol

Scheme 37: Hydrogen bonding/HAT/photoredox-catalysed synthesis of cyclic sulfonamides. 
<smiles></smiles>

241<smiles>[R]C(NC([R])OC(=O)N1C(=O)c2ccccc2C1=O)OCC</smiles>

242

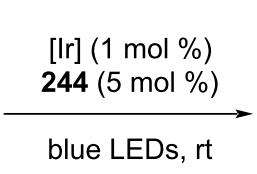

blue LEDs, rt<smiles></smiles>

246

30 examples

up to $97 \%$ yield, 99:1 er

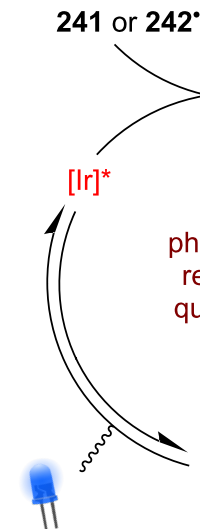

blue LED
[Ir]

$$
241^{\text {+t }} \text { or } 243
$$

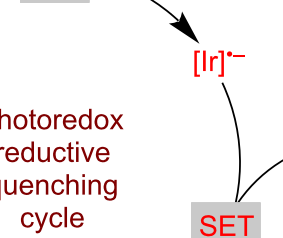

242

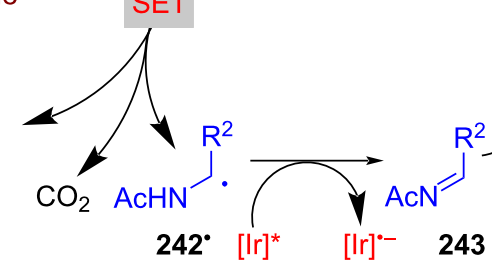<smiles>[R2]C=[WH]OP1(=O)OCCO1</smiles><smiles>[R]CN(C)Nn1ccc2ccc([R])cc21</smiles>

phosphate $\checkmark H$ Li,<smiles>O=P1(C23CCCC2CCC3)CCO1</smiles>

catalytic

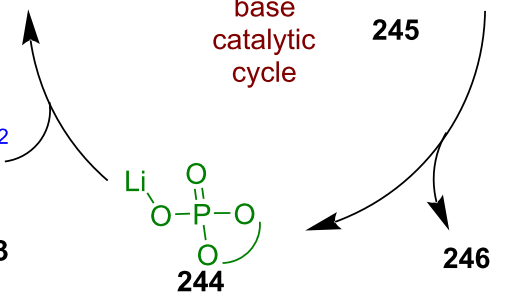

246

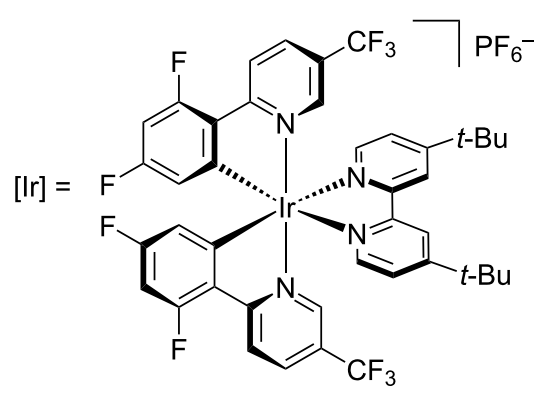

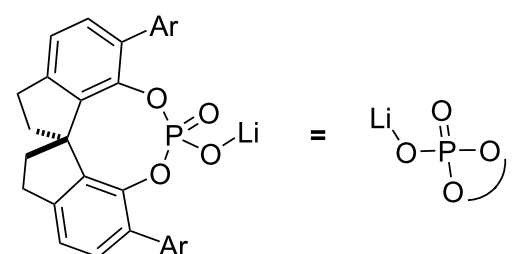

244

$\mathrm{Ar}=2,4,6-(\mathrm{PPr})_{3} \mathrm{C}_{6} \mathrm{H}_{2}$

Scheme 38: Hydrogen bonding/photoredox-catalysed reaction between imines and indoles.

lyst to give radical anion $249^{\circ-}$ that can then undergo a cation exchange with chiral cationic acid $\mathbf{2 5 0}$ and form a chiral ion pair 251. The two radical species then couple enantioselectively within the chiral environment, producing 247 in excellent yields and enantioselectivities (17 examples, up to 99:1 er). The authors noted that they cannot rule out the alternative mechanism whereby a radical addition of $\mathbf{2 4 8}^{\circ}$ to an acid coordinated $\mathbf{2 4 9}$ is followed by a single electron reduction of the resulting $N$-centred radical.
The previous example used a chiral cation to induce enantioselectivity, while Luo et al. used a chiral phosphate base $\mathbf{2 5 1}$ as a counterion to Mes-Acr ${ }^{+}$(Scheme 40) [101]. With this combination, they successfully developed an enantioselective variant of Nicewicz's hydroetherification reaction of alkenols 252 [102]. The proposed mechanism proceeds through a reductive quenching cycle that generates chiral ion pair 253. Subsequent enantioselective cyclisation gives tertiary alkyl radical $\mathbf{2 5 4}^{\mathbf{*}}$, which can abstract a hydrogen atom from 2-phenylmalonitrile 


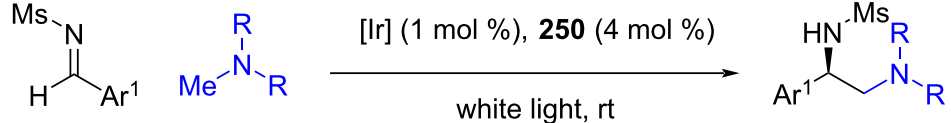

$$
\begin{aligned}
& 249248 \quad \text { BArF }^{-}=\left[\left\{3,5-\left(\mathrm{CF}_{3}\right)_{2} \mathrm{C}_{6} \mathrm{H}_{3}\right\}_{4} \mathrm{~B}\right]^{-} \quad 247 \\
& 17 \text { examples } \\
& \text { up to } \\
& 90 \% \text { yield, } \\
& \text { 99:1 er }
\end{aligned}
$$
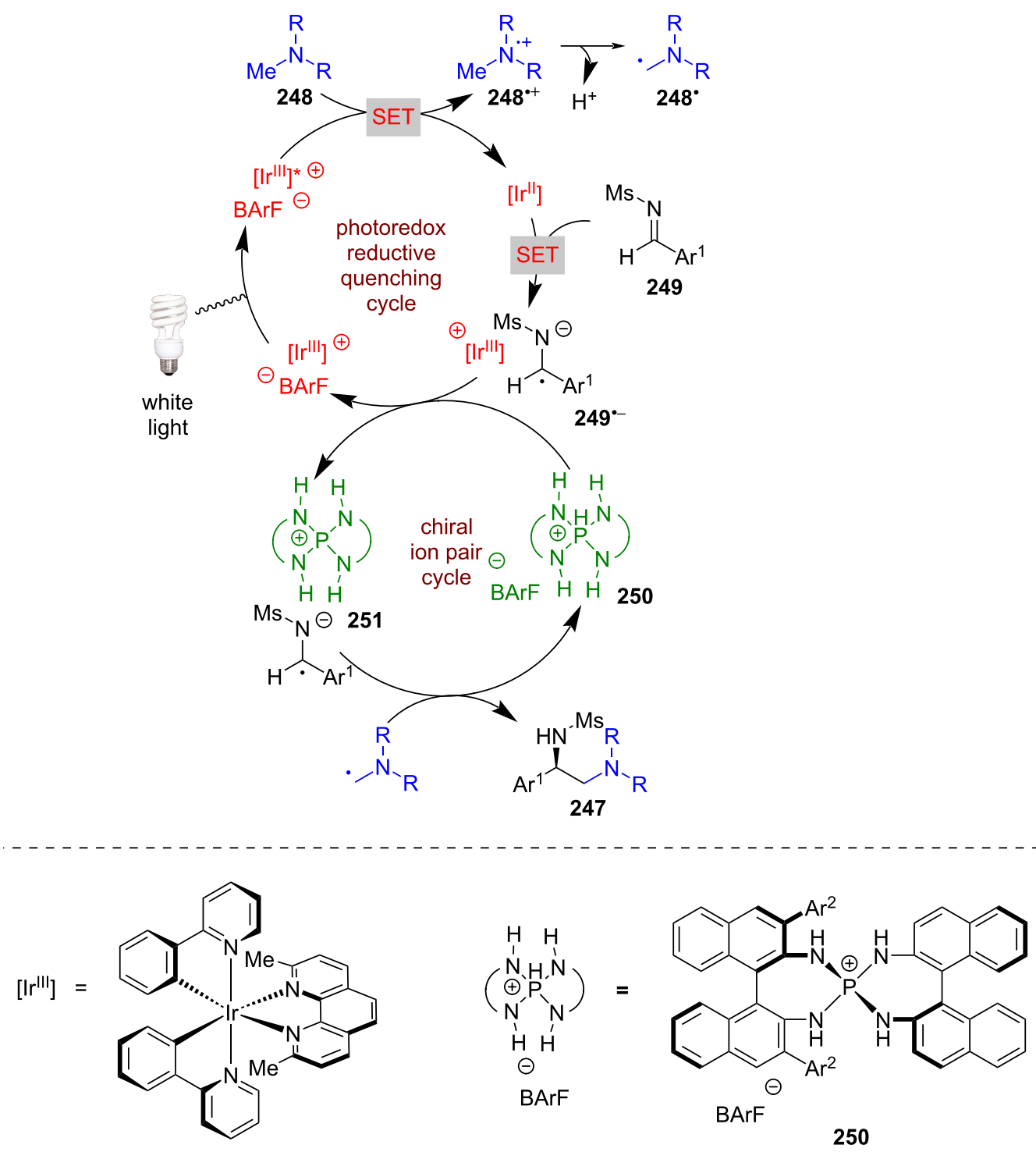

$\mathrm{Ar}^{2}=2-(\mathrm{Ph})-4-\left(\mathrm{CF}_{3}\right) \mathrm{C}_{6} \mathrm{H}_{3}$

Scheme 39: Chiral cation/photoredox-catalysed radical coupling of two $\alpha$-amino radicals.

(255) to afford the desired enantioenriched tetrahydrofuran 256 in excellent yields and moderate enantioselectivities (14 examples, up to $82: 18$ er).

Knowles et al. synthesised enantioenriched pyrroloindolines $\mathbf{2 5 7}$ from indoles 258 and TEMPO using an iridium-based photocatalyst and a similar chiral phosphate base $\mathbf{2 5 9}$ to that employed by Luo et al. (Scheme 41) [103]. The proposed mechanism implicates an oxidative quenching cycle using a sacrificial oxidant (TIPS-EBX), followed by a PCET step with hydrogen-bonded complex 260 to give chiral ion pair $\mathbf{2 6 0}^{\circ}$, which completes the photocatalytic cycle. Subsequent enantioselec- 


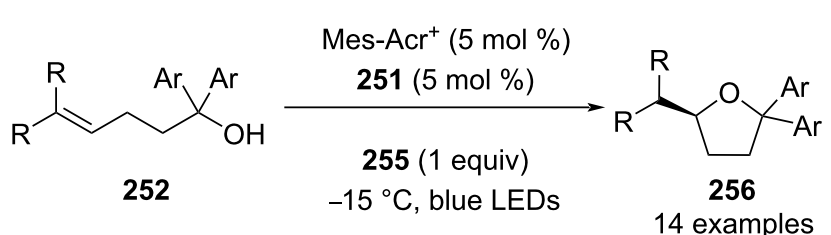

14 examples

up to

$90 \%$ yield,

$82: 18$ er

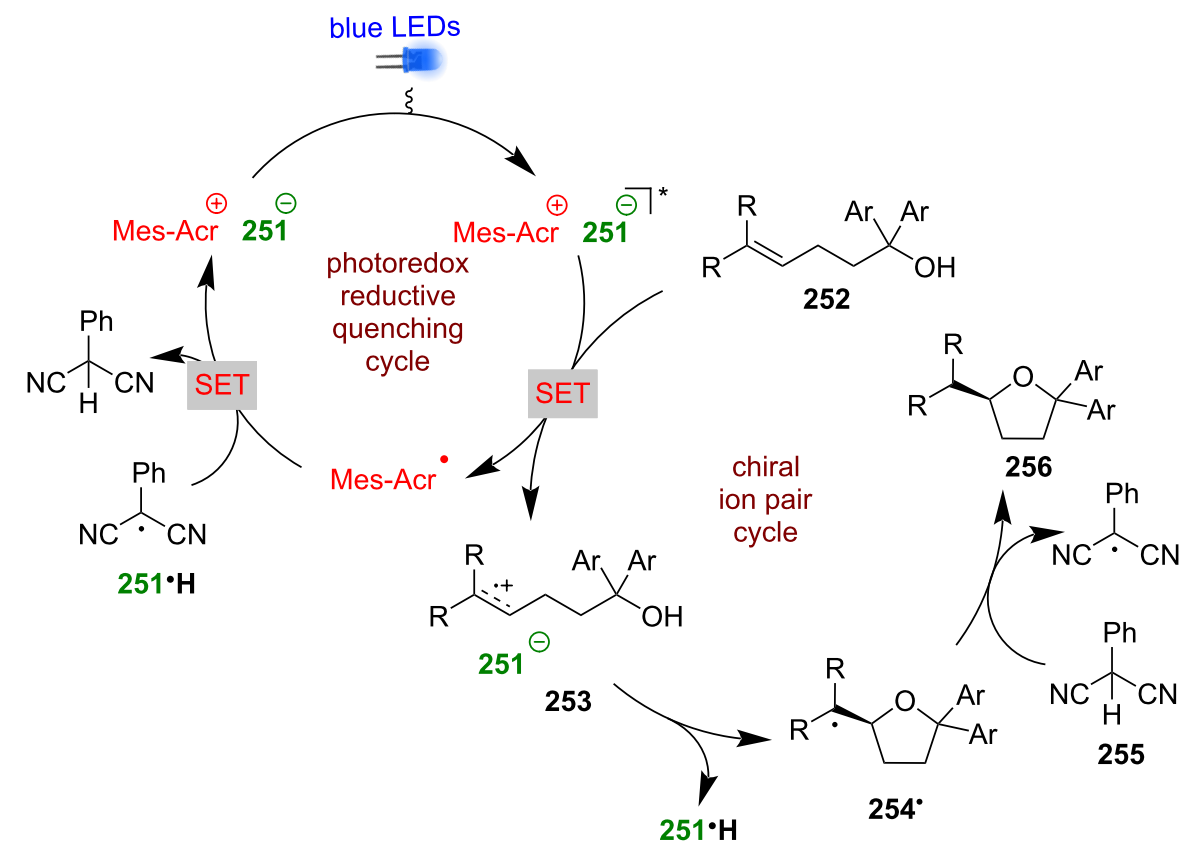

Ar=<smiles></smiles><smiles>N#CC(C#N)c1ccccc1</smiles>

255

Scheme 40: Chiral phosphate/photoredox-catalysed hydroetherfication of alkenols.

tive radical coupling with TEMPO gives catalyst-bound iminium ion 261, which then cyclises with the nearby amine to produce the desired product $\mathbf{2 5 7}$ in good yields and enantioselectivities (9 examples, up to 97:3 er).

Nicewicz et al. developed an enantioselective radical cation Diels-Alder reaction in both an intramolecular fashion, using alkenes 262, and an intermolecular fashion, using alkene $\mathbf{2 6 3}$ and cyclopentadiene 264 (Scheme 42) [104]. Using a similar strategy to Luo et al., Nicewicz et al. uses a preformed chiral photocatalyst composed of a cationic triaryl pyrillium, TP, twinned with a chiral counterion $\mathbf{2 6 5}$. With an electron-rich alkene, the reaction is proposed to proceed via a reductive quenching cycle to generate chiral ion pair $\mathbf{2 6 2}^{\circ+}$ and $\mathrm{TP}^{\circ}$. Subsequent enantioselective cycloaddition with a diene results in ion pair $\mathbf{2 6 6}^{\mathbf{}}$, which is then reduced by $\mathrm{TP}^{\bullet}$ to complete the catalytic cycle and affords the desired products 267 or 268 in moderate yields and enantioselectivities ( 3 examples, up to 75:25 er for $\mathbf{2 6 7}$ and 2 examples, up to 68:32 er for $\mathbf{2 6 8}$ ).

\section{Lewis acid catalysis}

Lewis acids have been known for decades to activate carbonyl compounds through the formation of coordination complexes that increases carbonyl electrophilicity [105]. The use of chiral 


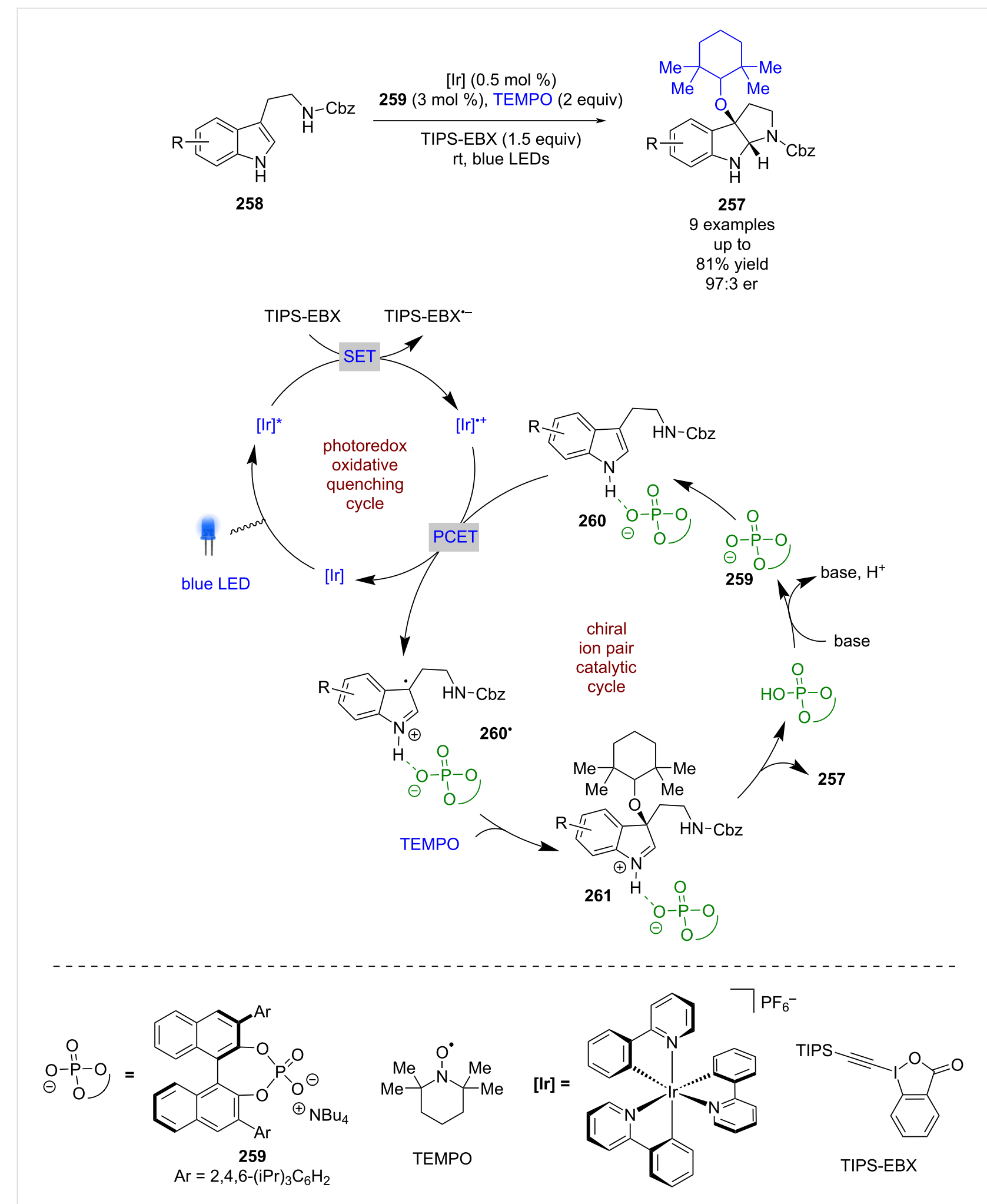

Scheme 41: Chiral phosphate/photoredox-catalysed synthesis of pyrroloindolines.

Lewis acids can induce asymmetry [106]. Yoon et al. applied this well-known form of catalysis to a photocatalytic system using enones 269 and 270 (Scheme 43a) [107]. Mechanistic studies of a closely related achiral reaction [20], showed this reaction likely operates via a radical chain mechanism. Initiation begins with the reductive quenching of the photocatalyst 

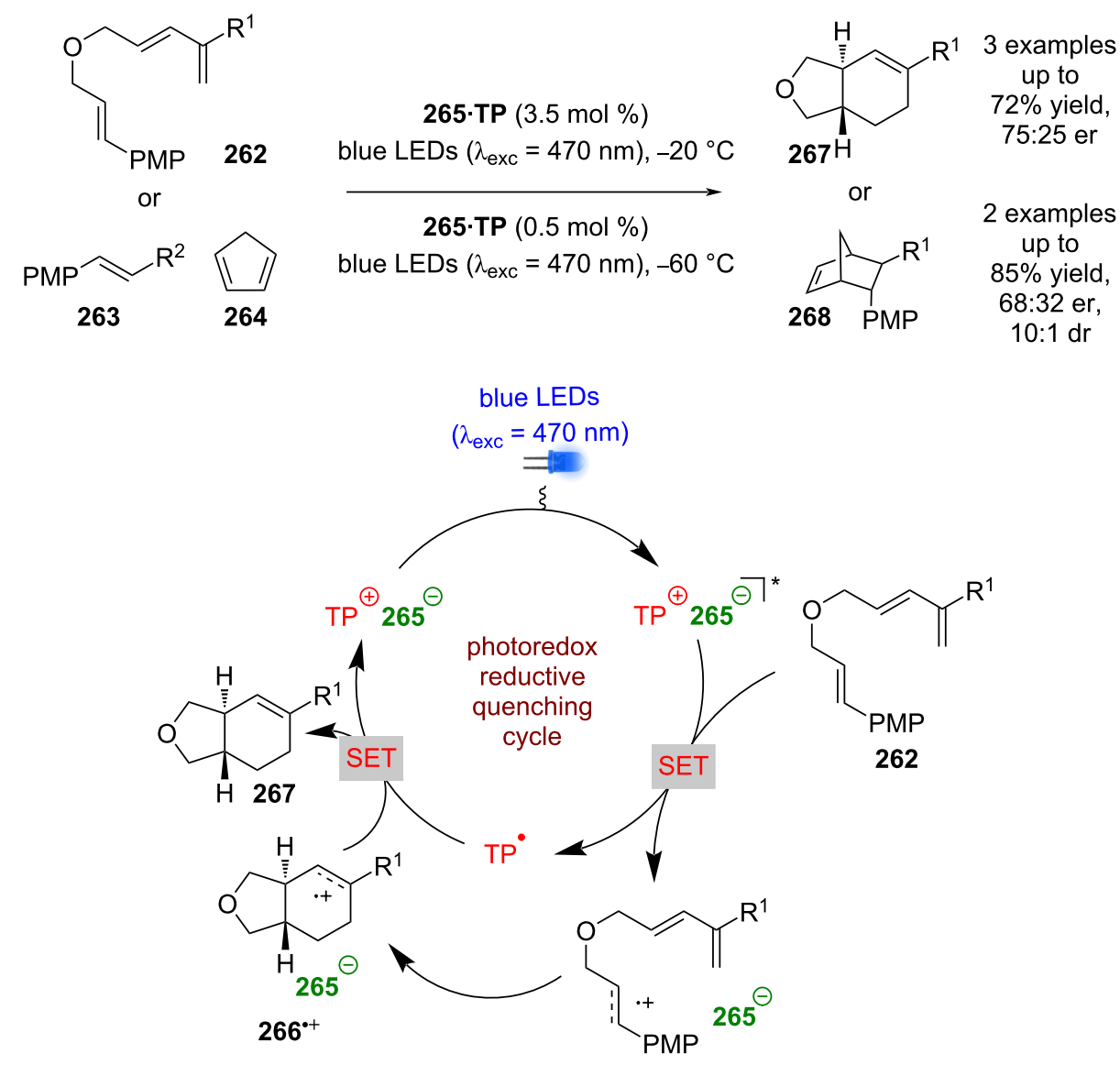

$262^{\bullet+}$<smiles>O=P1([PH3])Oc2ccc3c(c2-c2c(ccc4c2CCCC4)O1)CCCC3</smiles>

265

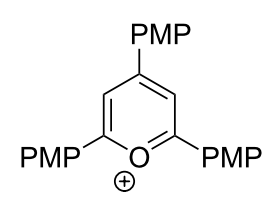

TP

Scheme 42: Chiral anion/photoredox-catalysed radical cation Diels-Alder reaction.

using $\mathrm{iPr}_{2} \mathrm{NEt}$ as a sacrificial reductant to give $[\mathrm{Ru}]^{\bullet-}$, which then reduces the Lewis acid-coordinated enone 271 to give alkyl radical $271^{\circ}$. In the presence of a second enone $\mathbf{2 7 0}$ and chiral ligands L1, an initial RCA occurs to generate $\alpha$-carbonyl radical $\mathbf{2 7 2}^{\circ}$, followed by cyclisation with the enolate to give ketyl radical $273^{\circ}$. Radical $273^{\circ}$ can then reduce another molecule of 271 to propagate the chain reaction and generate the desired formal photocycloaddition products 274 in good yields and enantioselectivities (12 examples, up to 97:3 er). Yoon et al. later expanded the scope of this reaction to cyclopropyl ketones $\mathbf{2 7 5}$ for the synthesis of formal [3+2] cycloaddition products 276 in excellent yields and enantioselectivities
(21 examples, up to $>99: 1$ er), this time using a gadolinium catalyst and chiral ligand L2 (Scheme 43b) [108].

By altering the radical precursor to $\alpha$-silyl amines 277 and using $\alpha, \beta$-unsaturated amides $\mathbf{2 7 8}$, Yoon et al. found that the reactions could be stopped at the RCA step to give enantioenriched 1,4-addition products 279 using a scandium catalyst and chiral ligand L3 (Scheme 44a) [109]. The putative mechanism proceeds via a reductive quenching cycle to give nucleophilic $\alpha$-amino radicals $277^{\circ}$, which can add to the $\beta$-position of Lewis acid complex 280 to give the $\alpha$-carbonyl radical $280^{\circ}$. Instead of a cyclisation, this radical is then reduced by the reduced photo- 
a<smiles>[R2]C=CC([R4])=O</smiles>

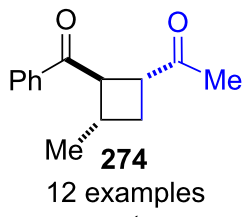

up to

$71 \%$ yield

9:1 dr, 97:3 er

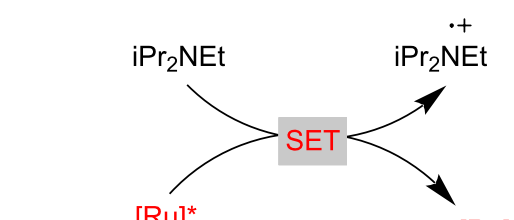

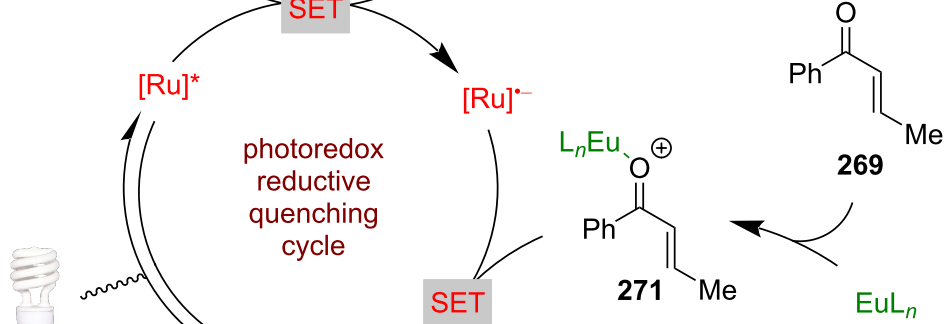

$\checkmark$

CFL<smiles>C=C=[IH]</smiles>

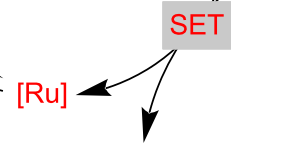

chain<smiles>C1CCCC1</smiles>

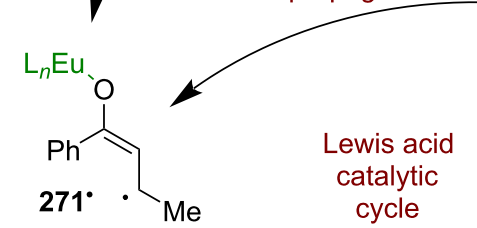<smiles>C=CC(C)=O</smiles>

270<smiles>CCO/C(=C/C(C)CCC(C)=O)c1ccccc1</smiles><smiles>CC=C(OCC)C1CC1C(C)=O</smiles>

b<smiles>[Y10]C=CC(=O)C1CC1([R1])[R1]</smiles>

275
[Ru] $(2.5 \mathrm{~mol} \%)$

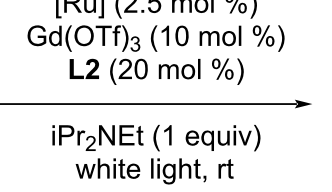

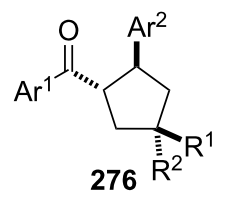

21 examples

up to

$95 \%$ yield,

$>99: 1$ er, $>20: 1 \mathrm{dr}$

$[\mathrm{Ru}]=$

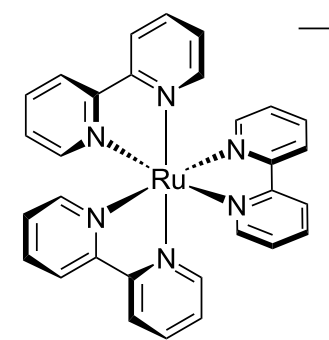
$2 \mathrm{Cl}^{-}$<smiles>CCCCNC(=O)C1CCCN1C(=O)C(N=Cc1ccccc1O)C(C)C</smiles>

L1<smiles>CCCCC1COC(c2cc(N(C)C)cc(C3=N[C@H](CCCC)CO3)n2)=N1</smiles>

Scheme 43: Lewis acid/photoredox-catalysed cycloadditions of carbonyls. (a) Formal [2 + 2] cycloaddition of enones using europium Lewis acid. (b) Formal [3 + 2] cycloaddition of cyclopropyl ketones with styrenes using a gadolinium Lewis acid catalyst. 

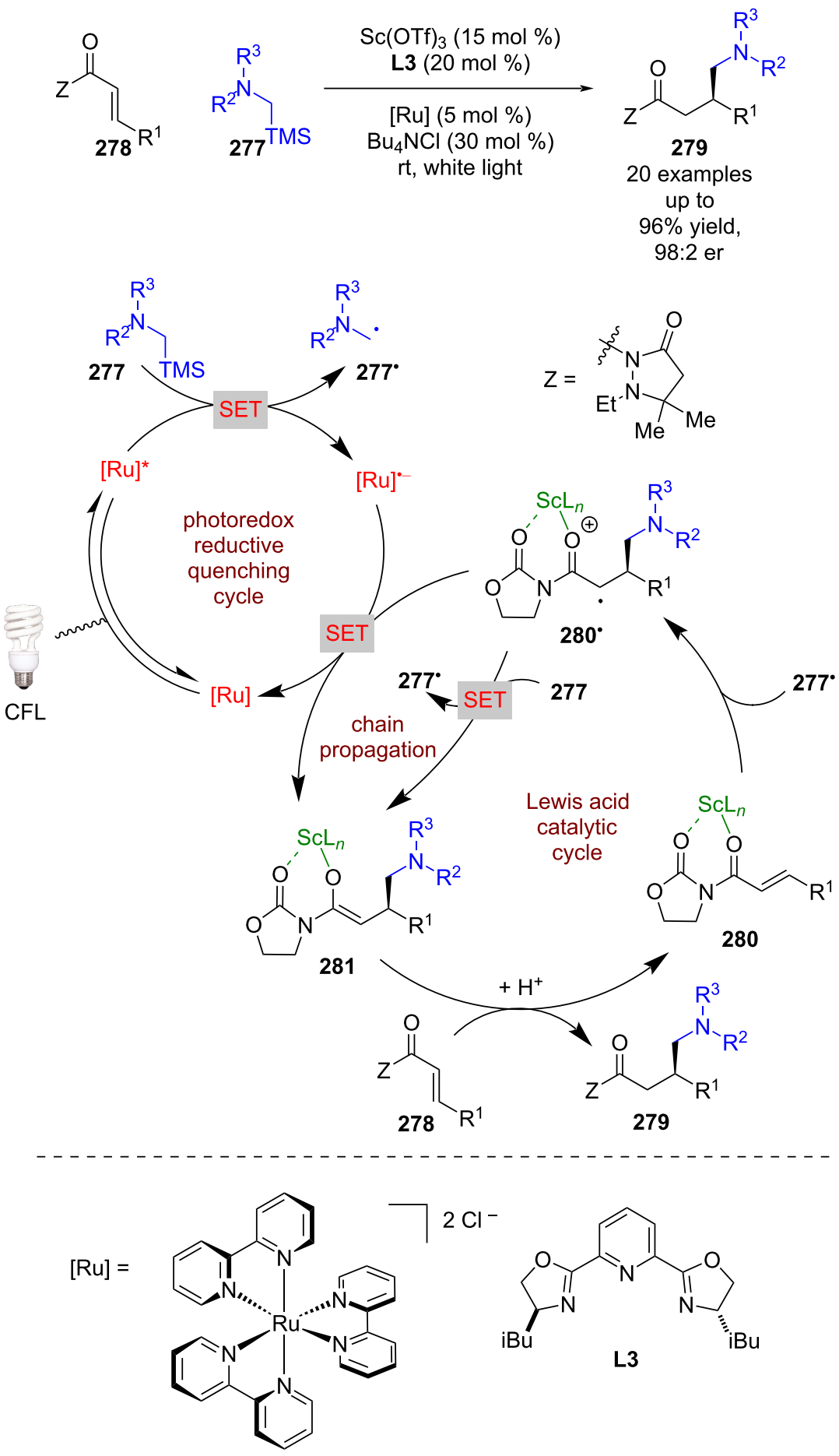

Scheme 44: Lewis acid/photoredox-catalysed RCA reaction using a scandium Lewis acid between $\alpha$-amino radicals and $\alpha, \beta$-unsaturated amides containing an oxazolidinone auxiliary.

catalyst to give the corresponding enolate $\mathbf{2 8 1}$, which is then protonated to produce $\mathbf{2 7 9}$. Alternatively, $\mathbf{2 8 0}^{\circ}$ could be reduced by another molecule of $\mathbf{2 7 7}$, propagating a radical chain process, as was determined to be the case in a previously de- veloped achiral reaction variant [110]. To improve complexation to the Lewis acid in RCA reactions, an auxiliary $(\mathrm{Z})$ is required; this auxiliary can be easily removed and recovered. 
Shibasaki and Kumagai very recently developed a similar reaction using a copper Lewis acid catalyst and a different auxiliary containing amide $\mathbf{2 8 2}$ with $\alpha$-silyl amines $\mathbf{2 7 7}$ to synthesise the corresponding RCA products $\mathbf{2 8 3}$ in excellent yields and enantioselectivities (22 examples, up to $>99: 1$ er) (Scheme 45) [111].

Huang et al. applied a similar catalytic system to that reported by Yoon et al. to a different radical addition reaction between nitrones 284 and aldehydes 285 (Scheme 46) [112]. The proposed mechanism involves a reductive quenching cycle using TEEDA as a sacrificial reductant to generate $[\mathrm{Ru}]^{\circ-}$. Simultaneously the chiral Lewis acid catalyst forms complex 286 with both starting materials. $[\mathrm{Ru}]^{--}$then reduces the activated aldehyde to give ketyl radical anion $\mathbf{2 8 6}^{\mathbf{-}}$, which adds to the nitrone via a proposed 6-membered transition state to afford radical cation $\mathbf{2 8 6}^{\circ+}$. Subsequent hydrogen atom abstraction from TEEDA $^{\bullet+}$ generates complex $\mathbf{2 8 6}^{-}$. Protonation and displacement by other substrate molecules releases the desired 1,2amino alcohol products 287 in excellent yields and enantioselectivities (27 examples, up to $>99: 1$ er).

Yoon et al. have also shown that these types of Lewis acid complexes can be used in an energy transfer process for the $[2+2]$ cycloaddition of enones $\mathbf{2 8 8}$ with alkenes $\mathbf{2 8 9}$ (Scheme 47) [113,114]. The triplet energy of $\mathbf{2 8 8}$, when complexed to the scandium Lewis acid $\left(E_{\mathrm{T}}=1.43 \mathrm{eV}\right)$, is significantly lower relative to the unbound substrate $\left(E_{\mathrm{T}}=2.34 \mathrm{eV}\right)$. They propose that
Lewis acid coordination permits discrimination between bound and unbound substrate as it allows for selective triplet sensitisation of the bound substrate by the excited state ruthenium photocatalyst. The subsequent enantioselective [2+2] photocycloaddition gives cyclobutane products 290 in excellent yields and enantioselectivities (43 examples, up to $>99: 1$ er).

Meggers et al. has contributed significantly to the field of enantioselective photocatalysis, introducing unique transition metal Lewis acids 291a-e that can coordinate to ketone substrates and form chiral photoactive complexes 292, which in many cases act as the in situ generated photocatalyst (Scheme 48) [115]. They have recently developed an example using an indazolebased ligand [116] to add to their well-established benzoxazole and benzothiazole ligands. Such complexes have then been used for $\alpha$-functionalisations [117], RCAs [118], and cycloaddition reactions [119]. As much of Meggers work has been summarised previously [120], here we will include only recent examples from each reaction class.

If an enolisable ketone 293 is used, enolate complex 294 can be formed in the presence of base (Scheme 49a) [116]. The complex in this example is then proposed to proceed via an oxidative quenching cycle with bromo nitrile 295 to form $\alpha$-cyano radicals $295^{\circ}$ that then add to another molecule of 294 enantioselectively to give ketyl radical $\mathbf{2 9 6}^{\circ}$. These radicals are then oxidised by the oxidised photocatalyst to generate the metalbound $\alpha$-functionalised product 297 , which can be displaced by<smiles>[R]C=CC([Y])=O</smiles>

282<smiles>[R]N([R])C[As]</smiles>

277

\section{$\left[\mathrm{Cu}(\mathrm{NCMe})_{4}\right]\left(\mathrm{PF}_{6}\right)(12 \mathrm{~mol} \%)$ L4 (15 mol \%)}

[Ir] $(0.5 \mathrm{~mol} \%),-20^{\circ} \mathrm{C}$ blue light $\left(\lambda_{\text {exc }}=448 \mathrm{~nm}\right)$<smiles>[Y]C(=O)CC([R])CN([R])[R]</smiles>

283

22 examples

up to

$97 \%$ yield,

$>99: 1$ er<smiles>CCC(C)(C)C(C)(C)C</smiles>

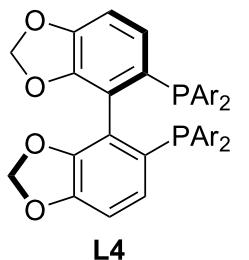<smiles>COc1ccc2c(n1)N([14C](C)(C)C)CC2</smiles>

$\operatorname{Ar}=3,5-x y|y|$

Scheme 45: Lewis acid/photoredox-catalysed RCA reaction using a copper Lewis acid between $\alpha$-amino radicals and $\alpha, \beta$-unsaturated amides containing an azaindoline auxiliary. 


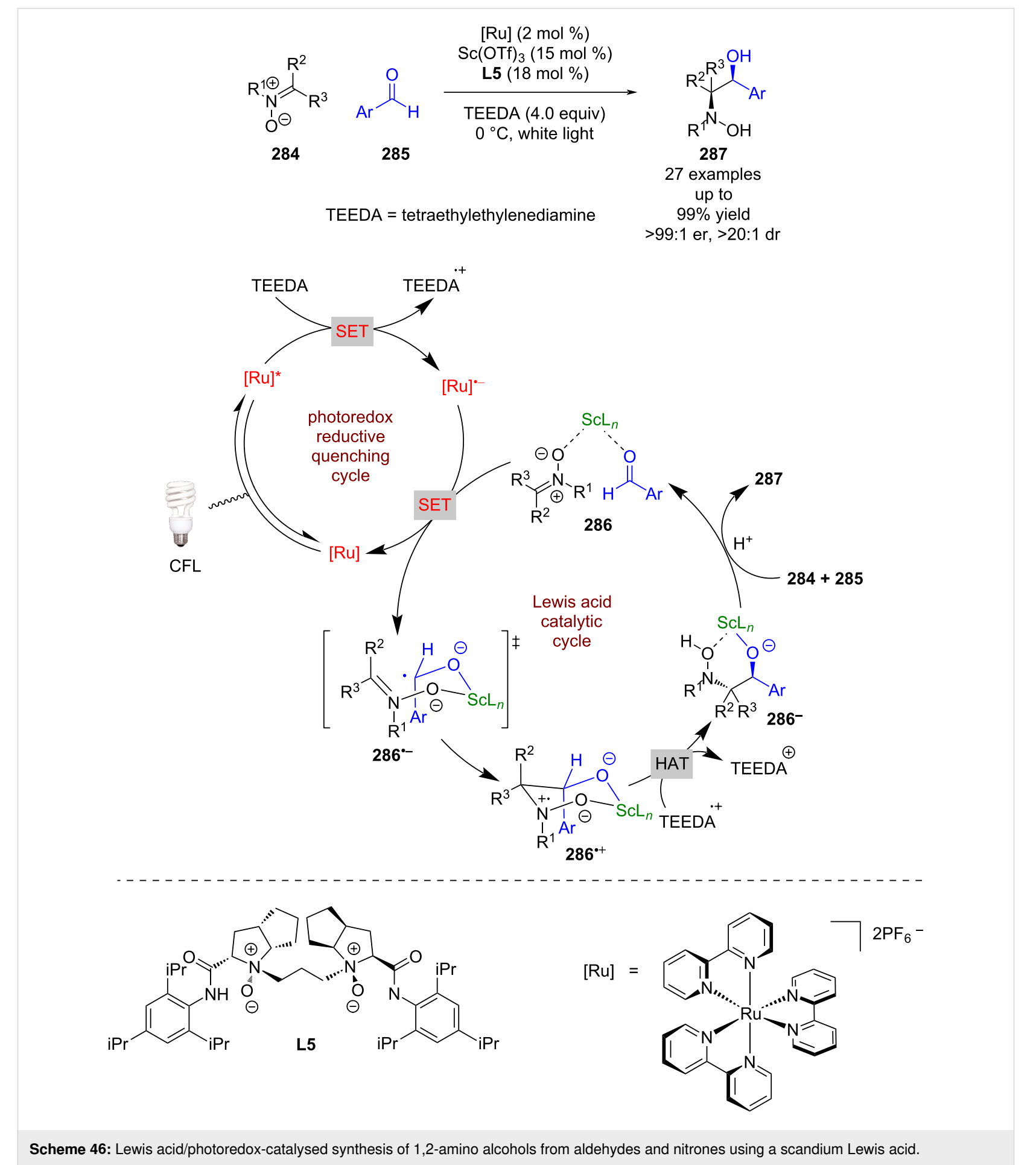

another molecule of $\mathbf{2 9 3}$ to finish the catalytic cycle and furnish the desired product 298 in good yields and excellent enantioselectivities (11 examples, up to 98:2 er). While a chain propagation mechanism is possible, the quantum yield of the reaction is $<1(\Phi=0.046)$, so a closed cycle is likely the dominant mechanism in this case. Another recent example of this type of reactivity was developed by $\mathrm{Xu}$ et al. using amides $\mathbf{2 9 9}$ in a difluo- roalkylation reaction; however, this reaction did require the use of an external photocatalyst (Scheme 49b) [121].

A limitation of this strategy is that only electrophilic radicals can be added to the nucleophilic enolate complex. Recently, Meggers showed that this type of reactivity can be reversed if an $\alpha$-chloro ketone $\mathbf{3 0 1}$ is used with $\alpha$-aminocarboxylic acids 
<smiles>N#C/C=C/C(=O)c1ccccc1O</smiles>

288<smiles>[R]C(=C)C</smiles>

289

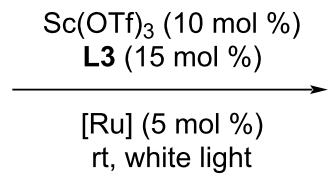

rt, white light

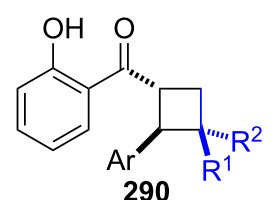

43 examples Up to $97 \%$ yield, $>99: 1$ er, $10: 1 \mathrm{dr}$

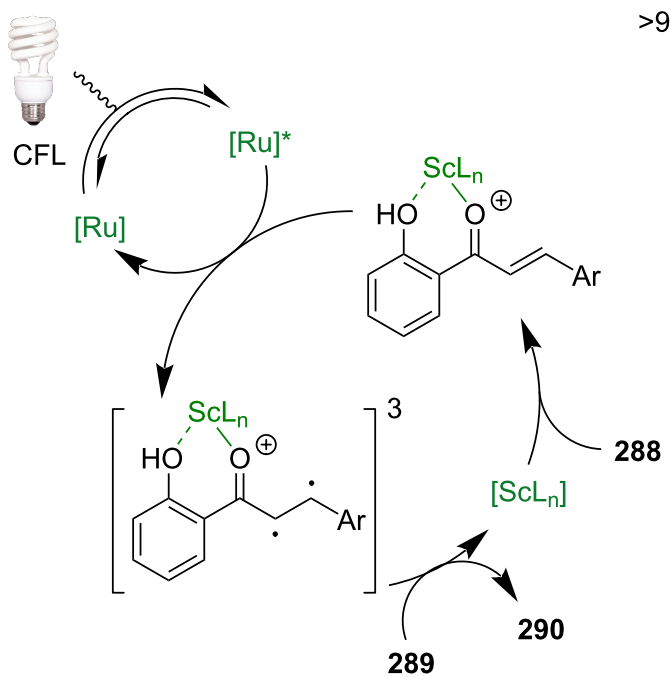

289

$[\mathrm{Ru}]=$<smiles>CCCN1C=CC=C2C=CC=CN21</smiles><smiles>CC(C)(C)C1COC(c2cccc(C3=N[C@@H](C(C)(C)C)CO3)n2)=N1</smiles>

L3

Scheme 47: Lewis acid/photocatalysed [2 + 2] photocycloadditions of enones and alkenes.

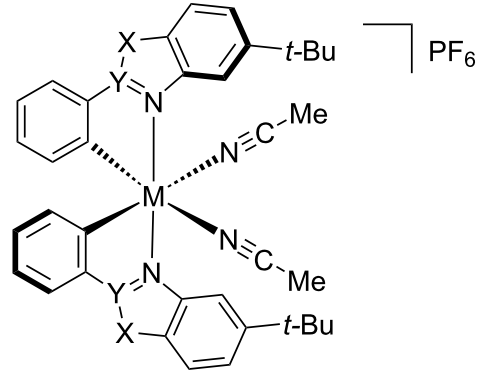

291a, $M=\operatorname{Ir}, X=O, Y=C$

291b, $M=\operatorname{Ir}, X=S, Y=C$

291c, $M=R h, X=O, Y=C$

291d, $M=R h, X=S, Y=C$

291e, $M=R h, X=C, Y=N$

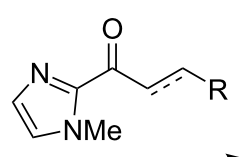

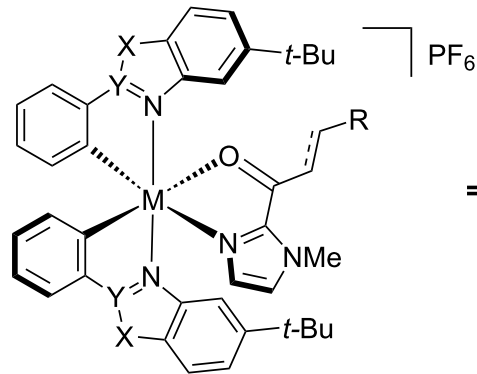

292 
a<smiles>[R]CC(=O)c1ncc[nH]1</smiles>

293<smiles>[R]C(Br)C#N</smiles><smiles>C=C(C)C=C=[13C]C([18OH])[18OH]</smiles>

blue LED<smiles>[R]C(Br)Br</smiles>

295

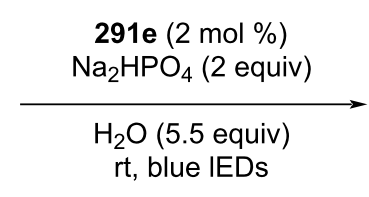

rt, blue IEDs<smiles>[R]C(N)C([R])C([R])C(=O)c1ncc[nH]1</smiles>

298

11 examples

up to

$80 \%$ yield

98:2 er, 3:1 dr

$\Phi=0.046$

$\mathrm{R}^{3^{2}} \mathrm{CN}$

$295^{\circ}$

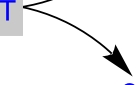

photoredox
reductive

quenching

cycle

$294^{\circ+}$

$\left.\right|_{\text {SET }} ^{94^{++}}$

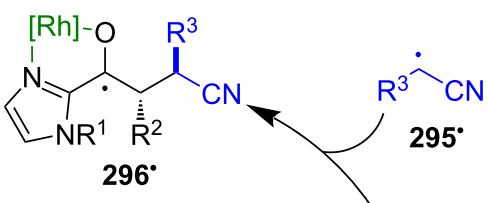

$296^{\circ}$<smiles>O[PbH]</smiles>

Lewis acid catalytic cycle<smiles></smiles>

294

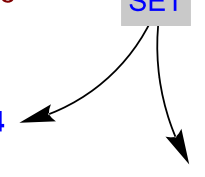

$\mathrm{NR}^{1} 29$

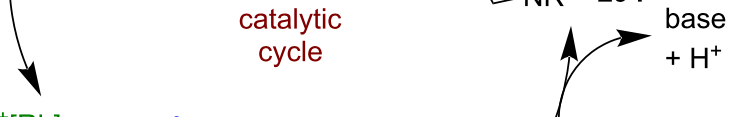<smiles></smiles>

297

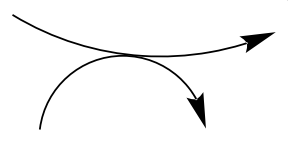<smiles></smiles>

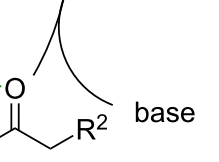
$\mathrm{NR}^{1}$<smiles>Cn1ccnc1C(=O)CBr</smiles><smiles>[R]N(C)C(=O)C(F)(F)Br</smiles>

299

293

298

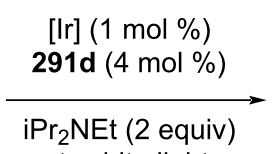

$\mathrm{rt}$, white light<smiles>[R]N([R])C(=O)C(F)(F)C([Al])C(=O)c1ncc[nH]1</smiles>

300

25 examples up to

$97 \%$ yield,

$>99: 1$ er 
302 (Scheme 50) [122]. In this reaction, 301 now forms coordination complex 303, which upon excitation is proposed to initiate a SET with $\mathbf{3 0 2}$ to form an electrophilic $\alpha$-carbonyl radical $\mathbf{3 0 3}^{\circ}$ after loss of chloride, and a nucleophilic $\alpha$-amino radical $\mathbf{3 0 2}^{\circ}$ after decarboxylation. Enantioselective radical coupling gives the metal-bound product, which can be displaced by another molecule of $\mathbf{3 0 1}$ to complete the cycle and release ketone 304 in good yields and excellent enantioselectivities (16 examples, up to 99:1 er). In this case the quantum yield was measured to be $<1(\Phi=0.0027)$, which suggests that a chain mechanism is unlikely.

A recent example of these catalysts being used for RCAs exploited Eosin $\mathrm{Y}$ as an external HAT photocatalyst to generate acyl radicals $305^{\circ}$ from aldehydes $\mathbf{3 0 5}$, which then add to the Lewis acid complex $\mathbf{3 0 6}$ enantioselectively to form $\alpha$-carbonyl radicals $\mathbf{3 0 7}^{\bullet}$ (Scheme 51a) [118]. The reverse HAT step completes the photocatalytic cycle and produces the complexed RCA product $\mathbf{3 0 7}$, which can be displaced by another substrate molecule 308 to finish the cycle and release the desired enantioenriched products 309 in moderate yields and excellent enantioselectivities (19 examples, up to $>99: 1$ er). In the same work, Meggers et al. also used compounds 310a-g as radical precursors, with a focus on 1,3-dioxolane 310c as a formyl radical surrogate (Scheme 51b).

Meggers' complexes can also be used for photocycloadditions (Scheme 52) [123]. A recent example used enone 311 to form the corresponding metal complex $\mathbf{3 1 2}$, which upon photoexcitation is proposed to behave like diradical 312*. HAT from the nearby aldehyde to the $\alpha$-position produces acyl radical $\mathbf{3 1 3}$, which undergoes intersystem crossing to the singlet state ketene 314 supported by DFT calculations. This intermediate then reacts through an enantioselective $[4+2]$ cycloaddition via transition state $314^{*}$ to give the complexed cyclisation product 315. This product is then displaced by another substrate molecule to finish the catalytic cycle and produce the cycloaddition products $\mathbf{3 1 6}$ as a single diastereomer with excellent yields and<smiles>[R]C(Cl)C(=O)c1[R1]ccn1</smiles>

301

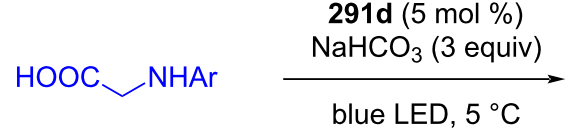

302<smiles>[R]C(CN)C(=O)c1ncc[nH]1</smiles>

304

16 examples

up to

$78 \%$ yield

99:1 er $\Phi=0.0027$<smiles></smiles>

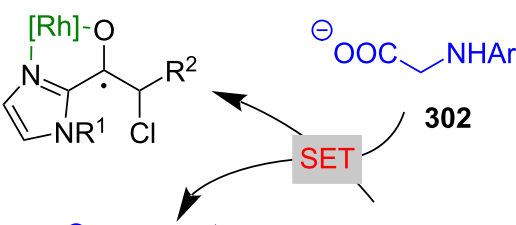<smiles>[13CH3][NH2+]CC(=O)[O-]</smiles><smiles>[R]C(Cl)C(=O)c1nccn1CC</smiles>

$303^{\circ}$<smiles>C=C(C)C(=O)O</smiles>

$302^{\circ}$

bifunctional catalytic cycle

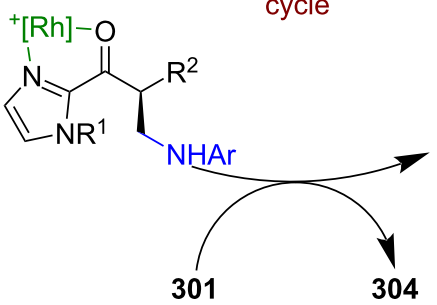

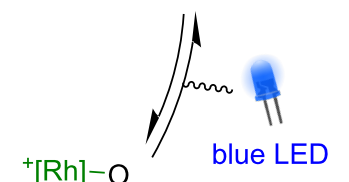


a<smiles>Cc1cc([18OH])n(C(=O)/C=C/CCl)n1</smiles><smiles>[R]C=O</smiles><smiles>[R]C(=O)C(CC(=O)n1nc(C)cc1C)C1CCCCC1</smiles>

309

19 examples $>99: 1 \mathrm{er}$

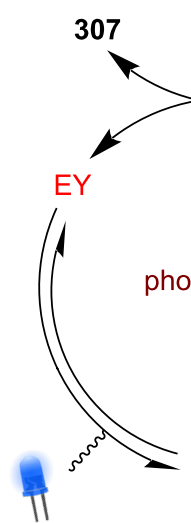

blue LED

$307^{\circ}$<smiles>CCCCC[Pt]=[Al]</smiles><smiles>C1CCCCC1</smiles>

HAT hotocatalytic cycle $E Y^{*}$

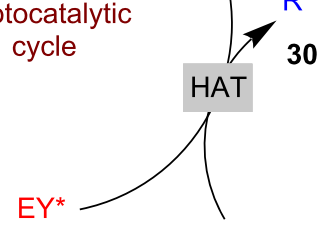<smiles></smiles>

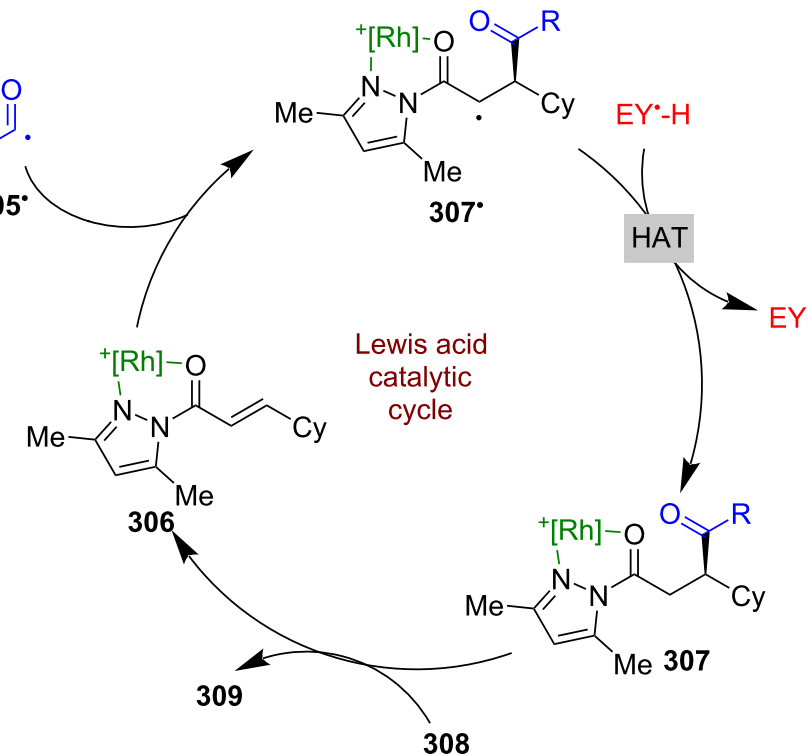

b

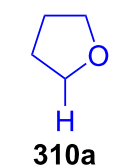

$81 \%$ yield

$>99: 1 \mathrm{er}$,

57:43 dr

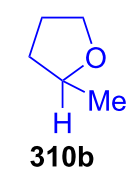

$78 \%$ yield

97:3 er,

$55: 45 \mathrm{dr}$<smiles>[13CH3]C1OCCO1</smiles>

310c

3 examples
Up to

$99 \%$ yield, $>99: 1 \mathrm{er}$

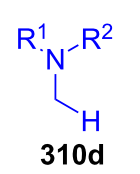

2 examples Up to $48 \%$ yield 98:2 er<smiles>[13CH3]S(=O)(=O)[18OH]</smiles>

$66 \%$ yield, 87:13 er
$\mathrm{Ph}$
$\mathrm{Ph}-\mathrm{P}_{1}=0$
$\mathrm{310f}$

$71 \%$ yield,
$84: 16$ er

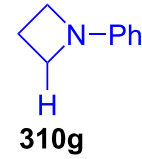

$40 \%$ yield,

95:5 er,<smiles>O=C(O)c1ccccc1-c1c2cc(Br)c(=O)c(Br)c-2oc2c(Br)c(O)c(Br)cc12</smiles>

Scheme 51: Lewis acid/photocatalysed RCA of enones. (a) Using aldehydes as acyl radical precursors. (b) Other substrates used as radical precursors.

enantioselectivities (20 examples, up to $>99: 1$ er). In this case, Recently, Xiao et al. developed a similar catalyst 317, using a the auxiliary is not easily removed, which is a limitation of this cobalt-based system where the chirality was conferred by the mode of catalysis.

use of chiral ligands rather than metal-centred chirality, which 
<smiles>[R]/C(=C/C(=O)n1ccc(C)n1)c1cc[R1]cc1C=S</smiles>

311 291d (4 mol \%)

$10^{\circ} \mathrm{C}$, blue LEDs $\left(\lambda_{\text {exc }}=450 \mathrm{~nm}\right)$

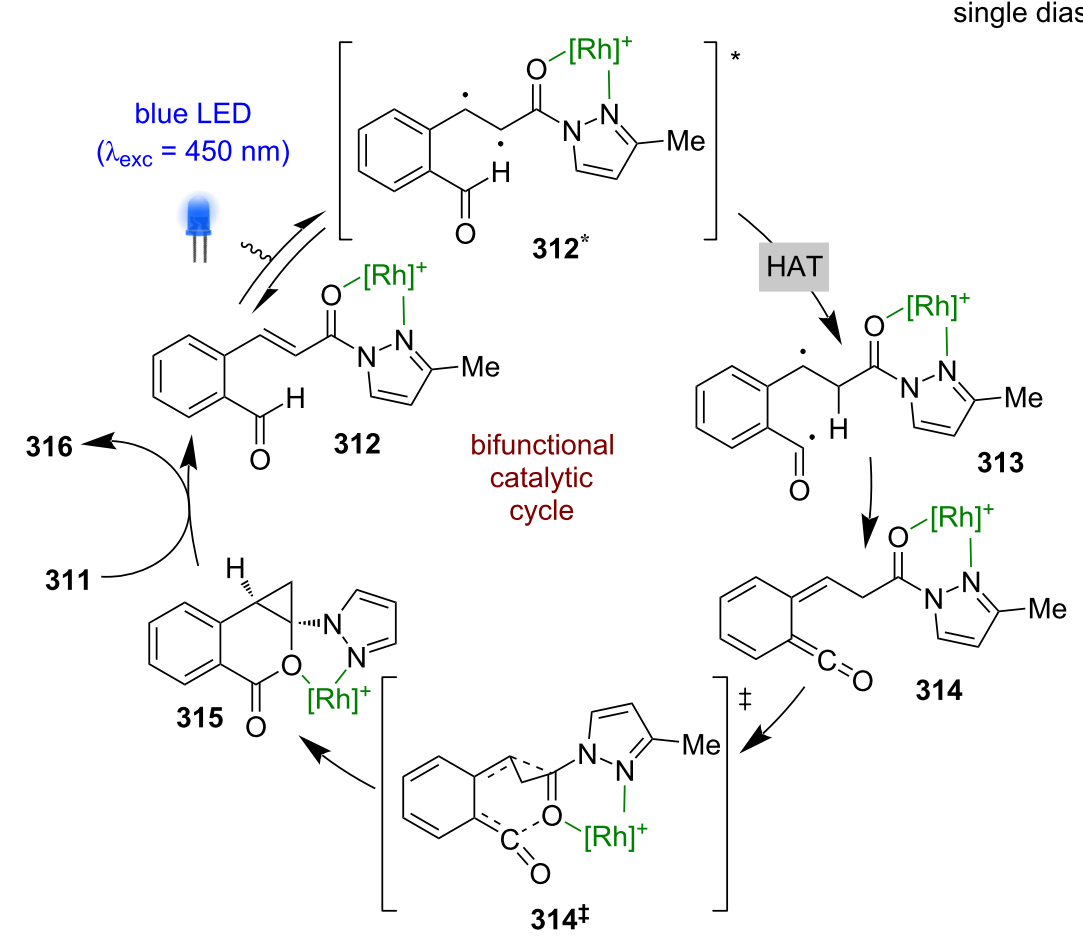

Scheme 52: Bifunctional Lewis acid/photocatalysis for a photocycloaddition of enones.

is the modus operandi of Meggers' technology (Scheme 53) [124]. They applied $\mathbf{3 1 7}$ to the enantioselective RCA reaction of enones 318 using DHPs 319 as radical precursors. If an alkyl DHP is used, then Fukuzumi's acridinium photocatalyst Mes$\mathrm{Acr}^{+}$is required. The proposed mechanism proceeds via a reductive quenching cycle to generate alkyl radicals $319^{\circ}$ and Mes-Acr'. The radical $319^{\circ}$ then adds enantioselectively to the complex formed between $\mathbf{3 1 7}$ and $\mathbf{3 1 8}$ to give $\alpha$-carbonyl radical $320^{\circ}$, which is then reduced to the corresponding enolate 320 by Mes-Acr to turn over the photocatalytic cycle. Protonation of $\mathbf{3 2 0}$ and displacement by another molecule of $\mathbf{3 1 8}$ completes the Lewis acid cycle and affords the desired enantioenriched RCA products $\mathbf{3 2 1}$ in excellent yields and good enantioselectivities (26 examples, up to 96:4 er). If acyl DHPs are used, then no external photocatalyst is required, which is proposed to be due to direct excitation of the substrate as demonstrated previously by Melchiorre et al. [45]. The complexes generated do not seem able to act as photocatalysts, but the reactions do demonstrate high quantum yields for both alkyl $(\Phi=0.57)$ and acyl $(\Phi=0.86)$ substituents, suggesting efficient photocatalytic cycles.

Other bifunctional Lewis acid/photoredox catalysts have also been reported. Xiao et al. developed a chiral ligand with a thioxanthone photoactive moiety L6, which when used in combination with $\mathrm{Ni}(\mathrm{acac})_{2}$ forms a bifunctional catalyst in situ (Scheme 54a) [125]. This system was then used for the oxygenation of $\beta$-ketoesters 322, via Lewis acid complex $\mathbf{3 2 3}$ in a similar mechanism to that proposed by Gao et al. in their PTC reaction shown in Scheme 23 [73], to give $\alpha$-hydroxy- $\beta$ ketoesters 324 in excellent yields and enantioselectivities (21 examples, up to 98:2 er). A similar system was then used for the alkylation of 1-indanone-derived substrates $\mathbf{3 2 5}$ although in this instance an external photocatalyst is required to 

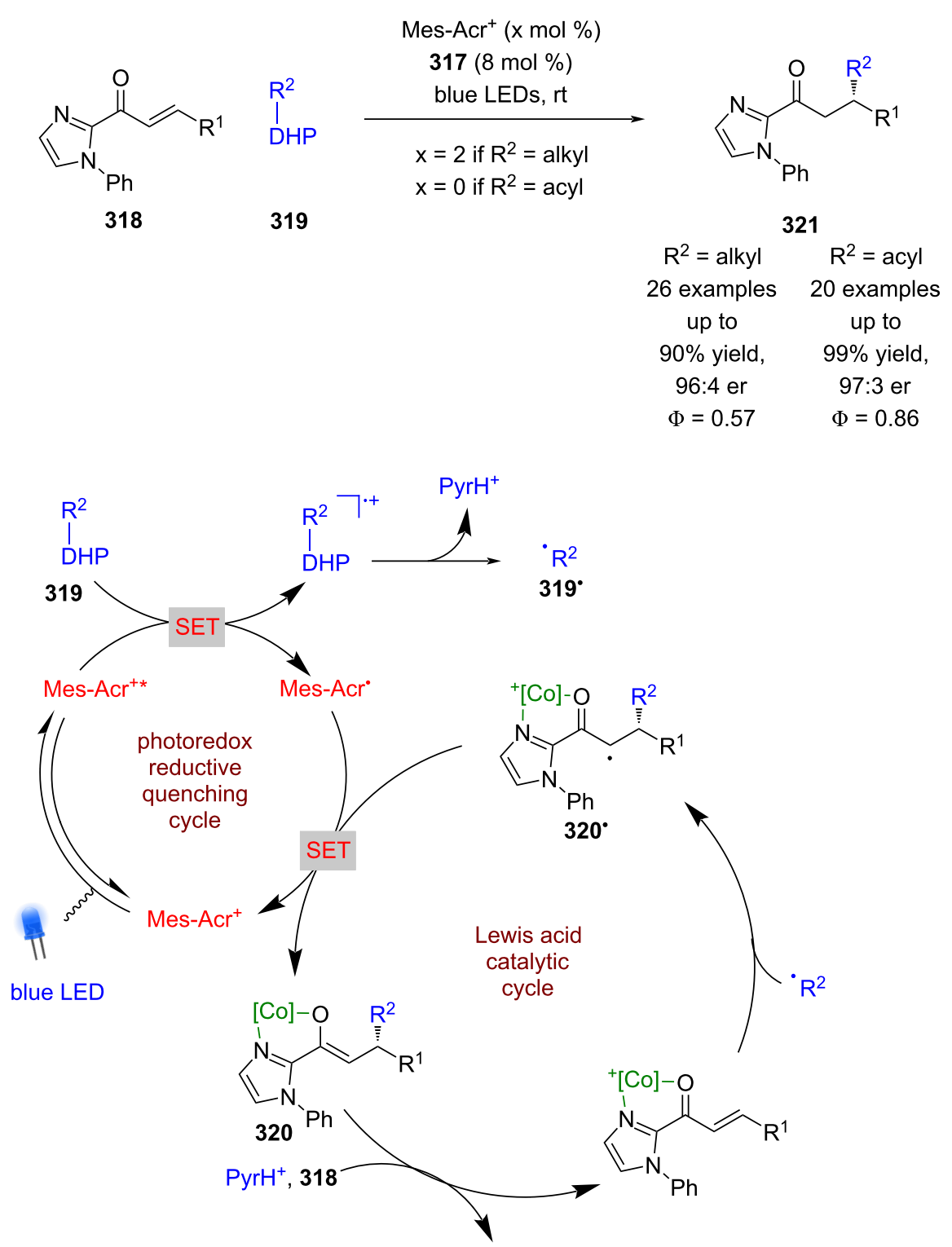

Pyr, 321

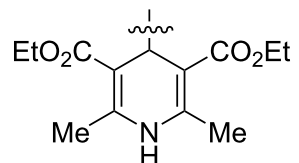

DHP<smiles>CCOC(=O)c1cc(C(=O)OCC)c([N+](=O)[O-])nc1Br</smiles>

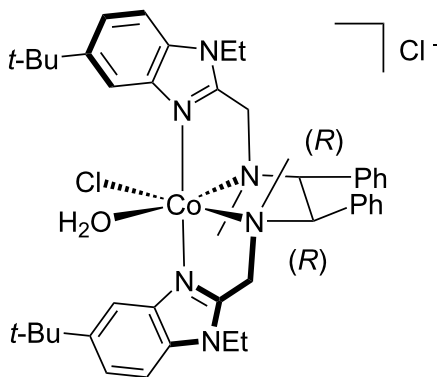

317<smiles></smiles>

Mes-Acr ${ }^{+}$ 
a<smiles>[R]C=C1C[R1]CC1=O</smiles>

322

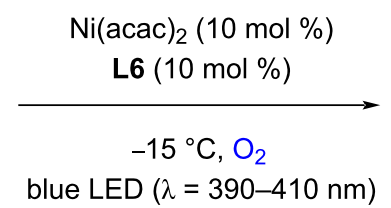<smiles>[R]CC1=C(CC)ONOC1[R]</smiles>

323 b

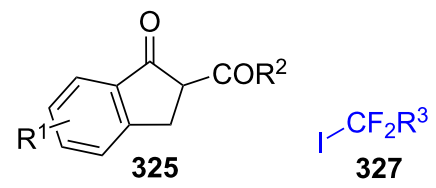

$\mathrm{NiBr}_{2} \cdot$ glyme (20 mol \%) L7 (20 mol\%), [Ir] (3 mol \%)

$\mathrm{NaHCO}_{3}$ (2.0 equiv) rt, blue LEDs<smiles>[R]C=C[C@]1(O)CC[R1]C1=O</smiles>

324

21 examples

up to

$97 \%$ yield,

98:2 er

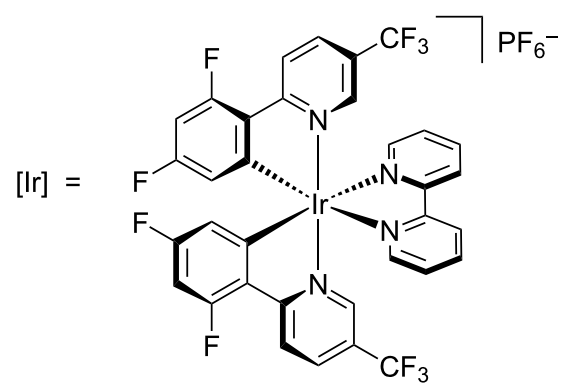<smiles>[Te]C(Cc1ccccc1)N=C(Cc1ccccc1)C1=NC(Cc2ccccc2)CO1</smiles><smiles>CC(COC(=O)c1ccc2c(=O)c3ccccc3sc2c1)(C1=NC(c2ccccc2)[C@H](c2ccccc2)O1)C1=NC(c2ccccc2)[C@H](c2ccccc2)O1</smiles>

Scheme 54: Lewis acid/photoredox-catalysed functionalisation of $\beta$-ketoesters. (a) Hydroxylation reaction catalysed by a bifunctional nickel/thioxanthone catalyst. (b) Alkylation reaction catalysed by a nickel/iridium dual catalysis system.

obtain the desired products $\mathbf{3 2 6}$ in moderate yields and good enantioselectivities (18 examples, up to 95:5 er) (Scheme 54b) [126]. The putative mechanism is similar to that proposed by Melchiorre et al. for their PTC perfluoroalkylation process shown in Scheme 24 [77].

Gong et al. used a $\mathrm{Cu}(\mathrm{II})$ catalyst with chiral ligands $\mathbf{L 8}$ or $\mathbf{L 9}$ as a bifunctional catalyst for the enantioselective alkylation of two classes of cyclic imines $\mathbf{3 2 8}$ and $\mathbf{3 2 9}$ using trifluoroborate salts 330 (Scheme 55) [127]. Trifluoroborate salts are commonly used in photoredox catalysis as alkyl/aryl radical precursors, and generally undergo a single electron oxidation. However, Gong et al. proposes an alternative mechanism for this reaction involving a ligand exchange process to give alkyl copper(II) complex 331, followed by a light-induced homolysis of the $\mathrm{Cu}-\mathrm{C}$ bond to give alkyl radicals $330^{\circ}$ and a reduced $\mathrm{Cu}(\mathrm{I})$ species. The alkyl radical $330^{\circ}$ then adds to the copper-bound imine 332 enantioselectively to give $N$-centred radical $\mathbf{3 3 2}^{\circ}$, which is then reduced by $\mathrm{Cu}(\mathrm{I})$ to give the alkylation products bound to the copper catalyst 333. Displacement by another molecule of substrate completes the cycle and releases $\mathbf{3 3 4}$ or $\mathbf{3 3 5}$ in excellent yields and enantioselectivities (27 examples, up to 97:3 er for $\mathbf{3 3 4}$ and 8 examples, up to 99:1 er for 335). The quantum yield was measured to be $<1(\Phi=0.06)$, so a radical chain mechanism is unlikely to be dominant.

Gong et al. later expanded the scope of this system to $\alpha$-silyl amines $\mathbf{3 3 6}$ as radical precursors and acyclic hydrazones $\mathbf{3 3 7}$ and found that in this case an oxazolidinone auxiliary was required to aid with complexation (Scheme 56a) [128]. 5,7,12,14Pentacenetetrone (PT) can act as both a HAT catalyst and a photocatalyst so that the alkyl radicals can be generated via 
<smiles>[R]COC(=O)C1=NS(=O)(=O)c2ccccc21</smiles>

or

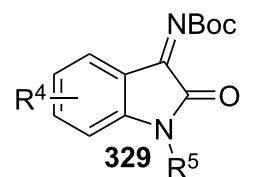

$\mathrm{Cu}\left(\mathrm{BF}_{4}\right)_{2} \cdot \mathrm{H}_{2} \mathrm{O}(10 \mathrm{~mol} \%)$ $\mathrm{R}^{1} \mathrm{BF}_{3} \mathrm{~K}$

330

\section{L8 OR L9 (11 $\mathrm{mol} \%)$}

$-20{ }^{\circ} \mathrm{C}$, blue LEDs<smiles>[R]CC1(C([R])[R])NS(=O)(=O)c2ccccc21</smiles>

or<smiles>[R]CN[C@]1(C[R16])C(=O)N([R5])c2cc[R1]cc21</smiles>

334

27 examples

up to $99 \%$ yield 97:3 er $\Phi=0.06$

335

8 examples up to $88 \%$ yield 99:1 er

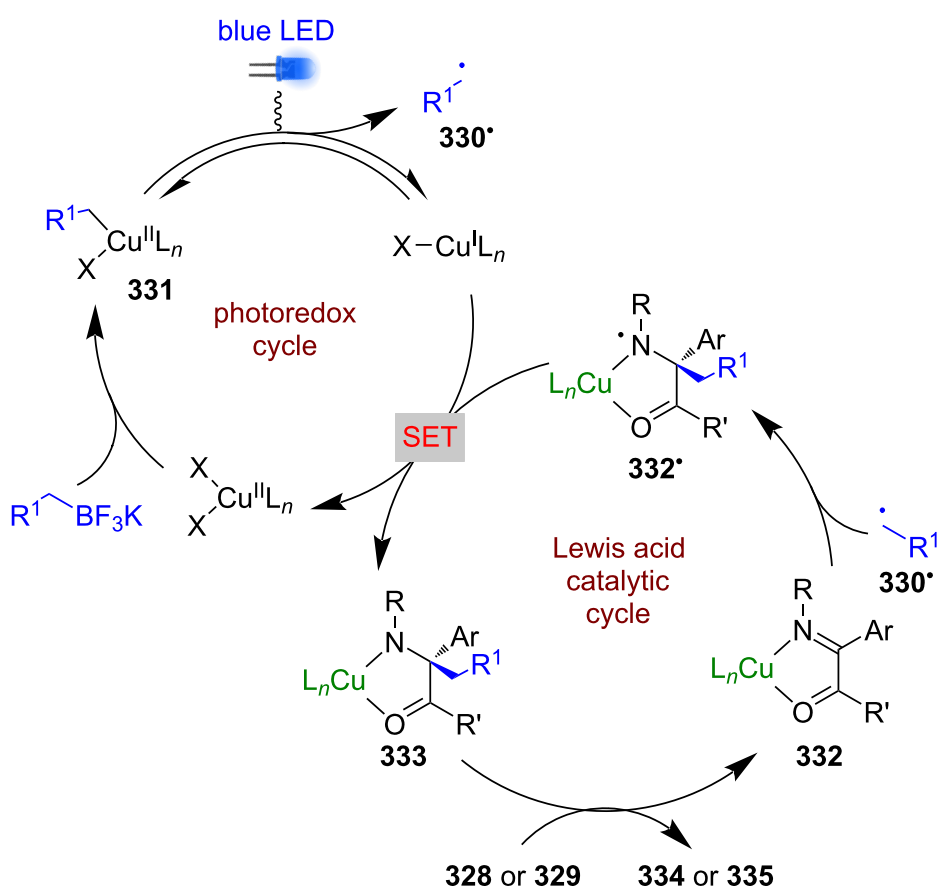<smiles>[Al]CC(C[Al])(C1=N[C@@H](c2ccccc2)CO1)C1=N[C@@H](c2ccccc2)CO1</smiles>

L8<smiles>c1ccc(CC(Cc2ccccc2)(C2=N[C@H]3Cc4ccccc4[C@H]3C2)C2=N[C@@H]3c4ccccc4C[C@H]3O2)cc1</smiles>

L9

$\mathrm{Ar}^{1}=4-(1-\mathrm{Ad}) \mathrm{C}_{6} \mathrm{H}_{4}$

Scheme 55: Bifunctional copper-photocatalysed alkylation of imines.

C-H activation of simple alkanes $\mathbf{3 3 8}$ rather than using a redoxactive group (Scheme 56b) [129]. Each reaction also had a quantum yield of $<1$ ( $\Phi=0.16$ for $\mathbf{a}$ and $\Phi=0.08$ for $\mathbf{b}$ ), so a radical chain mechanism is unlikely to be dominant.

Guo and Bach took a different approach to enantioselective Lewis acid/photocatalysis, building upon work by Lewis [130] and Barancyk [131] who showed that Lewis acids could catalyse photocycloadditions. A recognised significant challenge in making these reactions enantioselective, is outcompeting the racemic background pathway. Bach et al. found that $\mathrm{AlBr}_{3}$-activated oxazaborolidine-based catalysts 341 could induce a bathochromic shift in the absorption spectrum of the coordination complex relative to the uncoordinated coumarin derivative 
a<smiles>O=C1OCCN1N=C([Al])[Al]</smiles>

337<smiles>[R7]OC1=NS(=O)(=O)c2cc[Z17]cc21</smiles>

328<smiles>[R]N([Y])C[AsH3]</smiles>

336

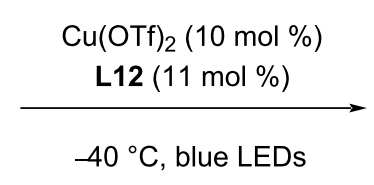

$\mathrm{Cu}\left(\mathrm{BF}_{4}\right)_{2} \cdot \mathrm{H}_{2} \mathrm{O}(10-20 \mathrm{~mol} \%)$ L10, L11, or L13 (11-22 $\mathrm{mol} \%)$

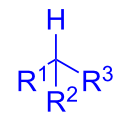

338<smiles>O=C1OCC2N([AlH2])CC([AlH2])NN12</smiles>

339

24 examples

up to

$82 \%$ yield,

99:1 er

$\Phi=0.16$

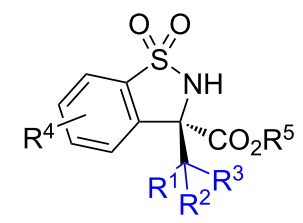

340

55 examples

up to,

$97 \%$ yield,

$>99: 1 \mathrm{er}$

$\Phi=0.08$<smiles>O=c1c2ccccc2c(=O)c2cc3c(=O)c4ccccc4c(=O)c3cc12</smiles>

PT<smiles>[R]C([R])(C1=N[C@H]2c3ccccc3C[C@H]2O1)C1=N[C@@H]2c3ccccc3C[C@H]2O1</smiles>

$\mathrm{R}=\mathrm{Me}, \mathrm{L} 10$

$=\mathrm{CH}_{2} \mathrm{C}_{6} \mathrm{H}_{4}(4-(t-\mathrm{Bu}))$, L11<smiles>OCC(C[Al])(C1=NC(c2ccccc2)CO1)C1=NC(c2ccccc2)CO1</smiles>

$\mathrm{Ar}=$ mesityl, $\mathbf{L} 12$ $=4-(t-B u) C_{6} \mathrm{H}_{4}, \mathrm{~L} 13$

Scheme 56: Copper/photocatalysed alkylation of imines. (a) Bifunctional copper catalysis using $\alpha$-silyl amines. (b) Dual copper/HAT-catalysed C-H activation of alkanes.

342, allowing for selective excitation of the former (Scheme 57) [132]. With a combination of low temperatures, high catalyst loading, and tuning the excitation wavelength, the cycloaddition product $\mathbf{3 4 3}$ could be obtained with high enantioselectivity (91:9 er) via the proposed transition state $\mathbf{3 4 4}$. Interestingly, the quantum yield of the catalysed reaction was found to be much higher $(\Phi=0.09)$ than the uncatalysed reaction ( $\Phi \geq 0.002)$, which is proposed to be due to both increased ISC rates and increased absorption at the excitation wavelength $\left(\lambda_{\mathrm{exc}}=366 \mathrm{~nm}\right)[133]$.

Bach et al. later exploited this reactivity using quinolone $\mathbf{3 4 5}$ (Scheme 58a) [134]. Interestingly, this reaction had the opposite trend for quantum yields compared to $\mathbf{3 4 2}$, with a higher quantum yield for the background reaction $(\Phi \geq 0.23)$ than for the Lewis acid-catalysed reaction $(\Phi=0.004)$, which is pro- posed to be due to a decrease in ISC rate when coordinated to the Lewis acid. The first intermolecular example using this catalyst system used cyclic ketones $\mathbf{3 4 6}$ with alkenes 347 to synthesise bicyclic compounds 348 (Scheme 58b) [135]. A similar reaction was also later developed for the cycloaddition of phenanthrene-derived aldehydes 349 with alkenes 350, using $457 \mathrm{~nm}$ excitation, which was possible due to the increased conjugation of the substrate, and a lower catalyst loading (Scheme 58c) [136].

Recently, Bach et al. showed that these catalysts can also be used for photochemical rearrangements using 2,4-dienones 355 (Scheme 59) [137]. The proposed mechanism involves Lewis acid coordination to give complex 356, which can be selectively excited in the presence of the unbound substrate. 356* then rearranges enantioselectively to generate cationic interme- 


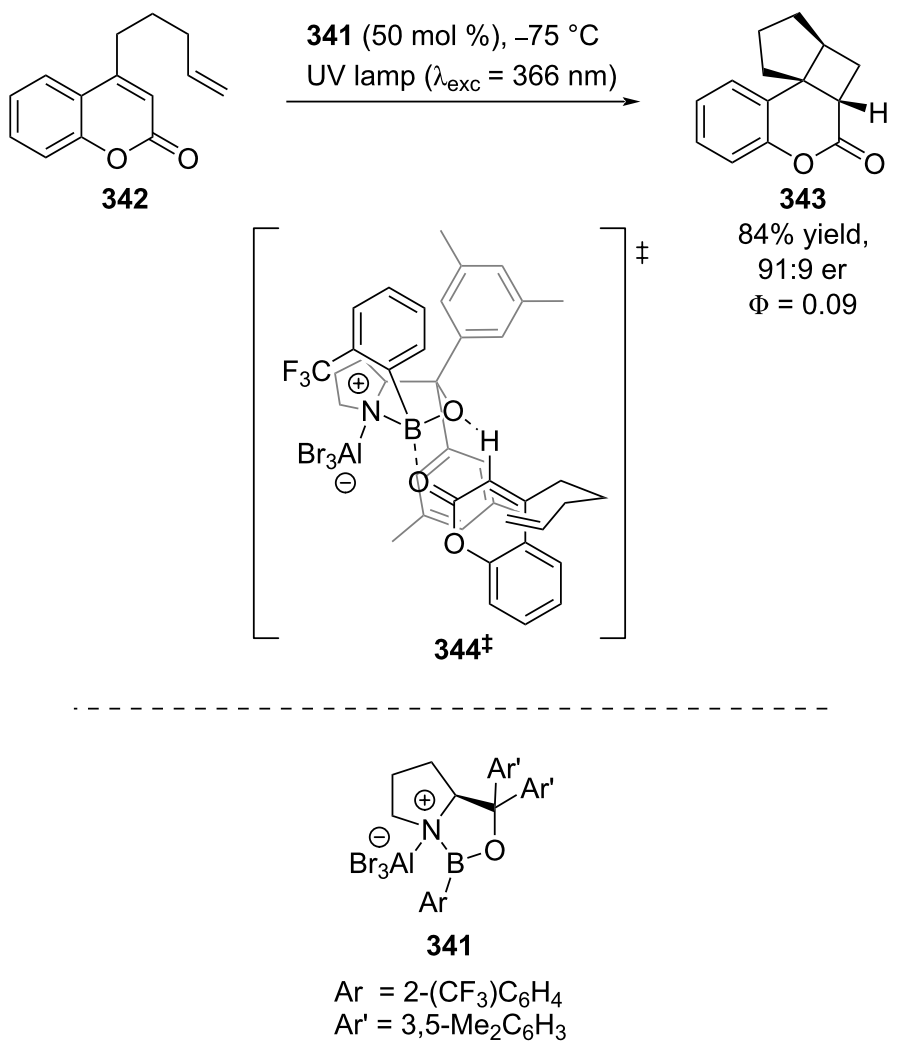

Scheme 57: Bifunctional Lewis acid/photocatalysed intramolecular [2 +2$]$ photocycloaddition.

diate $\mathbf{3 5 6}^{+}$, which then undergoes further rearrangement to furnish bicyclic products $\mathbf{3 5 7}$ in good yields and excellent enantioselectivities (15 examples, up to 99:1 er).

Previous work on photocycloadditions by Yoon et al. relied on adjacent phenols to form Lewis acid complexes, which is a significant synthetic limitation. To generalise the reaction and expand the substrate scope, Yoon et al. found that a combination of an oxazaborilidine Lewis acid 359 with an external photocatalyst allowed for the cycloaddition of simple cinnamate esters 360 with styrenes 361 (Scheme 60) [138]. Instead of exploiting the red-shift in absorption wavelength to confer photochemoselectivity, Yoon et al. proposed that complexation of the Lewis acid lowers the triplet energy of the coordination complex to such an extent that selective triplet sensitization via Dexter energy transfer from the photocatalyst and subsequent enantioselective [2+2] cycloaddition becomes operative as was proposed with the scandium catalysts in Scheme 47 [113,114].

This section has clearly demonstrated the immense diversity in types of Lewis acids that are compatible with photocatalysis, varying from heavy transition metal catalysts and lanthanoid catalysts to boron-centred ones. With this diversity in LA cata- lyst, comes a broad scope of reactivity that has been made possible by this class of dual mode catalysis.

\section{Transition metal catalysis}

The previous section included some examples of transition metals acting as Lewis acids, whereas this section focuses more on reactivity that is unique to transition metals, including inner sphere electron transfer events within the putative mechanisms. Transition metal complexes with achiral ligands have been widely used in combination with photocatalysts in racemic dual catalytic reactions $[139,140]$, with nickel/photoredox catalysis becoming a commonly used combination [141,142]. Transition metal complexes with chiral ligands have also been used extensively in enantioselective catalysis. A recent review on enantioselective metallaphotoredox catalysis summarises the combination of these two bodies of work well [15]. This section is further categorised into subsections by the transition metal used.

Nickel catalysis: The first enantioselective example of this dual mode catalysis reported was a decarboxylative arylation of $\alpha$-amino acids 363 with aryl bromides 364 bearing electronwithdrawing groups, developed by $\mathrm{Fu}$ and MacMillan using $\mathrm{NiCl}_{2}$, chiral ligand $\mathbf{L 1 4}$, and a heteroleptic iridium-based 
a<smiles>C=CCCC(=O)N1C=CC(=O)CC1</smiles>

345

b<smiles>[R]C([R])=C</smiles><smiles>[R1]C1=CC(=O)CCC1</smiles>

346

347
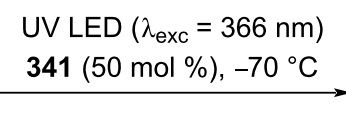

UVD $\left(\lambda_{\text {exc }}=366 \mathrm{~nm}\right)$

$353(50 \mathrm{~mol} \%),-75^{\circ} \mathrm{C}$

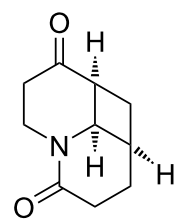

351

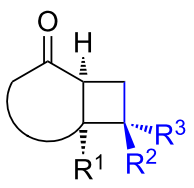

348

\section{7 examples \\ up to \\ $87 \%$ yield \\ 95:5 er \\ $\Phi=0.004$}<smiles>[R][R](C)=C([R])[R]</smiles>

350<smiles>O=Cc1cc2ccccc2c2ccccc12</smiles>

349
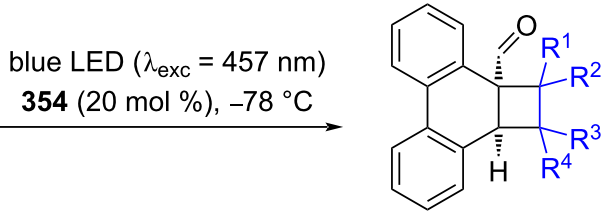

15 examples up to $93 \%$ yield

98:2 er $93: 7 \mathrm{dr}$
16 examples up to $82 \%$ yield 98:2 er

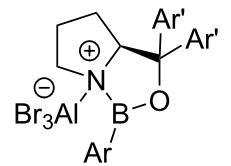

353
354

$\mathrm{Ar}=2,6-\mathrm{Me}_{2} \mathrm{C}_{6} \mathrm{H}_{3}$ $\mathrm{Ar}^{\prime}=3,5-\mathrm{Me}_{2} \mathrm{C}_{6} \mathrm{H}_{3}$

Scheme 58: Bifunctional Lewis acid/photocatalysed [2 + 2] photocycloadditions (a) Intramolecular cycloaddition of quinolones. (b) Intermolecular cycloaddition of cyclic enones with terminal alkenes. (c) Intermolecular cycloaddition of phenanthrene-derived aldehydes and tetrasubstituted alkenes.

photocatalyst (Scheme 61) [143]. The proposed mechanism involves a reductive quenching cycle resulting in $\alpha$-amino radicals $363^{\circ}$, and a nickel catalytic cycle that starts with oxidative addition of 364 onto a $\mathrm{Ni}^{0}$ complex to give $\mathrm{Ni}^{\mathrm{II}}$ intermediate 365. 365 is then intercepted by $363^{\circ}$ to give a $\mathrm{Ni}^{\mathrm{III}}$ intermediate 366, which upon reductive elimination releases enantioenriched arylated products $\mathbf{3 6 7}$ in good yields and excellent enantioselectivities (26 examples, up to $98: 2$ er). Both catalytic cycles are completed by a SET step between $\mathrm{Ni}^{\mathrm{I}}$ and $[\mathrm{Ir}]^{\circ-}$.

Following this report, a large array of reactions has been developed using chiral ligands with nickel/photoredox catalysis [144-146]. For example, Rovis and Doyle developed a desymmetrisation of cyclic meso-anhydrides 368 using benzyl trifluoroborate salts 369, chiral ligand $\mathbf{L 1 5}, \mathrm{Ni}(\mathrm{COD})_{2}$, and the photocatalyst 4CzIPN (Scheme 62a) [147]. More recently,
Walsh and Mao used a similar dual catalyst system for the enantioselective cross-electrophile coupling of $\alpha$-chloro esters 370 and aryl iodides $\mathbf{3 7 1}$ using Hantzsch ester as a sacrificial reductant (Scheme 62b) [148]. Montgomery and Martin achieved similar reactivity via a $\mathrm{C}-\mathrm{H}$ arylation of benzamides $\mathbf{3 7 2}$ using aryl bromides $\mathbf{3 7 3}$, although only a limited number of enantioselective examples were reported (Scheme 62c) [149].

Expansion to a system using TBADT by Wang, which is known to generate acyl radicals from aldehydes [150], allowed for the enantioselective acyl-carbamoylation of alkenes $\mathbf{3 7 7}$ with aldehydes 378 (Scheme 63) [151]. The putative mechanism in this case, based on prior work by MacMillan et al. [152], proceeds via HAT from 378 to the excited state photocatalyst to generate acyl radical $\mathbf{3 7 8}^{\bullet}$ and $[\mathrm{W}]^{5-} \mathrm{H}^{+}$. Subsequent addition of $\mathbf{3 7 8}^{\bullet}$ to $\mathrm{Ni}^{0}$ affords $\mathrm{Ni}^{\mathrm{I}}$ intermediate 379 , which oxidatively adds into 
<smiles>[R]C1=CC(=O)C([R])([R])C=C1[R]</smiles>

355 blue LED $\left(\lambda_{\text {exc }}=437 \mathrm{~nm}\right)$

$358(10 \mathrm{~mol} \%),-78^{\circ} \mathrm{C}$

$\mathrm{R}^{3}$

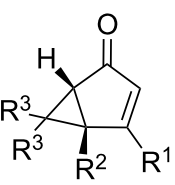

357

15 examples

up to

$80 \%$ yield

99:1 er

355
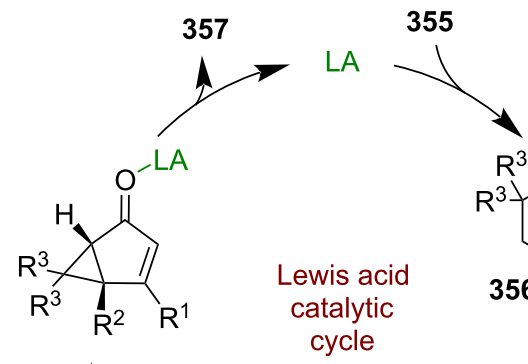

$\mathrm{R}^{-\mathrm{LA}}$<smiles>[R]C1=CC(=O)C([R])(CC)C=C1C</smiles>

356

A ycle
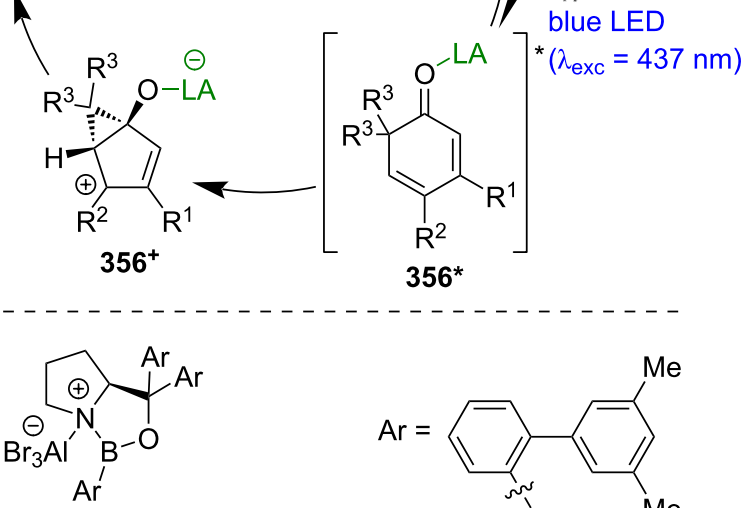

LA, 358

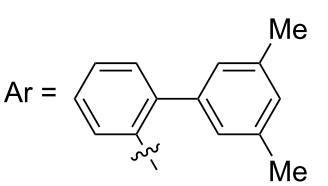

Scheme 59: Bifunctional Lewis acid/photocatalysed rearrangement of 2,4-dieneones.

$$
\begin{aligned}
& \text { O } \quad 359(25 \mathrm{~mol} \%) \\
& \mathrm{MeO}_{\mathrm{Ar}^{1}} \rightleftharpoons \mathrm{Ar}^{2}
\end{aligned}
$$

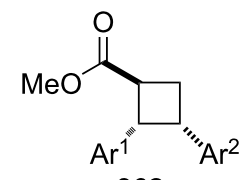

16 examples

up to

$97 \%$ yield,

$>99: 1$ er

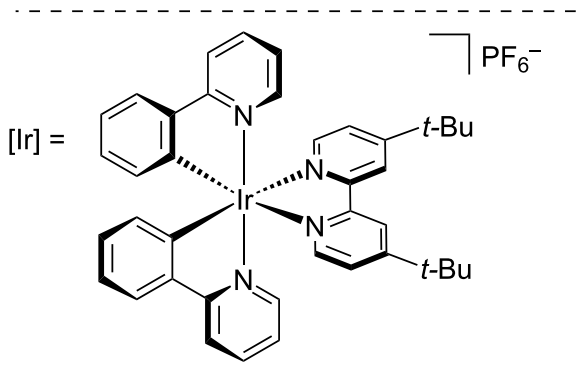

$\mathrm{NTf}_{2} \mathrm{Ar}$

$\mathrm{Ar}=2,4,6-\mathrm{F}_{3} \mathrm{C}_{6} \mathrm{H}_{2}$

$A r^{\prime}=3,5-\mathrm{Me}_{2} \mathrm{C}_{6} \mathrm{H}_{3}$ 


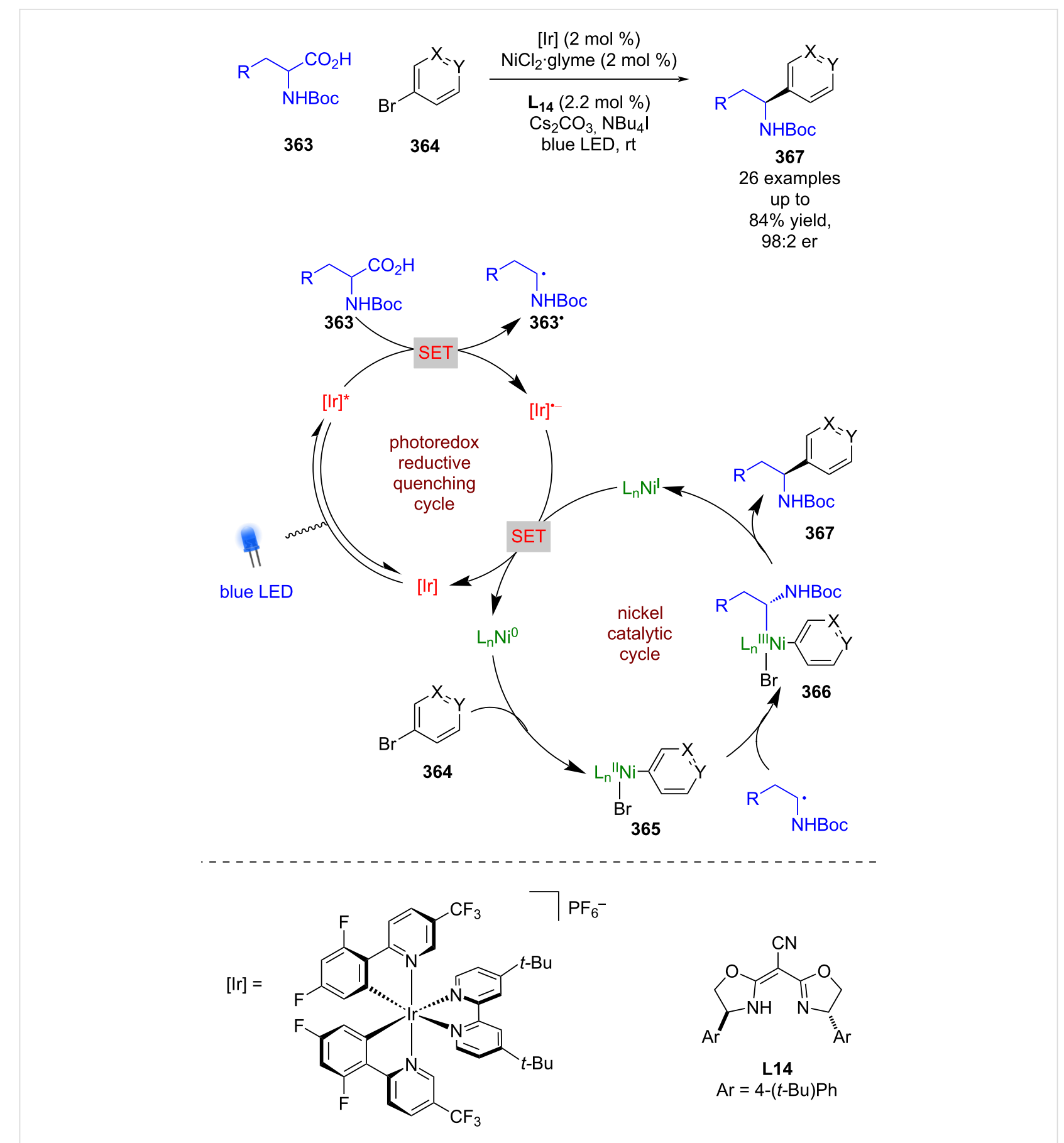

Scheme 61: Nickel/photoredox-catalysed arylation of $\alpha$-amino acids using aryl bromides.

$\mathbf{3 7 7}$ to give the $\mathrm{Ni}^{\mathrm{III}}$ species $\mathbf{3 8 0}$. 380 then undergoes an enantioselective migratory insertion to generate complex $\mathbf{3 8 1}$, which can reductively eliminate to furnish the desired products $\mathbf{3 8 2}$ in excellent yields and enantioselectivities (36 examples, up to 98:2 er). Concomitantly $[\mathrm{W}]^{5-} \mathrm{H}^{+}$undergoes a disproportionation reaction to generate $[\mathrm{W}]^{4-}$ and $[\mathrm{W}]^{6-} 2 \mathrm{H}^{+}$, which reduces the $\mathrm{Ni}^{\mathrm{I}}$ species and completes the cycle. This nickel catalytic cycle $[\mathrm{Ni}(0), \mathrm{Ni}(\mathrm{I}), \mathrm{Ni}(\mathrm{III})]$ is different to that shown in
Scheme 61 [Ni(0), Ni(I), Ni(II), Ni(III)], but both are plausible and it is difficult to determine which is in operation. Towards this, Molander and Gutierrez recently reported an interesting computational investigation that assessed the feasibility of different possible mechanisms for tertiary radicals in nickel/ photoredox dual catalysis and concluded that multiple mechanisms are plausible, and which one is in operation is both substrate and ligand dependant [153]. 


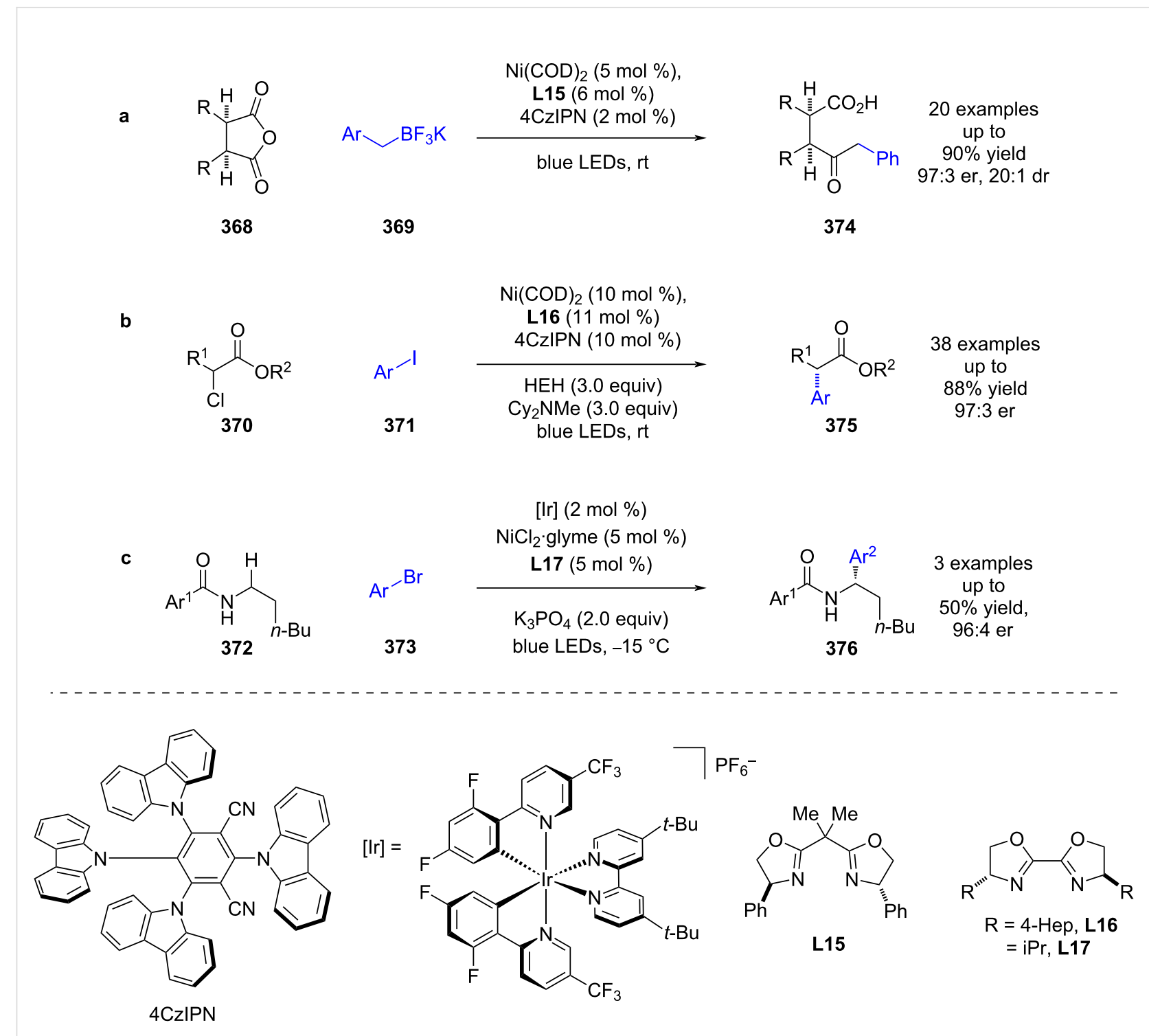

Scheme 62: Nickel/photoredox catalysis. (a) Desymmetrisation of cyclic meso-anhydrides using benzyl trifluoroborate salts. (b) Cross-electrophile coupling of $\alpha$-chloro esters with aryl iodides, using Hantzsch ester as a sacrificial reductant. (c) C-H Arylation of benzamides with aryl bromides.

Copper catalysis: Other metal complexes have also been used in combination with photocatalysis. For example, Peters and Fu found that copper catalysts can mediate the $\mathrm{C}-\mathrm{N}$ cross coupling of $\alpha$-chloro amides 383 (Scheme 64) [154]. They propose that following ligand substitution with an indole or carbazole $\mathbf{3 8 4}$, the resulting photoactive complex $\mathbf{3 8 5}$ is excited upon light absorption. The reaction then proceeds via an oxidative quenching pathway by 383 resulting in the $\mathrm{Cu}^{\mathrm{II}}$ complex 386 and an alkyl radical $383^{\circ}$, which then adds to copper to give a $\mathrm{Cu}^{\mathrm{III}}$ intermediate $\mathbf{3 8 7}$ that reductively eliminates to complete the cycle and release enantioenriched $\mathrm{C}-\mathrm{N}$ coupling product 388 in excellent yields and enantioselectivities (20 examples, up to $>99: 1$ er).
Since this report, chiral copper complexes have been used in other enantioselective bifunctional photocatalysis reactions. Zhang et al., developed an enantioselective difunctionalisation of alkenes 389 using alkynes 390 and alkyl or aryl iodides 391 that proceeds via a radical cascade reaction (Scheme 65) [155]. They propose that the copper acetylide intermediate 392 is photoactive and photocatalyses the reaction, proceeding via an oxidative quenching pathway. The formed radicals then add to 389 to afford alkyl radical $393^{\circ}$, which then adds to the $\mathrm{Cu}^{\mathrm{II}}$ centre to give a $\mathrm{Cu}^{\mathrm{III}}$ intermediate 394 , which upon enantioselective reductive elimination completes the cycle and generates the desired products $\mathbf{3 9 5}$ in good yields and excellent enantioselectivities (41 examples, up to 99:1 er). The quantum yield was 
<smiles></smiles>

377

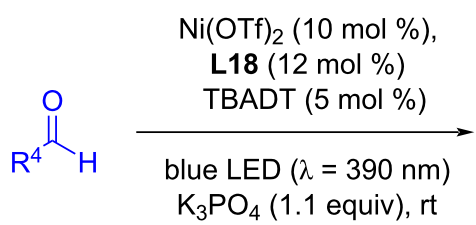

378

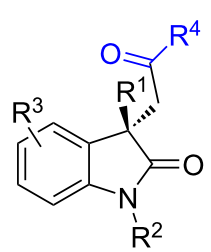

382

36 examples

up to

$95 \%$ yield

98:2 er

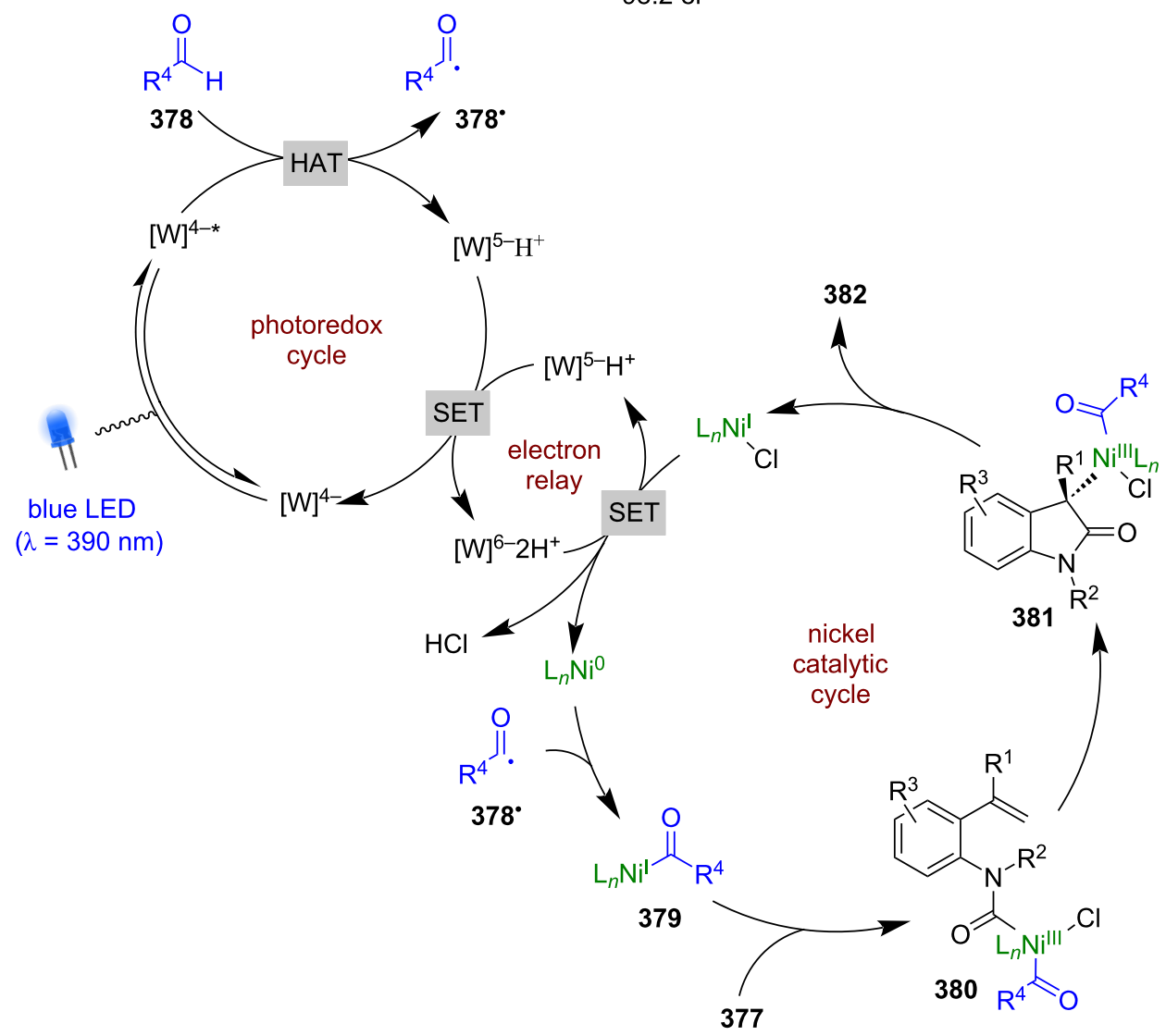

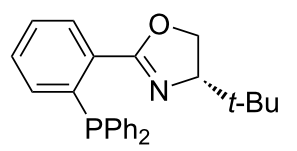

L18
$[\mathrm{W}]=\mathrm{TBADT}=\left(n-\mathrm{Bu}_{4} \mathrm{~N}\right)_{4} \mathrm{~W}_{10} \mathrm{O}_{32}$

Scheme 63: Nickel/photoredox catalysis for the acyl-carbamoylation of alkenes with aldehydes using TBADT as a HAT catalyst.

measured to be $<1(\Phi=0.006)$, suggesting a radical chain mechanism is unlikely to be dominant.

Enantioselective copper catalysis has also been used in combination with an external photocatalyst. For instance, Liu et al. reported a decarboxylative cyanation of phthalimide esters 396 using a combination of $\mathrm{CuBr}$, TMSCN, an iridium-based photocatalyst, and chiral ligand L21 (Scheme 66) [156]. Based on previous cyanation reactions [157], they propose an oxidative quenching cycle where benzyl radicals $396^{\circ}$ are formed from 396 after a reductive decarboxylation, $[\mathrm{Ir}]^{{ }^{*+}}$ then oxidises the $\mathrm{Cu}^{\mathrm{I}}$ catalyst to $\mathrm{Cu}^{\mathrm{II}}$ which accepts a second cyanide ion to 
<smiles>[R16]C(=O)C([R1])Cl</smiles>

383<smiles>c1ccc2c(c1)[nH]c1ccccc12</smiles>

$384, \mathrm{Nu}$
$\mathrm{CuCl}(1 \mathrm{~mol} \%)$

L19 (1.2 $\mathrm{mol} \%)$

LiOt-Bu ( 1.5 equiv)

blue LED, $-40^{\circ} \mathrm{C}$
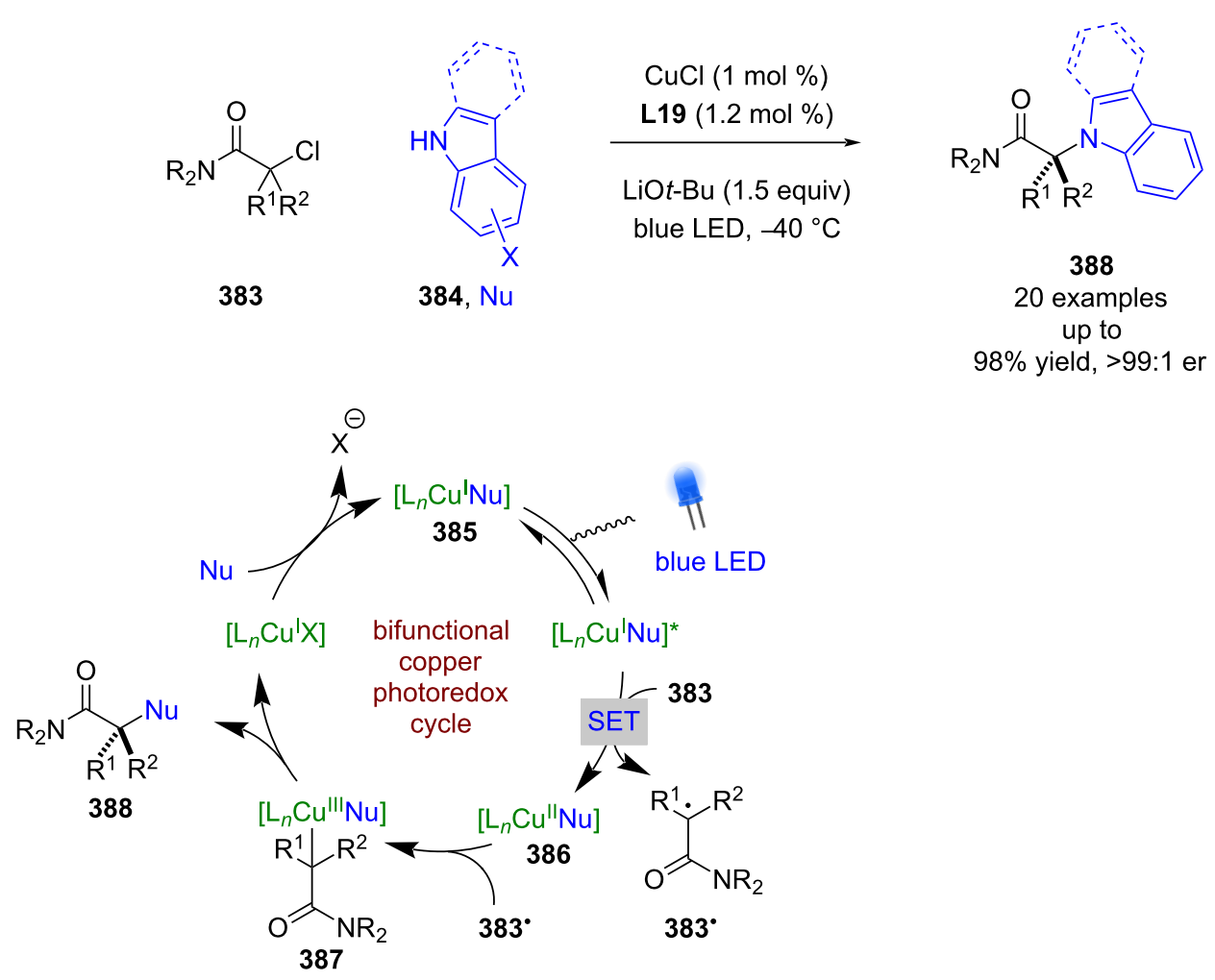<smiles>[Ge]=C1Cc2cccc3c2[C@]12CCc1cccc(c12)CP3</smiles>

Scheme 64: Bifunctional copper/photoredox-catalysed C-N coupling between $\alpha$-chloro amides and carbazoles or indoles.

generate the active dicyano species 397. Radical addition of $396^{\circ}$ to 397 generates $\mathrm{Cu}^{\mathrm{III}}$ intermediate 398 , which after reductive elimination regenerates the catalyst and produces enantioenriched nitriles 399 in excellent yields and enantioselectivities (31 examples, up to $>99: 1 \mathrm{er}$ ).

A series of cyanation reactions have subsequently been developed using similar reactivity. For example, propargyl radicals were successfully used in concert with the more strongly reducing Ph-PTZ photocatalyst, and with a different leaving group to achieve the first enantioselective propargylic radical cyanation (Scheme 67a) [158]. Employing oxime esters 400 as radical precursors afforded enantioenriched dicyano alkanes 401 (Scheme 67b) [159]. Han and Mei developed a radical cascade system using phthalimide esters $\mathbf{4 0 2}$, styrenes $\mathbf{4 0 3}$, and TMSCN to obtain enantioenriched difunctionalised products 404 (Scheme 67c) [160]. Wang and Xu reported a similar radical cascade process using a single catalyst system with perfluorinated alkyl iodides $\mathbf{4 0 5}$ and TMSCN to afford enantioenriched difunctionalised alkenes $\mathbf{4 0 6}$ via a similar mechanism to that proposed by Fu [154] in Scheme 64 (Scheme 67d) [161]. Notably, the quantum yields that were measured for these reactions were all $<1$, suggesting chain mechanisms may not be dominant but also showing reactions Scheme 67a $(\Phi=0.65)$ and Scheme $67 \mathrm{~d}(\Phi=0.51)$ are quite efficient processes.

Palladium catalysis: While there have now been many examples of dual palladium catalysis merged with photocatalysis [140], there are relatively few enantioselective variations. A highly enantioselective reaction using palladium and photoredox catalysis was reported by $\mathrm{Yu}$ et al. using chiral ligand $\mathbf{L 2 3}$ in an allylic alkylation reaction (Scheme 68a) [162]. Using DHPs 407 as radical precursors, they propose an analogous set of catalytic cycles to those proposed for nickel cataly- 

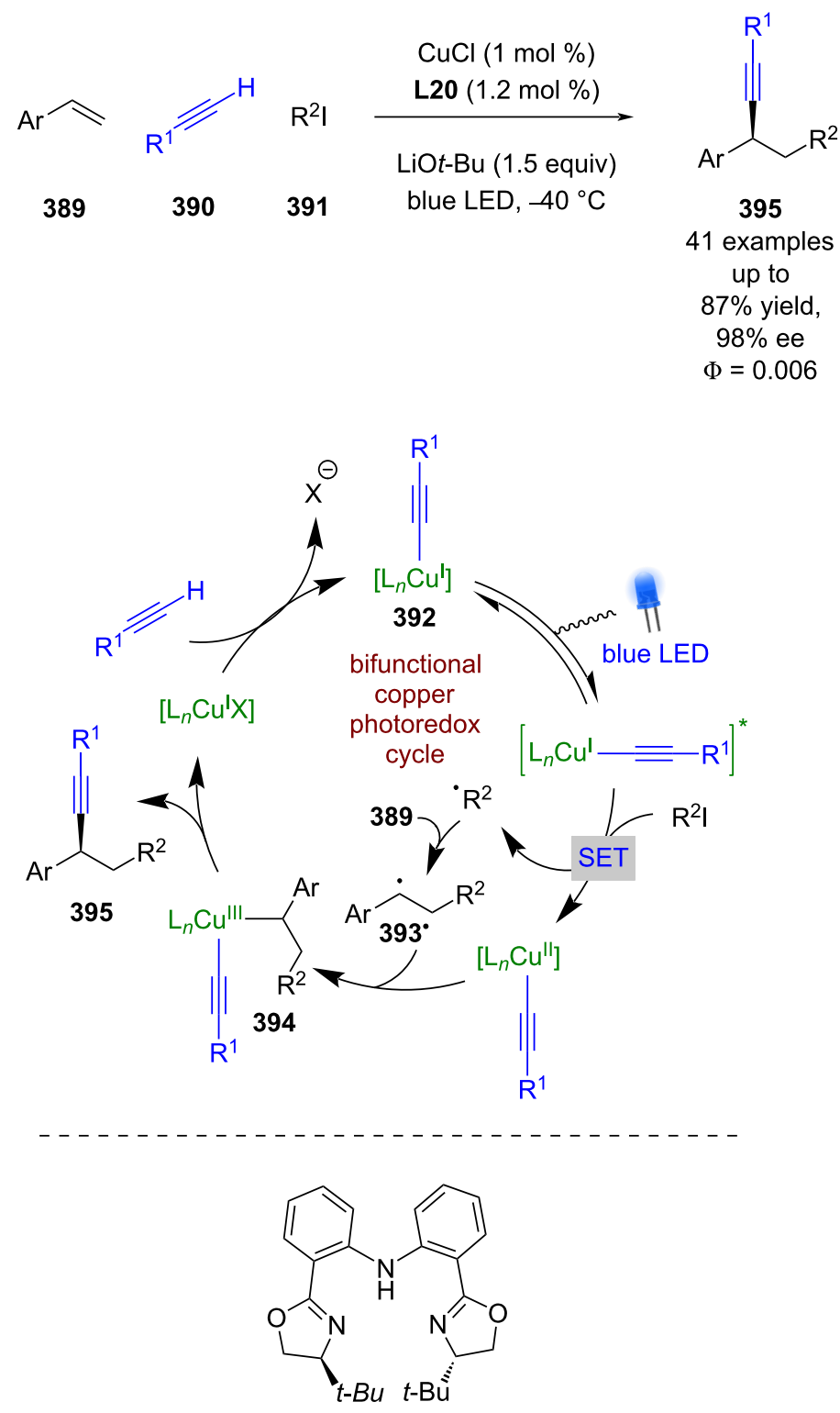

L20

Scheme 65: Bifunctional copper/photoredox-catalysed difunctionalisation of alkenes with alkynes and alkyl or aryl iodides.

sis. The iridium-based photocatalyst proceeds via a reductive quenching cycle to form benzylic radicals $\mathbf{4 0 7}^{\circ}$; simultaneously $\mathrm{Pd}^{0}$ reacts with alkene $\mathbf{4 0 8}$ to form a $\pi$-allyl palladium(II) complex 409 , which is then intercepted by $407^{\circ}$ to form a Pd $\mathrm{Pd}^{\mathrm{III}}$ intermediate 410. Subsequent reductive elimination releases enantioenriched allylation products $\mathbf{4 1 1}$ in good yields and excellent enantioselectivities (43 examples, up to 99:1 er). A SET event between the resulting $\mathrm{Pd}^{\mathrm{I}}$ and $[\mathrm{Ir}]^{\circ-}$ then completes both catalytic cycles. $\mathrm{Yu}$ et al. recently extended this reactivity to anilines 412 that can form $\alpha$-amino radicals under similar reaction conditions to obtain the corresponding products $\mathbf{4 1 3}$ in compa- rable yields and enantioselectivities (31 examples, up to 98:2 er) (Scheme 68b) [163].

Manganese catalysis: Dual catalysis involving a manganese catalyst in combination with photoredox catalysis is far less explored. An example was reported by Nam et al. for the enantioselective epoxidation of terminal alkenes $\mathbf{4 1 4}$ using $\mathrm{H}_{2} \mathrm{O}$ as the oxygen source (Scheme 69) [164]. The proposed mechanism uses a stoichiometric cobalt reagent as a sacrificial oxidant in an oxidative quenching cycle to generate $[\mathrm{Ru}]^{\bullet+}$, which then oxidises $\mathrm{Mn}^{\mathrm{II}}$ in the presence of water to $\mathrm{Mn}^{\mathrm{III}} \mathrm{OH}$ and turn over 
<smiles>[Y9]C([AlH2])C(=O)ON1C(=O)c2ccccc2C1=O</smiles>

396

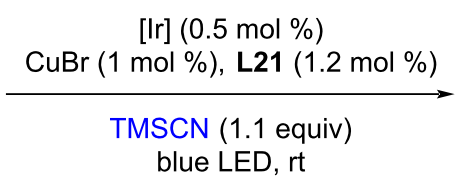

blue LED, rt

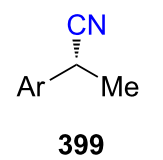

31 examples,

up to

$98 \%$ yield

$>99: 1 \mathrm{er}$

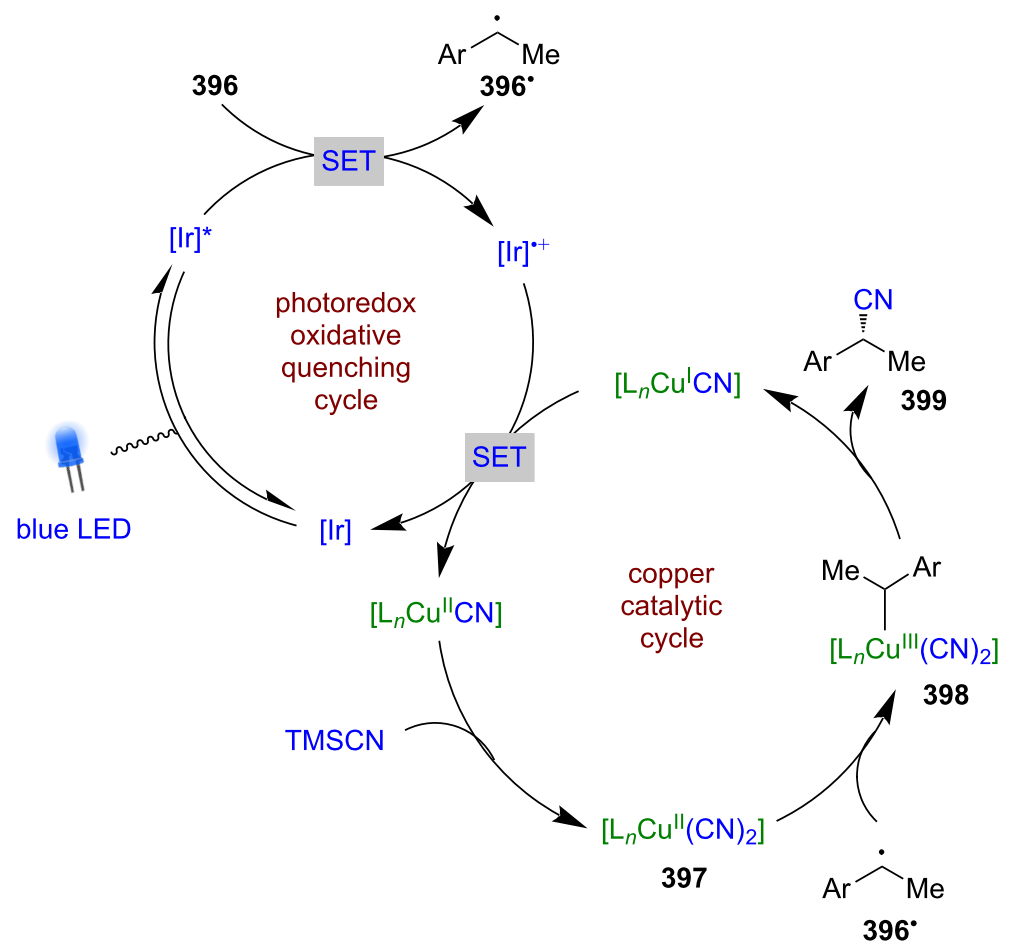

$[\mathrm{Ir}]=$<smiles>c1ccc2c(c1)C[C@H]1OC(C3(C4=N[C@@H]5c6ccccc6C[C@H]5O4)CC3)=NC21</smiles>

L21

Scheme 66: Copper/photoredox-catalysed decarboxylative cyanation of benzyl phthalimide esters.

the photocatalytic cycle. Another similar SET event generates the active $\mathrm{Mn}^{\mathrm{IV}} \mathrm{O}$ species, which catalyses the epoxidation of $\mathbf{4 1 4}$ to give epoxides $\mathbf{4 1 5}$ in moderate yields and enantioselectivities (6 examples, up to 80:20 er). The two SET events required imply a two-photon mechanism is in operation; however, this is not discussed further by the authors. Interestingly, acetic acid seems vital for both yield and enantioselectivity, although the reason for this remains unclear.
Chromium catalysis: Kanai et al. combined chromium catalysis with Mes-Acr ${ }^{+}$for the enantioselective allylation of aldehydes $\mathbf{4 1 7}$ in the presence of chiral ligand L21 (Scheme 70) [165]. They proposed that the reaction proceeds via a reductive quenching cycle with unactivated alkenes $\mathbf{4 1 8}$ to form radical cations $\mathbf{4 1 8}^{\circ+}$ that can be deprotonated to give allylic radicals 418 $^{\circ}$. Radicals $418^{\circ}$ can then be intercepted by a $\mathrm{Cr}^{\mathrm{II}}$ catalyst to form a $\mathrm{Cr}^{\mathrm{III}}$ intermediate $\mathbf{4 1 9}$, which can then nucleophilically 


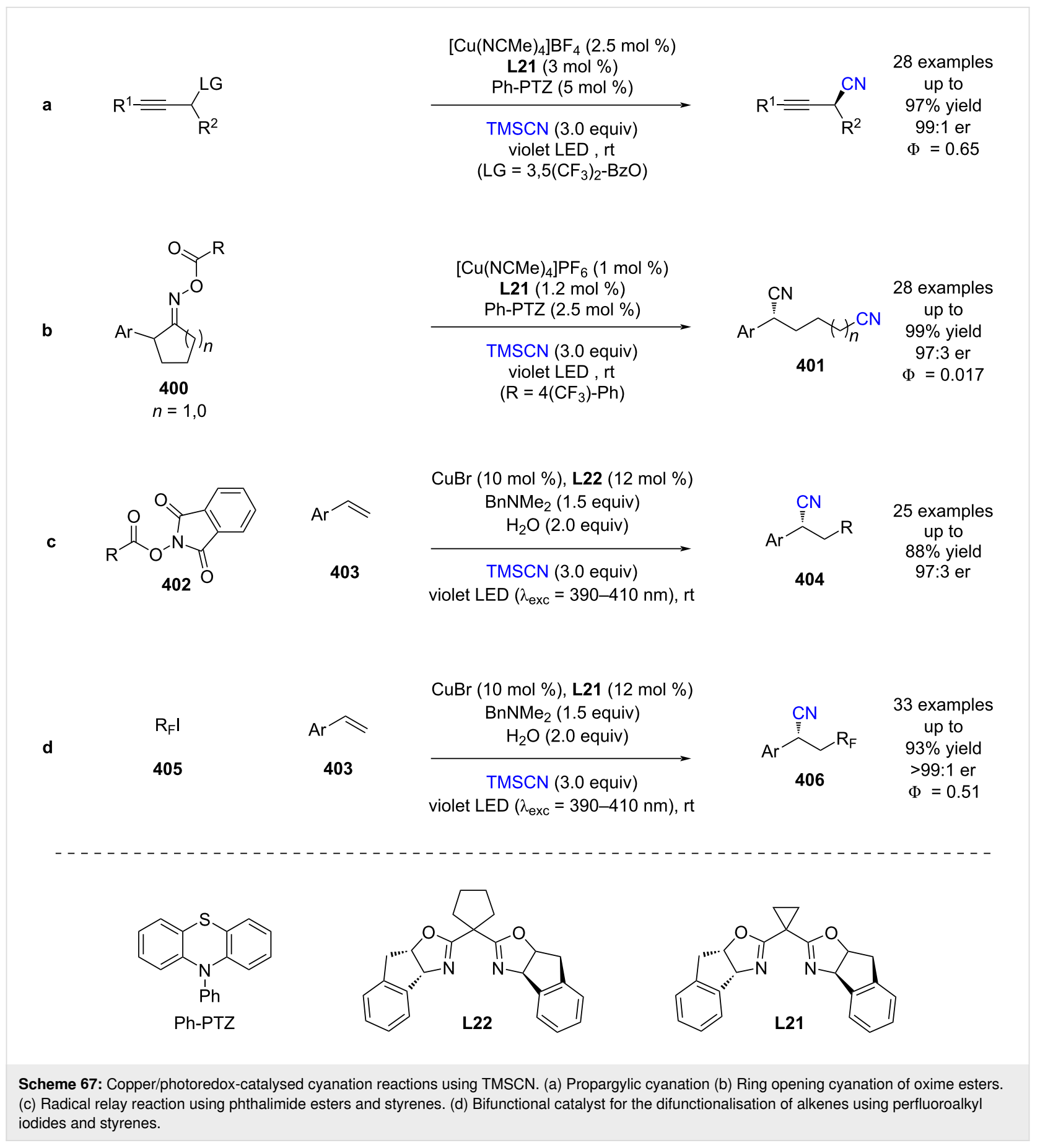

add to the aldehyde to give enantioenriched alcohols $\mathbf{4 2 0}$ after protonation in excellent yields and enantioselectivities (22 examples, up to $>99: 1 \mathrm{er}$ ). The resulting $\mathrm{Cr}^{\mathrm{III}}$ species can then undergo a SET event with $\mathrm{PC}^{\cdot-}$ to complete both catalytic cycles.

\section{Enzyme catalysis}

Enzymes in nature use their bespoke binding environments to catalyse reactions with extreme selectivity; however, there are only a limited number of reactions that occur in nature where this is possible [166]. One method to extend their reactivity is to use them in combination with photocatalysis. There are now many examples that employ this strategy for both racemic and enantioselective transformations and these are well covered in Gulder's review [7]. One of the earliest enantioselective examples was reported by Hyster et al. for the dehalogenation of halolactones $\mathbf{4 2 1}$ in the presence of ketoreductases (KREDs) and NADPH (Scheme 71) [167]. The proposed mechanism im- 


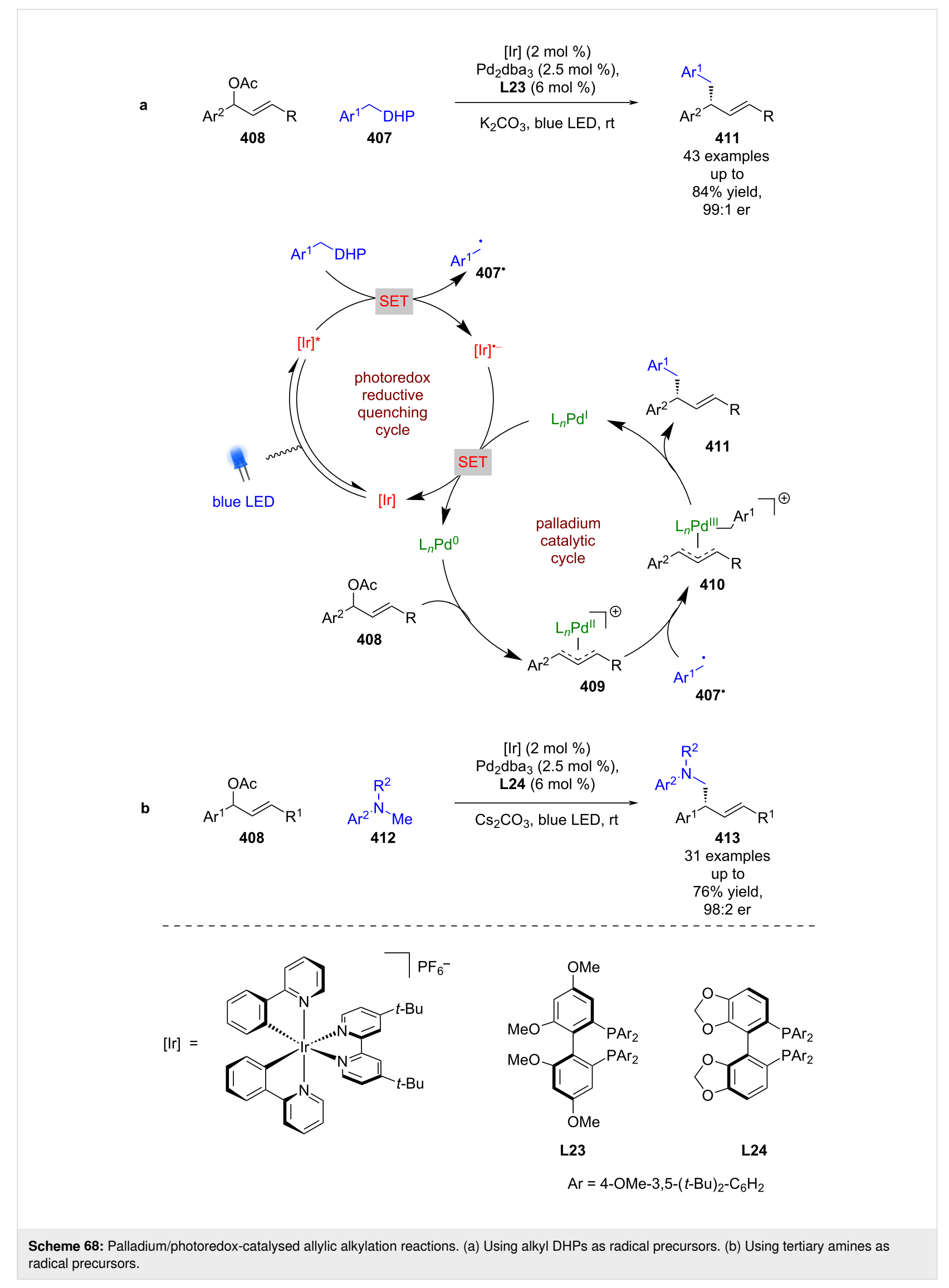




$$
\begin{aligned}
& 416(2 \mathrm{~mol} \%) \text {, }[\mathrm{Ru}] \text { (10 } \mathrm{mol} \%) \\
& \text { R } \underset{414}{\stackrel{\left[\mathrm{Co}^{\prime \prime \prime}\right]}{\text { white light }\left(\lambda_{\mathrm{exc}}>420 \mathrm{~nm}\right), \mathrm{rt}}} \\
& {\left[\mathrm{Co}{ }^{\prime \prime \prime}\right]=\left[\mathrm{Co}\left(\mathrm{NH}_{3}\right)_{5} \mathrm{Cll}_{\mathrm{Cl}}\right.}
\end{aligned}
$$

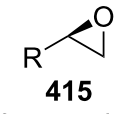

6 examples

up to

$68 \%$ yield,

80:20 er

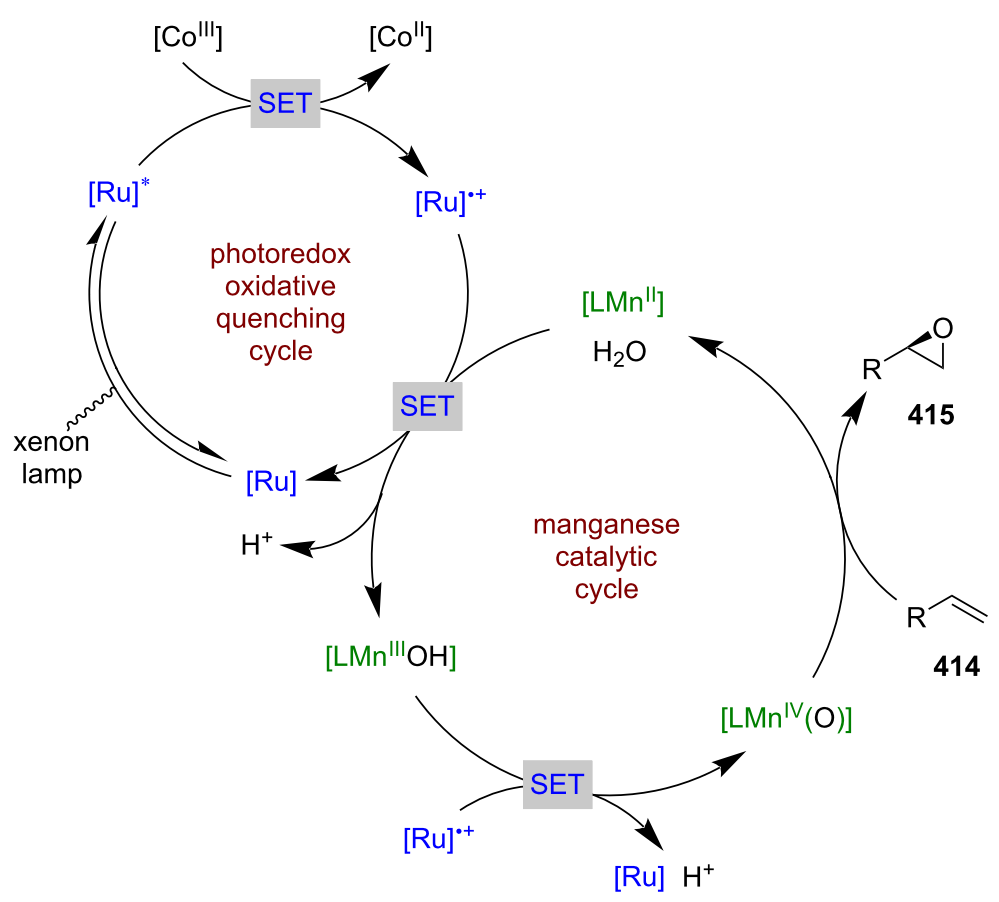

$[\mathrm{Ru}]=$

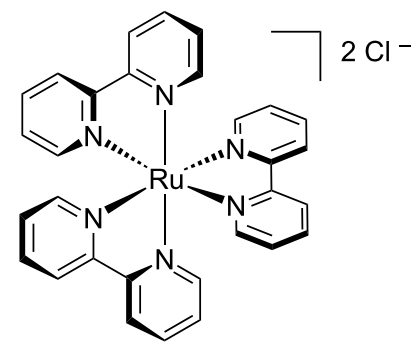

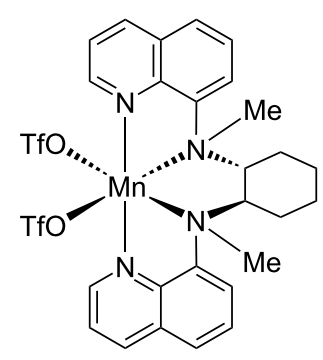

416<smiles></smiles>

[Co'll]

Scheme 69: Manganese/photoredox-catalysed epoxidation of terminal alkenes.

plicates an enzyme active site containing 421 and NADPH that forms an EDA complex, which upon photoexcitation gives intermediate 422. Loss of bromide followed by enantioselective HAT from $\mathrm{NADPH}^{\bullet+}$ gives enzyme-bound lactone $\mathbf{4 2 3}$ and $\mathrm{NADP}^{+}$. Both compounds are then displaced by $\mathbf{4 2 1}$ and $\mathrm{NADPH}$ to complete the cycle, with $\mathrm{NADP}^{+}$being reduced either by isopropyl alcohol or glucose dehydrogenase (GDH). Different conditions can also be used to synthesise either enan- tiomer in excellent yields and enantioselectivities (9 examples, up to 98:2 and 97:3 er), which is important for enzymatic reactions as one cannot simply use the opposite enantiomer.

Hyster et al. expanded this methodology to the cyclisation reactions of $\alpha$-chloro amides 424 (Scheme 72) [168]. In this instance, 'ene'-reductases (ERs) were found to be optimal and HAT occurs after radical addition to the pendant alkene to give 


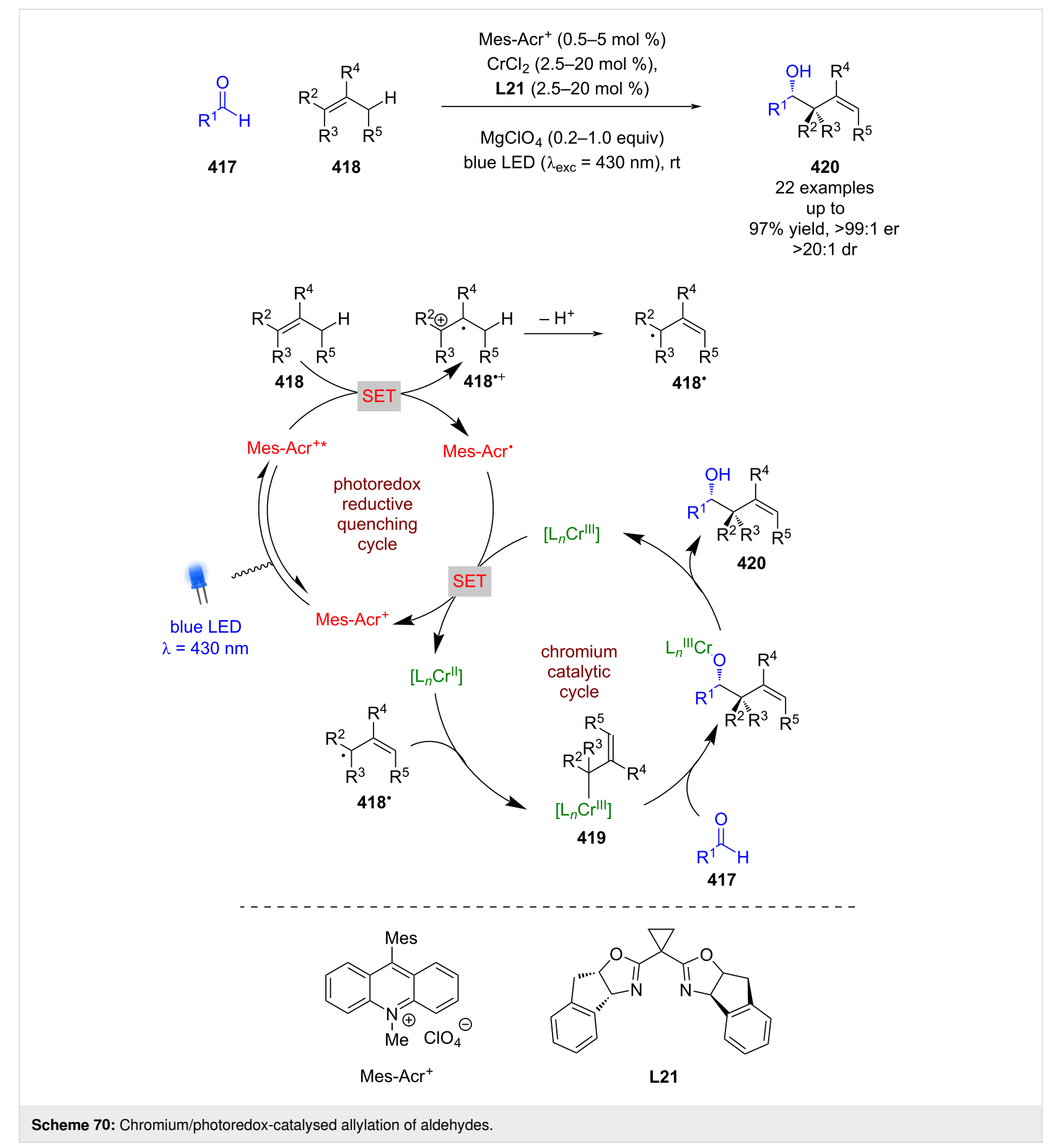

enantioenriched lactams $\mathbf{4 2 5}$ via tertiary radical $\mathbf{4 2 6}$ in excellent yields and enantioselectivities (16 examples, up to 99:1 er). The quantum yield of the reaction was determined to be $<1$ $(\Phi=0.078)$, so a radical chain reaction is unlikely.

An example of enzymes being used in combination with an external photocatalyst was developed by Ward and Wenger using a water-soluble iridium photocatalyst for the enantioselective reduction of cyclic imines 427 (Scheme 73) [169]. The reaction is proposed to proceed via an oxidative quenching cycle to give alkyl radical $\mathbf{4 2 7}^{\circ}$, which is then trapped by ascorbic acid $\left(\mathrm{AscH}_{2}\right)$ in a HAT process to give a racemic mixture of cyclic amine $\mathbf{4 2 8}$. When coupled with a highly selective enzyme-mediated oxidation using a monoamine oxidase (MAO$\mathrm{N}-9$ ), the $(S)$-enantiomer can be selectively removed and recycled to give the near enantiopure $(R)$-amine. The scope of this transformation was found to be limited to two substrates, allowing for little variation in structure or substituents. 
<smiles>[Y20]COC(=O)C([R])(C)Br</smiles>

421<smiles>[R]C(C)(Br)C(=O)OCC</smiles>

421

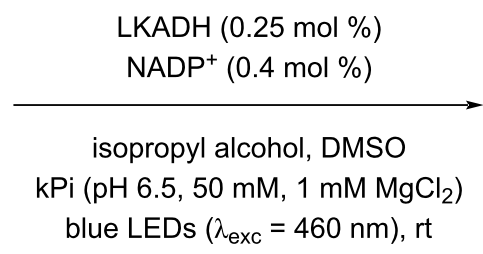

RasADH (1 mol \%) $\mathrm{NADP}^{+}(1 \mathrm{~mol} \%)$

GDH-105, glucose $(200 \mathrm{mM})$ TRIS (pH 7.0, $\left.50 \mathrm{mM}, 10 \mathrm{mM} \mathrm{CaCl}_{2}\right)$ blue LEDs $\left(\lambda_{\text {exc }}=460 \mathrm{~nm}\right)$, it<smiles>[R]C(C)C(=O)OCN</smiles>

423

9 examples

up to

91\% yield, 98:2 er<smiles>[R]C(C)C(=O)OCN</smiles>

423

9 examples

up to

$82 \%$ yield, $97: 3$ er

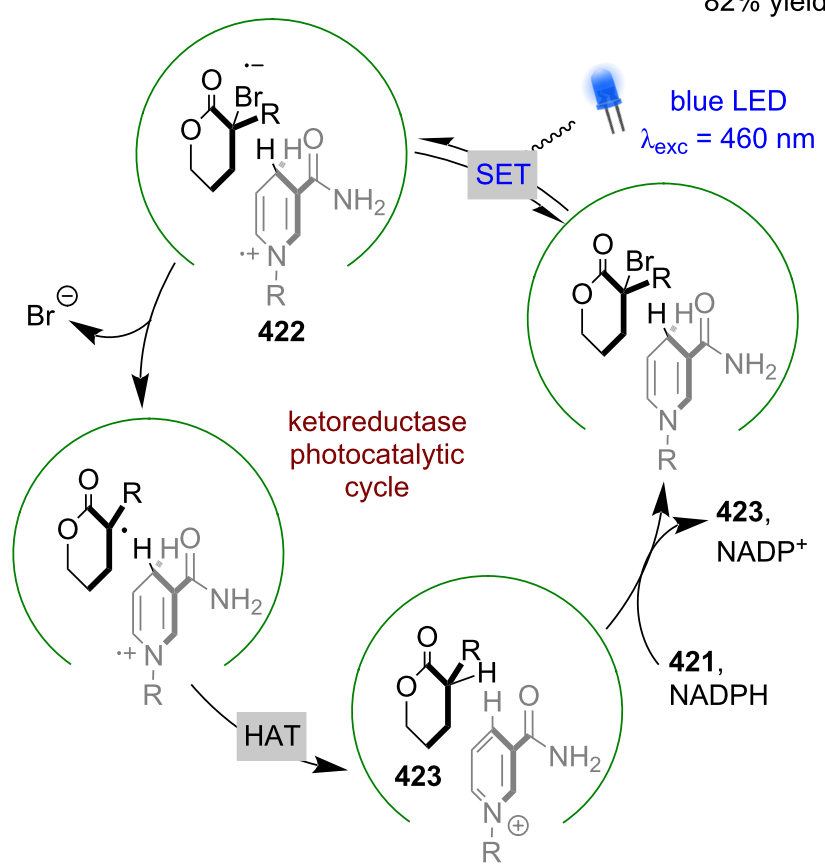

Scheme 71: Enzyme/photoredox-catalysed dehalogenation of halolactones.<smiles>[R]/C(=C\C(=O)N(C)C)C(=O)CCl</smiles>

424

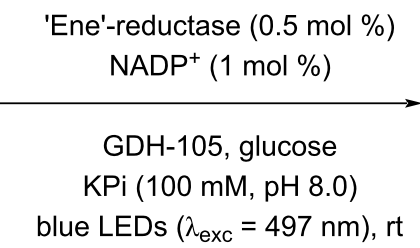

via<smiles>[R]C([R])[C@]1(I)CC(=O)N(C)[Tl]1</smiles><smiles>[R]C([R])C(C)CC(=O)N(C)C</smiles>

425

16 examples up to $99 \%$ yield 99:1 er $\Phi=0.078$

Scheme 72: Enzyme/photoredox-catalysed dehalogenative cyclisation. 


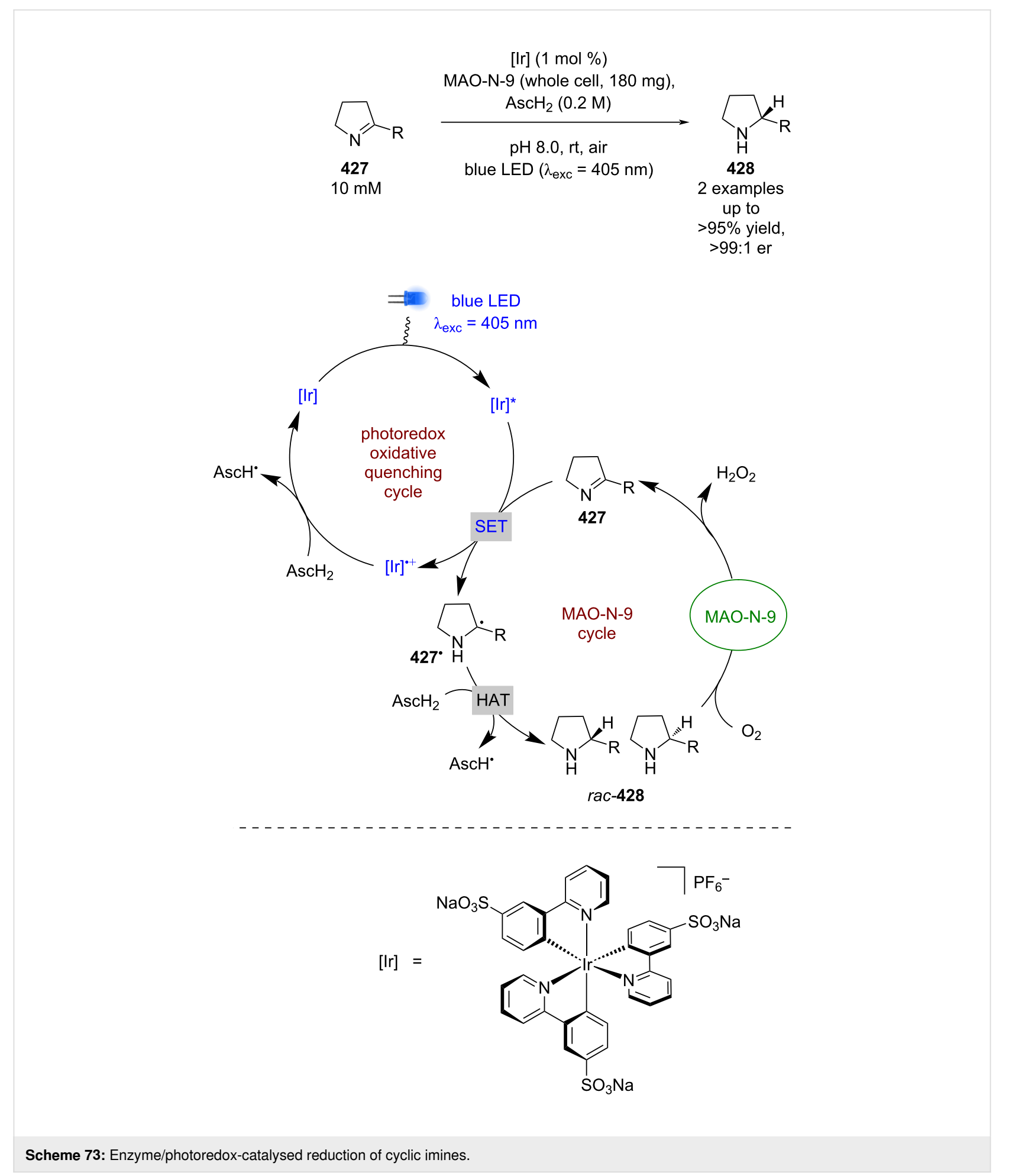

Zhao and Hartwig reported an enantioselective reduction of electron-deficient alkenes (Scheme 74) [170]. To do this, the authors assembled a collection of electron-deficient alkenes 429 that interacted with ERs for the selective reduction of either the $(E)$ or $(Z)$-isomers. Separately, they optimised photoisomerisation conditions using either a flavin (FMN) or iridium-based photocatalyst, which proceeds through an energy transfer process. These reactions were combined for the enantioselective reduction of either the mismatched isomer of the alkene or mixtures of isomers where separation is not possible, in excellent yields and enantioselectivities (16 examples, up to $>99: 1$ er). 

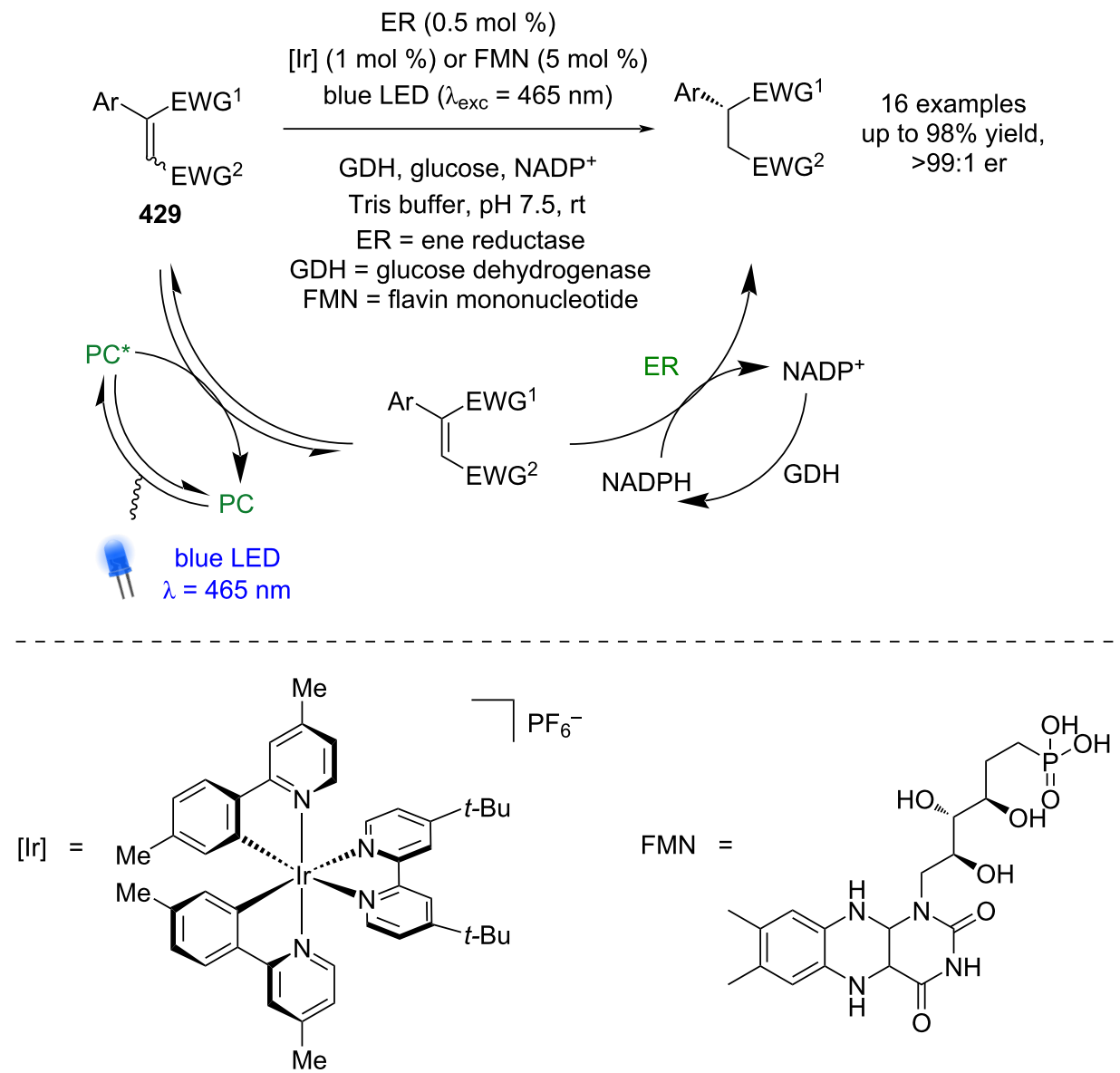

Scheme 74: Enzyme/photocatalysed enantioselective reduction of electron-deficient alkenes as mixtures of $(E) /(Z)$-isomers

A significant challenge in many enantioselective photocatalysed reactions is minimising the amount of racemic background reaction. Hyster et al. proposed that the binding of a substrate by an enzyme could alter its redox properties so that the photoredox step only occurs within the enzyme binding site. They applied this hypothesis to a deacetoxylation reaction of tetralones 430 (Scheme 75a) [171]. The authors propose that Rose Bengal (RB) proceeds through a reductive quenching cycle in the presence of NADPH to give $\mathrm{RB}^{\circ-}$, which then reduces enzyme-bound $\mathbf{4 3 0}$ preferentially over free $\mathbf{4 3 0}$ to give radical anion $\mathbf{4 3 0}^{\circ}$. . Deacetoxylation generates tertiary radical 431 $^{\circ}$ and subsequent enantioselective HAT with NADPH releases enantioenriched tetralone $\mathbf{4 3 1}$ after oxidation of NADP ${ }^{*}$ in good yields and enantioselectivities (12 examples, up to 97:3 er). This methodology was recently expanded to include heteroaromatic alkenes $\mathbf{4 3 2}$ using a similar single electron reduction to alkyl radical $\mathbf{4 3 2}^{\circ}$ followed by ER-mediated enantioselective HAT to give reduced products $\mathbf{4 3 3}$ in excellent yields and enantioselectivities (22 examples, up to $>99: 1$ er) (Scheme 75b) [172].
Guan and He developed a concurrent photooxidation and enzyme-mediated alkylation of indoles 434 with ketones 435 to obtain enantioenriched indole-3-ones $\mathbf{4 3 6}$ using wheat germ lipase (WGL) (Scheme 76) [173]. This reaction is proposed to proceed via a reductive quenching cycle, producing radical cation $\mathbf{4 3 4}^{\bullet+}$ and $[\mathrm{Ru}]^{\bullet-}$, which is then oxidised by $\mathrm{O}_{2}$ to complete the cycle and release $\mathrm{O}_{2}{ }^{--}$. Radical cation $\mathbf{4 3 4}^{\circ+}$ can then trap $\mathrm{O}_{2}{ }^{--}$to form hydroperoxyl intermediate 437, that upon loss of water, is further oxidised to the indole-3-one 438. Within the enzyme active site, $\mathbf{4 3 5}$ can nucleophilically add to $\mathbf{4 3 8}$ to give enantioenriched $\mathbf{4 3 6}$ in good yields and enantioselectivities (19 examples, up to $93: 7$ er).

Enzymes are commonly used for kinetic resolutions of primary amines [174]. However, by nature they are limited to a theoretical 50\% yield; dynamic kinetic resolutions (DKRs) are a common adaptation that can increase the theoretical yield to $100 \%$ but require a mechanism for racemisation of the disfavoured enantiomer. Zhou et al. developed a dual catalytic system for the racemisation of amines 439 using HAT and 
a<smiles>[R]C1C2CCC(C2=O)C1([Y10])OC(C)=O</smiles>

430 $\operatorname{NtDBR}(1 \mathrm{~mol} \%), \mathrm{RB}(0.5 \mathrm{~mol} \%)$
$\operatorname{NADP}^{+}(1 \mathrm{~mol} \%)$

GDH-105, glucose, $\mathrm{pH} 8.0$

green LEDs $\left(\lambda_{\text {exc }}=530 \mathrm{~nm}\right)$

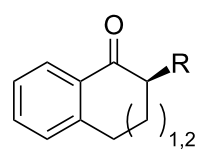

431

12 examples

up to

$85 \%$ yield,

97:3 er

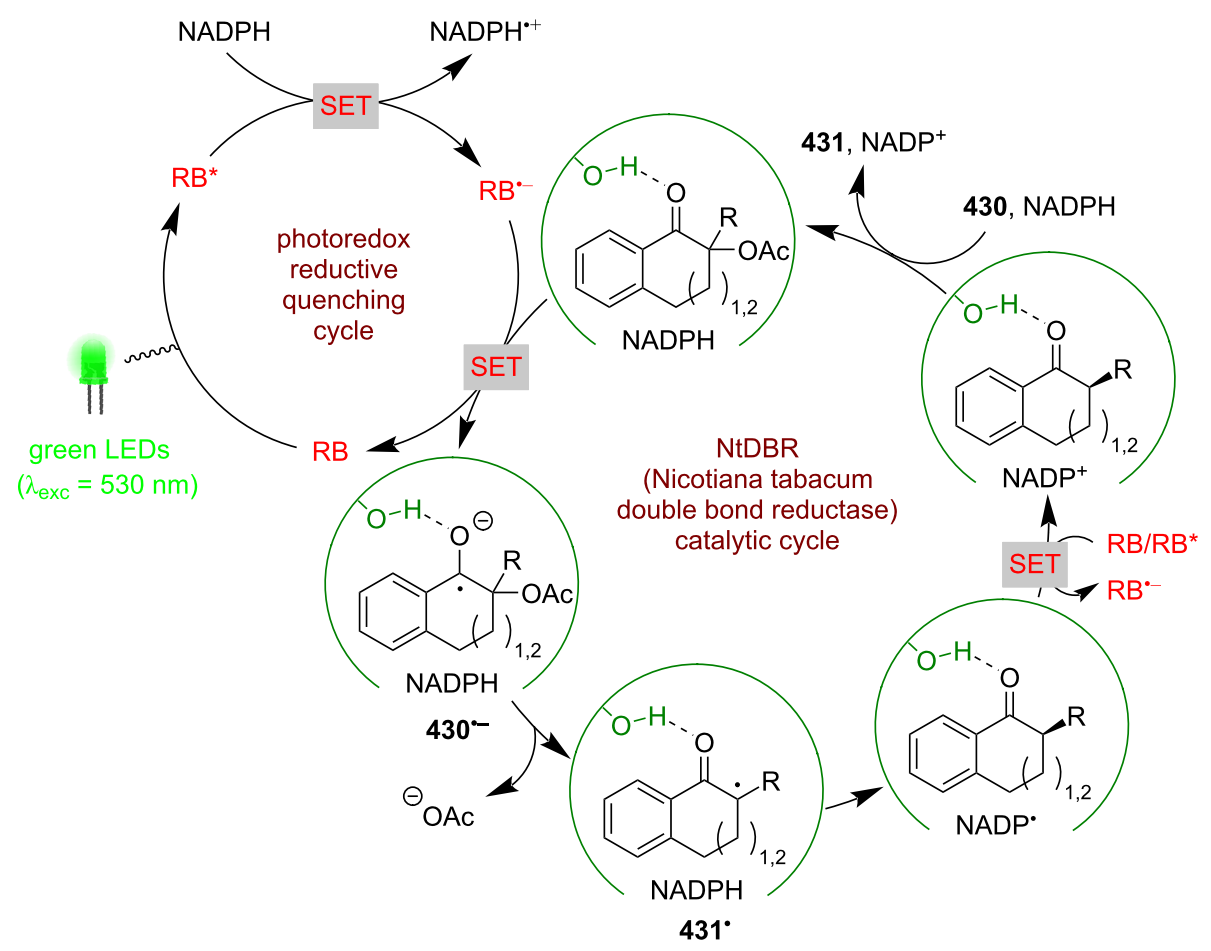

b<smiles>[R]C(=C)[Y]1cc([R])ccn1</smiles>

432 NostocER (1 mol \%)

[Ru] $(0.5 \mathrm{~mol} \%)$ $\operatorname{NADP}^{+}(1 \mathrm{~mol} \%)$

GDH-105, glucose (2 equiv) Tricine (100 mM, pH 9) blue LEDs, $4{ }^{\circ} \mathrm{C}$

via<smiles>[R]c1ccncc1C([R])C</smiles>

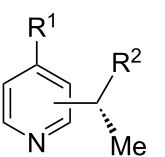

433

22 examples

up to, $99 \%$ yield, $>99: 1$ er

$432^{\circ}$

$[\mathrm{Ru}]=$

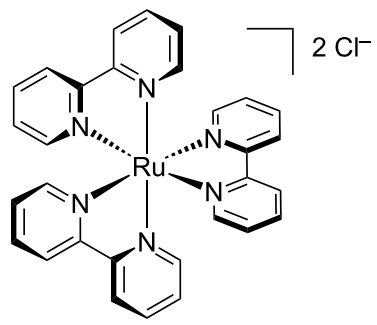

$\mathrm{RB}=$ rose bengal =<smiles>O=C(O)c1c(Cl)c(Cl)c(Cl)c(Cl)c1-c1c2cc(I)c(=O)c(I)c-2oc2c(I)c(O)c(I)cc12</smiles> 
<smiles>[Y]c1cc2ccccc2[nH]1</smiles><smiles>[R]CC([R])=O</smiles>

434
[Ru] $(2 \mathrm{~mol} \%)$, WGL (0.16 $\mathrm{mol} \%)$ white light, $\mathrm{O}_{2}$, rt

WGL $=$ wheat germ lipase

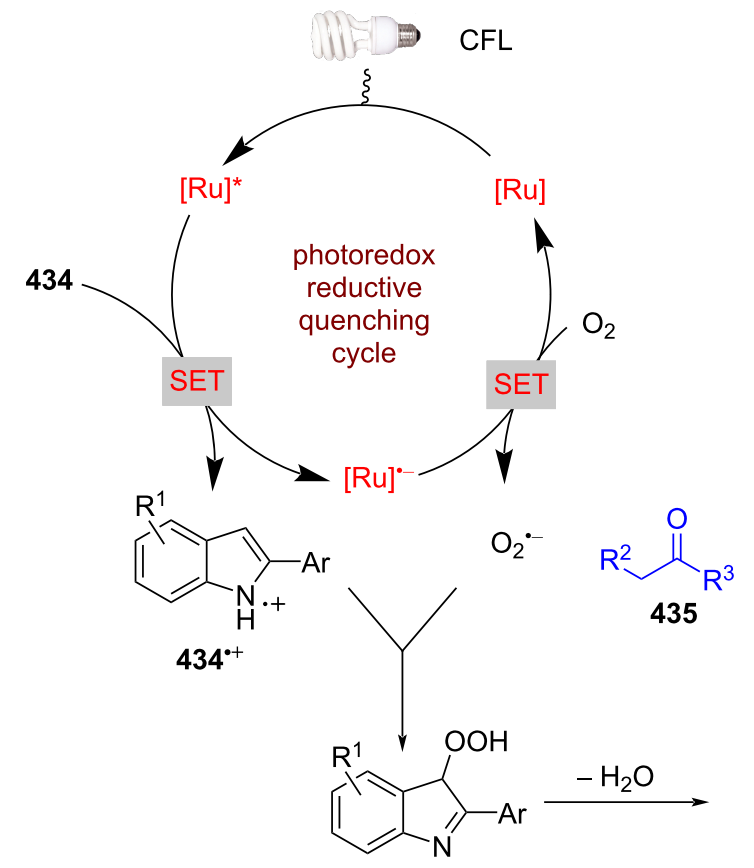

437
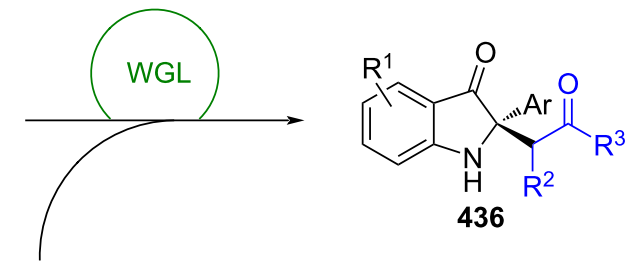

$[\mathrm{Ru}]=$<smiles></smiles>

438<smiles>[R]C(=O)C([R])C1([Al])Nc2ccccc2C1=O</smiles>

436

19 examples

up to

$70 \%$ yield,

$93: 7$ er

$4: 1 \mathrm{dr}$

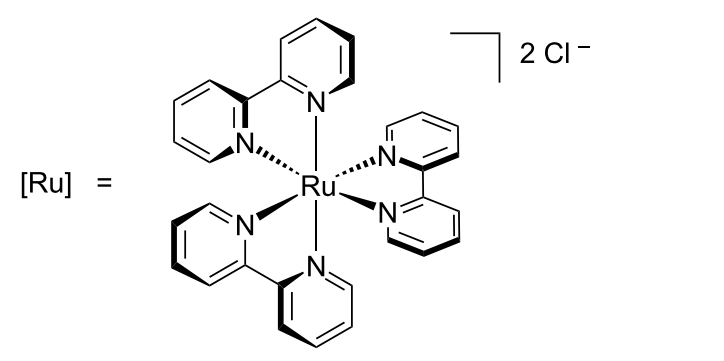

Scheme 76: Enzyme/photoredox-catalysed synthesis of indole-3-ones from 2-arylindoles.

photoredox catalysis [175]. They then combined this with an enzyme-mediated acylation to achieve a DKR of primary amines using Novozym 435 (Scheme 77). The proposed mechanism for this process involves a reductive quenching cycle with $n$-octylthiol to generate thiyl radicals $440^{\circ}$ and release of $\mathrm{H}^{+}$ The thiyl radical $440^{\circ}$ is then implicated in either the turnover of the photocatalyst to regenerate the thiol or abstraction of a hydrogen atom from 439 to give $\alpha$-amino radical $\mathbf{4 3 9}^{\circ}$, which in turn can abstract a hydrogen atom from the thiol to give either enantiomer of $\mathbf{4 3 9}$, setting up a series of equilibria. When used in the presence of the appropriate enzyme and acylating reagent 441, a single enantiomer is preferentially acylated to give enantioenriched amides $\mathbf{4 4 2}$ in excellent yields and enantioselectivities (20 examples, up to $>99: 1$ er).

Cheruzel et al. has synthesised a series of hybrid metalloenzymes to include ruthenium photosensitising units [176,177] and have recently applied them as bifunctional photocatalysts 

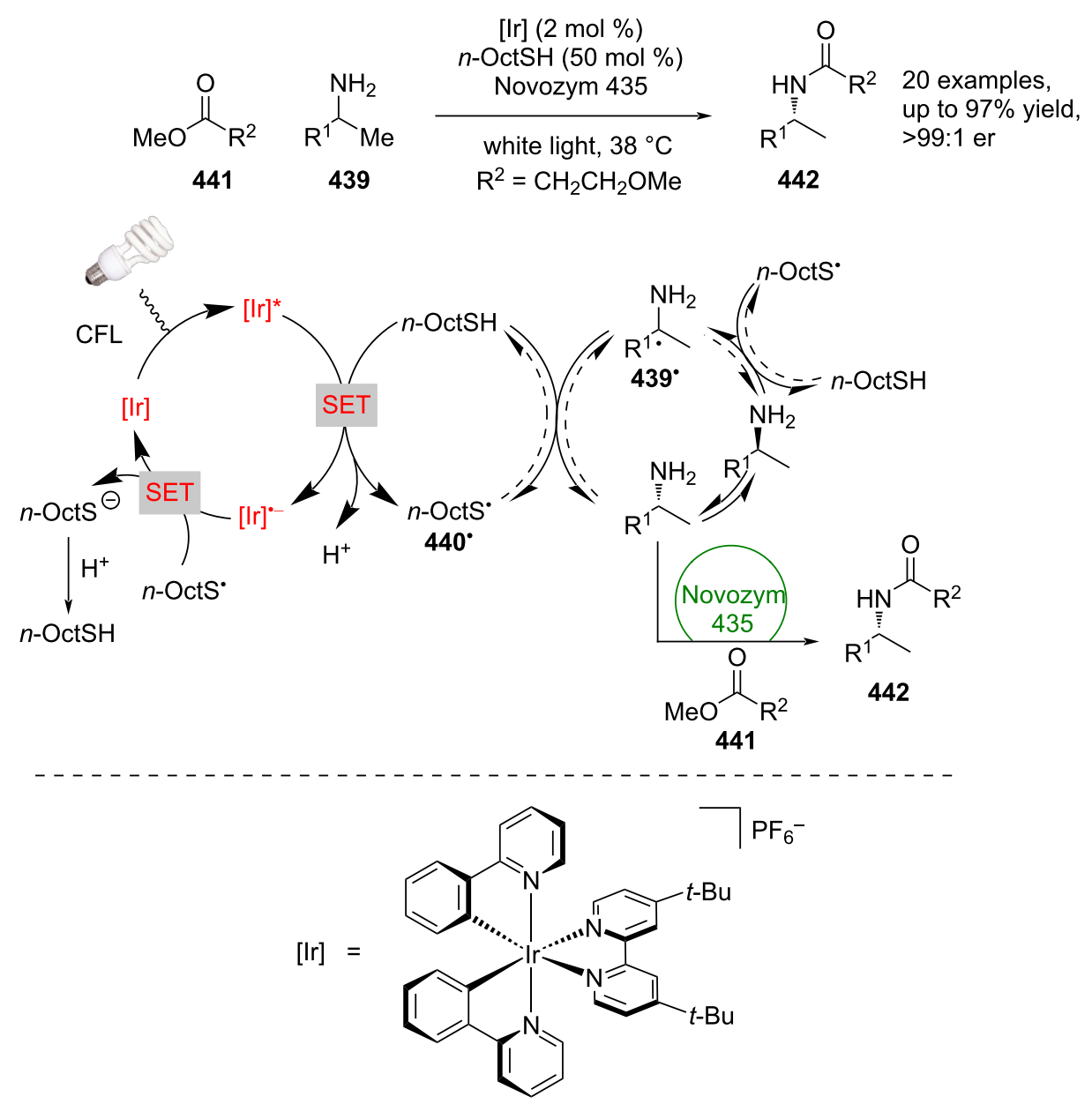

Scheme 77: Enzyme/HAT/photoredox catalysis for the DKR of primary amines.

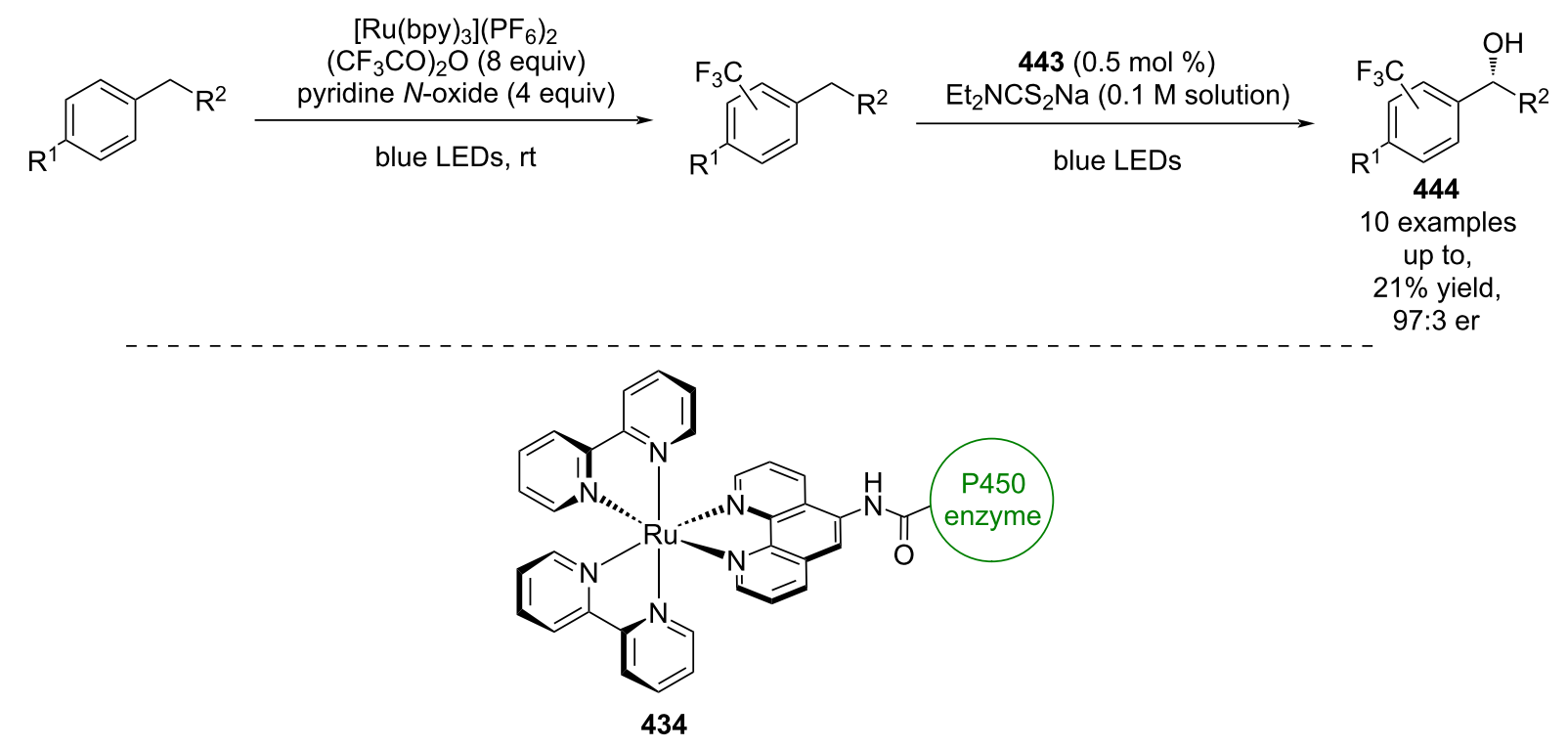

Scheme 78: Bifunctional enzyme/photoredox-catalysed benzylic C-H hydroxylation of trifluoromethylated arenes. 
(Scheme 78) [178]. They combined a known trifluoromethylation reaction, with a hydroxylation catalysed by bifunctional photocatalyst $\mathbf{4 4 3}$ to synthesise alcohols $\mathbf{4 4 4}$. Notably, the initial trifluoromethylation gives a mixture of isomers and the enzyme used can selectively oxidise different isomers, which explains the low yields.

\section{Conclusion}

Over the last 15 years enantioselective photocatalysis has seen tremendous growth. Well-established modes of enantioselective catalysis have been revolutionised by the introduction of photochemical processes, be that altering the behaviour of enzyme systems or utilising familiar catalytic intermediates, such as enamines or metal complexes, with photoredox-generated radicals.

There are certain photochemical processes that are still underutilised in the context of enantioselective photocatalysis. EnT reactions in particular are investigated far less than photoredox catalysis, leading to a field largely dominated by $[2+2]$ cycloadditions with significantly less reaction diversity, even though the works of Bach and Meggers show the potential for greater reaction scope. Comparatively, enantioselective photoredox catalysis is well-established; however, a somewhat limited series of functional groups have been documented as radical precursors in this review, such as tertiary amines, carboxylic acids, and phthalimide esters. Recent developments in photoredox catalysis have allowed for the generation of radicals from much more challenging substrates by increasing the reducing power of the photocatalyst. It is expected that this will carry through to asymmetric catalysis and allow for a wider scope of enantioselective transformations.

Analogously, combinations of photocatalysts with new modes of enantioselective catalysis will also allow for new reactivity, for example, expanding transition metal dual catalysis systems to other metals or further developing existing systems such as NHC dual catalysis. Additionally, while there has been a considerable amount of research carried out using carbonyl-derived substrates, less functionalised starting materials generally have not been investigated to the same degree within enantioselective photocatalysis. Illustrative of this point, of the 114 reactions shown in this review, 92 of them exploit a carbonyl or carbonyl derivative for enantioselectivity.

Most photocatalytic transformations rely on external photocatalysts; however, as exemplified by the works of Melchiorre, Alemán, and others, recognising that substrates or intermediates can be themselves photoactive allows for the simplification of reaction procedures and also for new reactivity. It would be interesting to see further developments in this field by exploiting other potentially photoactive reaction intermediates in the same way.

As previously mentioned, a deeper underpinning understanding of the mechanisms and fundamental photophysics of enantioselective photocatalysis will significantly accelerate the development of new reactions. Therefore, both experimental and computational mechanistic investigations of existing reactions are crucial for the future of this field.

\section{Acknowledgements}

The Graphical abstract was illustrated by Yrral Galura, ykg.illani@gmail.com

\section{Funding}

We thank AstraZeneca for funding (C. P). A.D.S. thanks the Royal Society for a Wolfson Research Merit Award.

\section{ORCID ${ }^{\circledR}$ iDs}

Callum Prentice - https://orcid.org/0000-0002-2083-1499 Andrew D. Smith - https://orcid.org/0000-0002-2104-7313 Eli Zysman-Colman - https://orcid.org/0000-0001-7183-6022

\section{References}

1. Nicewicz, D. A.; MacMillan, D. W. C. Science 2008, 322, 77-80. doi:10.1126/science.1161976

2. Bauer, A.; Westkämper, F.; Grimme, S.; Bach, T. Nature 2005, 436 1139-1140. doi:10.1038/nature03955

3. Fensterbank, L.; Goddard, J.-P.; Ollivier, C. Visible-Light-Mediated Free Radical Synthesis. Visible Light Photocatalysis in Organic Chemistry; John Wiley \& Sons, 2018; pp 25-71. doi:10.1002/9783527674145.ch2

4. Strieth-Kalthoff, F.; James, M. J.; Teders, M.; Pitzer, L.; Glorius, F. Chem. Soc. Rev. 2018, 47, 7190-7202. doi:10.1039/c8cs00054a

5. Brimioulle, R.; Lenhart, D.; Maturi, M. M.; Bach, T. Angew. Chem., Int. Ed. 2015, 54, 3872-3890. doi:10.1002/anie.201411409

6. Jiang, C.; Chen, W.; Zheng, W.-H.; Lu, H. Org. Biomol. Chem. 2019, 17, 8673-8689. doi:10.1039/c9ob01609k

7. Seel, C. J.; Gulder, T. ChemBioChem 2019, 20, 1871-1897. doi:10.1002/cbic.201800806

8. Brenninger, C.; Jolliffe, J. D.; Bach, T. Angew. Chem., Int. Ed. 2018, 57, 14338-14349. doi:10.1002/anie.201804006

9. Huo, H.; Meggersa, E. Chimia 2016, 70, 186-191. doi:10.2533/chimia.2016.186

10. Coote, S. C.; Bach, T. Enantioselective Photocatalysis. Visible Light Photocatalysis in Organic Chemistry; John Wiley \& Sons, 2018; pp 335-361. doi:10.1002/9783527674145.ch11

11. Silvi, M.; Melchiorre, P. Nature 2018, 554, 41-49. doi:10.1038/nature25175

12. Zou, Y.-Q.; Hörmann, F. M.; Bach, T. Chem. Soc. Rev. 2018, 47, 278-290. doi:10.1039/c7cs00509a

13. Burg, F.; Bach, T. J. Org. Chem. 2019, 84, 8815-8836. doi:10.1021/acs.joc.9b01299 
14. Holden, C. M.; Melchiorre, P. Photochemistry and Excited-State Reactivity of Organocatalytic Intermediates. In Photochemistry; Albini, A.; Protti, S., Eds.; Royal Society of Chemistry: Cambridge. U.K., 2019; Vol. 47, pp 344-378. doi:10.1039/9781788016520-00344

15. Zhang, H.-H.; Chen, H.; Zhu, C.; Yu, S. Sci. China: Chem. 2020, 63, 637-647. doi:10.1007/s11426-019-9701-5

16. Saha, D. Chem. - Asian J. 2020, 15, 2129-2152. doi:10.1002/asia.202000525

17. Arokianathar, J. N.; Frost, A. B.; Slawin, A. M. Z.; Stead, D.; Smith, A. D. ACS Catal. 2018, 8, 1153-1160. doi:10.1021/acscatal.7b02697

18. Betori, R. C.; May, C. M.; Scheidt, K. A. Angew. Chem., Int. Ed. 2019, 58, 16490-16494. doi:10.1002/anie.201909426

19. Rostoll-Berenguer, J.; Blay, G.; Muñoz, M. C.; Pedro, J. R.; Vila, C. Org. Lett. 2019, 21, 6011-6015. doi:10.1021/acs.orglett.9b02157

20. Cismesia, M. A.; Yoon, T. P. Chem. Sci. 2015, 6, 5426-5434. doi:10.1039/c5sc02185e

21. Bahamonde, A.; Melchiorre, P. J. Am. Chem. Soc. 2016, 138, 8019-8030. doi:10.1021/jacs.6b04871

22. Zhu, Y.; Zhang, L.; Luo, S. J. Am. Chem. Soc. 2014, 136, 14642-14645. doi:10.1021/ja508605a

23. Nagib, D. A.; Scott, M. E.; MacMillan, D. W. C. J. Am. Chem. Soc. 2009, 131, 10875-10877. doi:10.1021/ja9053338

24. Shih, H.-W.; Vander Wal, M. N.; Grange, R. L.; MacMillan, D. W. C. J. Am. Chem. Soc. 2010, 132, 13600-13603. doi:10.1021/ja106593m

25. Welin, E. R.; Warkentin, A. A.; Conrad, J. C.; MacMillan, D. W. C. Angew. Chem., Int. Ed. 2015, 54, 9668-9672. doi:10.1002/anie.201503789

26. Gualandi, A.; Marchini, M.; Mengozzi, L.; Kidanu, H. T.; Franc, A.; Ceroni, P.; Cozzi, P. G. Eur. J. Org. Chem. 2020, 1187. doi:10.1002/ejoc.201901801

27. Capacci, A. G.; Malinowski, J. T.; McAlpine, N. J.; Kuhne, J.; MacMillan, D. W. C. Nat. Chem. 2017, 9, 1073-1077. doi: $10.1038 /$ nchem. 2797

28. Yang, Q.; Zhang, L.; Ye, C.; Luo, S.; Wu, L.-Z.; Tung, C.-H. Angew. Chem., Int. Ed. 2017, 56, 3694-3698. doi:10.1002/anie.201700572

29. Dong, C.-L.; Ding, X.; Huang, L.-Q.; He, Y.-H.; Guan, Z. Org. Lett. 2020, 22, 1076-1080. doi:10.1021/acs.orglett.9b04613

30. Yang, X.; Xie, Z.; Li, Y.; Zhang, Y. Chem. Sci. 2020, 11, 4741-4746. doi:10.1039/d0sc00683a

31. Rigotti, T.; Casado-Sánchez, A.; Cabrera, S.; Pérez-Ruiz, R.; Liras, M.; de la Peña O'Shea, V. A.; Alemán, J. ACS Catal. 2018, 8, 5928-5940. doi:10.1021/acscatal.8b01331

32. Arceo, E.; Jurberg, I. D.; Álvarez-Fernández, A.; Melchiorre, P. Nat. Chem. 2013, 5, 750-756. doi:10.1038/nchem.1727

33. Arceo, E.; Bahamonde, A.; Bergonzini, G.; Melchiorre, P. Chem. Sci. 2014, 5, 2438-2442. doi:10.1039/c4sc00315b

34. Crisenza, G. E. M.; Mazzarella, D.; Melchiorre, P. J. Am. Chem. Soc. 2020, 142, 5461-5476. doi:10.1021/jacs.0c01416

35. Silvi, M.; Arceo, E.; Jurberg, I. D.; Cassani, C.; Melchiorre, P. J. Am. Chem. Soc. 2015, 137, 6120-6123. doi:10.1021/jacs.5b01662

36. Filippini, G.; Silvi, M.; Melchiorre, P. Angew. Chem., Int. Ed. 2017, 56, 4447-4451. doi:10.1002/anie.201612045

37. Narayanam, J. M. R.; Tucker, J. W.; Stephenson, C. R. J. J. Am. Chem. Soc. 2009, 131, 8756-8757. doi:10.1021/ja9033582

38. Freeman, D. B.; Furst, L.; Condie, A. G.; Stephenson, C. R. J. Org. Lett. 2012, 14, 94-97. doi:10.1021/ol202883v

39. Murphy, J. J.; Bastida, D.; Paria, S.; Fagnoni, M.; Melchiorre, P. Nature 2016, 532, 218-222. doi:10.1038/nature17438
40. Zhao, J.-J.; Zhang, H.-H.; Shen, X.; Yu, S. Org. Lett. 2019, 21, 913-916. doi:10.1021/acs.orglett.8b03840

41. Cao, Z.-Y.; Ghosh, T.; Melchiorre, P. Nat. Commun. 2018, 9, 3274. doi:10.1038/s41467-018-05375-2

42. Silvi, M.; Verrier, C.; Rey, Y. P.; Buzzetti, L.; Melchiorre, P. Nat. Chem. 2017, 9, 868-873. doi:10.1038/nchem.2748

43. Mazzarella, D.; Crisenza, G. E. M.; Melchiorre, P. J. Am. Chem. Soc. 2018, 140, 8439-8443. doi:10.1021/jacs.8b05240

44. Verrier, C.; Alandini, N.; Pezzetta, C.; Moliterno, M.; Buzzetti, L.; Hepburn, H. B.; Vega-Peñaloza, A.; Silvi, M.; Melchiorre, P. ACS Catal. 2018, 8, 1062-1066. doi:10.1021/acscatal.7b03788

45. Goti, G.; Bieszczad, B.; Vega-Peñaloza, A.; Melchiorre, P. Angew. Chem. 2019, 131, 1226-1230. doi:10.1002/ange.201810798

46. Bonilla, P.; Rey, Y. P.; Holden, C. M.; Melchiorre, P. Angew. Chem., Int. Ed. 2018, 57, 12819-12823. doi:10.1002/anie.201808183

47. Perego, L. A.; Bonilla, P.; Melchiorre, P. Adv. Synth. Catal. 2020, 362, 302-307. doi:10.1002/adsc.201900973

48. Hörmann, F. M.; Kerzig, C.; Chung, T. S.; Bauer, A.; Wenger, O. S.; Bach, T. Angew. Chem., Int. Ed. 2020, 59, 9659-9668. doi:10.1002/anie.202001634

49. Rigotti, T.; Mas-Ballesté, R.; Alemán, J. ACS Catal. 2020, 10, 5335-5346. doi:10.1021/acscatal.0c01413

50. Wei, G.; Zhang, C.; Bureš, F.; Ye, X.; Tan, C.-H.; Jiang, Z. ACS Catal. 2016, 6, 3708-3712. doi:10.1021/acscatal.6b00846

51. DiRocco, D. A.; Rovis, T. J. Am. Chem. Soc. 2012, 134, 8094-8097. doi:10.1021/ja3030164

52. Lathrop, S. P.; Rovis, T. Chem. Sci. 2013, 4, 1668. doi:10.1039/c3sc22292f

53. Dai, L.; Ye, S. Org. Lett. 2020, 22, 986-990. doi:10.1021/acs.orglett.9b04533

54. Dai, L.; Xia, Z.-H.; Gao, Y.-Y.; Gao, Z.-H.; Ye, S. Angew. Chem., Int. Ed. 2019, 58, 18124-18130. doi:10.1002/anie.201909017

55. Yang, W.; Hu, W.; Dong, X.; Li, X.; Sun, J. Angew. Chem., Int. Ed. 2016, 55, 15783-15786. doi:10.1002/anie.201608371

56. Mavroskoufis, A.; Rajes, K.; Golz, P.; Agrawal, A.; Ruß, V.; Götze, J. P.; Hopkinson, M. N. Angew. Chem., Int. Ed. 2020, 59, 3190-3194. doi:10.1002/anie.201914456

57. Rono, L. J.; Yayla, H. G.; Wang, D. Y.; Armstrong, M. F.; Knowles, R. R. J. Am. Chem. Soc. 2013, 135, 17735-17738. doi:10.1021/ja4100595

58. Li, S.; Xiang, S.-H.; Tan, B. Chin. J. Chem. 2020, 38, 213-214. doi:10.1002/cjoc.201900472

59. Proctor, R. S. J.; Davis, H. J.; Phipps, R. J. Science 2018, 360, 419-422. doi:10.1126/science.aar6376

60. Yin, Y.; Dai, Y.; Jia, H.; Li, J.; Bu, L.; Qiao, B.; Zhao, X.; Jiang, Z. J. Am. Chem. Soc. 2018, 140, 6083-6087. doi:10.1021/jacs.8b01575

61. Cao, K.; Tan, S. M.; Lee, R.; Yang, S.; Jia, H.; Zhao, X.; Qiao, B.; Jiang, Z. J. Am. Chem. Soc. 2019, 141, 5437-5443. doi:10.1021/jacs.9b00286

62. Liu, X.; Liu, Y.; Chai, G.; Qiao, B.; Zhao, X.; Jiang, Z. Org. Lett. 2018, 20, 6298-6301. doi:10.1021/acs.orglett.8b02791

63. Zheng, D.; Studer, A. Angew. Chem., Int. Ed. 2019, 58, 15803-15807. doi:10.1002/anie.201908987

64. Qiao, B.; Li, C.; Zhao, X.; Yin, Y.; Jiang, Z. Chem. Commun. 2019, 55, 7534-7537. doi:10.1039/c9cc03661j

65. Shao, T.; Li, Y.; Ma, N.; Li, C.; Chai, G.; Zhao, X.; Qiao, B.; Jiang, Z. iScience 2019, 16, 410-419. doi:10.1016/j.isci.2019.06.007 
66. Li, J.; Kong, M.; Qiao, B.; Lee, R.; Zhao, X.; Jiang, Z. Nat. Commun. 2018, 9, 2445. doi:10.1038/s41467-018-04885-3

67. Zeng, G.; Li, Y.; Qiao, B.; Zhao, X.; Jiang, Zhiyong. Chem. Commun. 2019, 55, 11362-11365. doi:10.1039/c9cc05304b

68. Liu, Y.; Liu, X.; Li, J.; Zhao, X.; Qiao, B.; Jiang, Z. Chem. Sci. 2018, 9, 8094-8098. doi:10.1039/c8sc02948b

69. Shao, T.; Yin, Y.; Lee, R.; Zhao, X.; Chai, G.; Jiang, Z. Adv. Synth. Catal. 2018, 360, 1754-1760. doi:10.1002/adsc.201800135

70. Li, J.; Gu, Z.; Zhao, X.; Qiao, B.; Jiang, Z. Chem. Commun. 2019, 55, 12916-12919. doi:10.1039/c9cc07380a

71. Cheng, Y.-Z.; Zhao, Q.-R.; Zhang, X.; You, S.-L. Angew. Chem., Int. Ed. 2019, 58, 18069-18074. doi:10.1002/anie.201911144

72. Pecho, F.; Zou, Y.-Q.; Gramüller, J.; Mori, T.; Huber, S. M.; Bauer, A.; Gschwind, R. M.; Bach, T. Chem. - Eur. J. 2020, 26, 5190-5194. doi:10.1002/chem.202000720

73. Lian, M.; Li, Z.; Cai, Y.; Meng, Q.; Gao, Z. Chem. - Asian J. 2012, 7, 2019-2023. doi:10.1002/asia.201200358

74. Wang, Y.; Zheng, Z.; Lian, M.; Yin, H.; Zhao, J.; Meng, Q.; Gao, Z. Green Chem. 2016, 18, 5493-5499. doi:10.1039/c6gc01245k

75. Wang, Y.; Yin, H.; Tang, X.; Wu, Y.; Meng, Q.; Gao, Z. J. Org. Chem. 2016, 81, 7042-7050. doi:10.1021/acs.joc.6b00856

76. Tang, X.-F.; Zhao, J.-N.; Wu, Y.-F.; Zheng, Z.-H.; Feng, S.-H.; Yu, Z.-Y.; Liu, G.-Z.; Meng, Q.-W. Org. Biomol. Chem. 2019, 17, 7938-7942. doi:10.1039/c9ob01379b

77. Woźniak, Ł.; Murphy, J. J.; Melchiorre, P. J. Am. Chem. Soc. 2015, 137, 5678-5681. doi:10.1021/jacs.5b03243

78. Cauble, D. F.; Lynch, V.; Krische, M. J. J. Org. Chem. 2003, 68, 15-21. doi:10.1021/jo020630e

79. Müller, C.; Bauer, A.; Bach, T. Angew. Chem., Int. Ed. 2009, 48, 6640-6642. doi:10.1002/anie.200901603

80. Müller, C.; Bauer, A.; Maturi, M. M.; Cuquerella, M. C.; Miranda, M. A.; Bach, T. J. Am. Chem. Soc. 2011, 133, 16689-16697. doi:10.1021/ja207480q

81. Alonso, R.; Bach, T. Angew. Chem., Int. Ed. 2014, 53, 4368-4371. doi:10.1002/anie.201310997

82. Maturi, M. M.; Bach, T. Angew. Chem., Int. Ed. 2014, 53, 7661-7664. doi:10.1002/anie.201403885

83. Tröster, A.; Alonso, R.; Bauer, A.; Bach, T. J. Am. Chem. Soc. 2016, 138, 7808-7811. doi:10.1021/jacs.6b03221

84. Li, X.; Jandl, C.; Bach, T. Org. Lett. 2020, 22, 3618-3622. doi:10.1021/acs.orglett.0c01065

85. Hölzl-Hobmeier, A.; Bauer, A.; Silva, A. V.; Huber, S. M.; Bannwarth, C.; Bach, T. Nature 2018, 564, 240-243. doi:10.1038/s41586-018-0755-1

86. Plaza, M.; Jandl, C.; Bach, T. Angew. Chem., Int. Ed. 2020, 59, 12785-12788. doi:10.1002/anie.202004797

87. Wimberger, L.; Kratz, T.; Bach, T. Synthesis 2019, 51, 4417-4424. doi:10.1055/s-0039-1690034

88. Tröster, A.; Bauer, A.; Jandl, C.; Bach, T. Angew. Chem., Int. Ed. 2019, 58, 3538-3541. doi:10.1002/anie.201814193

89. Vallavoju, N.; Selvakumar, S.; Jockusch, S.; Sibi, M. P.; Sivaguru, J. Angew. Chem., Int. Ed. 2014, 53, 5604-5608. doi:10.1002/anie.201310940

90. Skubi, K. L.; Kidd, J. B.; Jung, H.; Guzei, I. A.; Baik, M.-H.; Yoon, T. P. J. Am. Chem. Soc. 2017, 139, 17186-17192. doi:10.1021/jacs.7b10586

91. Skubi, K. L.; Swords, W. B.; Hofstetter, H.; Yoon, T. P. ChemPhotoChem 2020, 4, 685-690. doi:10.1002/cptc.202000094
92. Zheng, J.; Swords, W. B.; Jung, H.; Skubi, K. L.; Kidd, J. B.; Meyer, G. J.; Baik, M.-H.; Yoon, T. P. J. Am. Chem. Soc. 2019, 141, 13625-13634. doi:10.1021/jacs.9b06244

93. Liu, Y.; Li, J.; Ye, X.; Zhao, X.; Jiang, Z. Chem. Commun. 2016, 52, 13955-13958. doi:10.1039/c6cc07105h

94. Griffiths, J.; Chu, K.-Y.; Hawkins, C. J. Chem. Soc., Chem. Commun. 1976, 676-677. doi:10.1039/c39760000676

95. Hou, M.; Lin, L.; Chai, X.; Zhao, X.; Qiao, B.; Jiang, Z. Chem. Sci. 2019, 10, 6629-6634. doi:10.1039/c9sc02000d

96. Lin, L.; Bai, X.; Ye, X.; Zhao, X.; Tan, C.-H.; Jiang, Z. Angew. Chem., Int. Ed. 2017, 56, 13842-13846. doi:10.1002/anie.201707899

97. Shin, N. Y.; Ryss, J. M.; Zhang, X.; Miller, S. J.; Knowles, R. R. Science 2019, 366, 364-369. doi:10.1126/science.aay2204

98. Roos, C. B.; Demaerel, J.; Graff, D. E.; Knowles, R. R. J. Am. Chem. Soc. 2020, 142, 5974-5979. doi:10.1021/jacs.0c01332

99. Shen, M.-L.; Shen, Y.; Wang, P.-S. Org. Lett. 2019, 21, 2993-2997. doi:10.1021/acs.orglett.9b00442

100.Uraguchi, D.; Kinoshita, N.; Kizu, T.; Ooi, T. J. Am. Chem. Soc. 2015, 137, 13768-13771. doi:10.1021/jacs.5b09329

101.Yang, Z.; Li, H.; Li, S.; Zhang, M.-T.; Luo, S. Org. Chem. Front. 2017, 4, 1037-1041. doi:10.1039/c6qo00806b

102. Hamilton, D. S.; Nicewicz, D. A. J. Am. Chem. Soc. 2012, 134, 18577-18580. doi:10.1021/ja309635w

103. Gentry, E. C.; Rono, L. J.; Hale, M. E.; Matsuura, R.; Knowles, R. R. J. Am. Chem. Soc. 2018, 140, 3394-3402. doi:10.1021/jacs.7b13616

104. Morse, P. D.; Nguyen, T. M.; Cruz, C. L.; Nicewicz, D. A. Tetrahedron 2018, 74, 3266-3272. doi:10.1016/j.tet.2018.03.052

105. Mukaiyama, T.; Narasaka, K.; Banno, K. Chem. Lett. 1973, 2 , 1011-1014. doi:10.1246/cl.1973.1011

106. Wadamoto, M.; Ozasa, N.; Yanagisawa, A.; Yamamoto, H. J. Org. Chem. 2003, 68, 5593-5601. doi:10.1021/jo020691c

107.Du, J.; Skubi, K. L.; Schultz, D. M.; Yoon, T. P. Science 2014, 344, 392-396. doi:10.1126/science.1251511

108. Amador, A. G.; Sherbrook, E. M.; Yoon, T. P. J. Am. Chem. Soc. 2016, 138, 4722-4725. doi:10.1021/jacs.6b01728

109. Ruiz Espelt, L.; McPherson, I. S.; Wiensch, E. M.; Yoon, T. P. J. Am. Chem. Soc. 2015, 137, 2452-2455. doi:10.1021/ja512746q

110. Ruiz Espelt, L.; Wiensch, E. M.; Yoon, T. P. J. Org. Chem. 2013, 78, 4107-4114. doi:10.1021/j0400428m

111.Pagire, S. K.; Kumagai, N.; Shibasaki, M. Chem. Sci. 2020, 11, 5168-5174. doi:10.1039/d0sc01890b

112.Ye, C.-X.; Melcamu, Y. Y.; Li, H.-H.; Cheng, J.-T.; Zhang, T.-T.; Ruan, Y.-P.; Zheng, X.; Lu, X.; Huang, P.-Q. Nat. Commun. 2018, 9 , 410. doi:10.1038/s41467-017-02698-4

113. Miller, Z. D.; Lee, B. J.; Yoon, T. P. Angew. Chem., Int. Ed. 2017, 56, 11891-11895. doi:10.1002/anie.201706975

114. Blum, T. R.; Miller, Z. D.; Bates, D. M.; Guzei, I. A.; Yoon, T. P. Science 2016, 354, 1391-1395. doi:10.1126/science.aai8228

115. Huo, H.; Harms, K.; Meggers, E. J. Am. Chem. Soc. 2016, 138, 6936-6939. doi:10.1021/jacs.6b03399

116. Steinlandt, P. S.; Zuo, W.; Harms, K.; Meggers, E. Chem. - Eur. J. 2019, 25, 15333-15340. doi:10.1002/chem.201903369

117. Huang, X.; Webster, R. D.; Harms, K.; Meggers, E. J. Am. Chem. Soc. 2016, 138, 12636-12642. doi:10.1021/jacs.6b07692

118.Kuang, Y.; Wang, K.; Shi, X.; Huang, X.; Meggers, E.; Wu, J. Angew. Chem., Int. Ed. 2019, 58, 16859-16863. doi:10.1002/anie.201910414 
119.Huang, X.; Lin, J.; Shen, T.; Harms, K.; Marchini, M.; Ceroni, P.; Meggers, E. Angew. Chem., Int. Ed. 2018, 57, 5454-5458. doi:10.1002/anie.201802316

120.Huang, X.; Meggers, E. Acc. Chem. Res. 2019, 52, 833-847. doi:10.1021/acs.accounts.9b00028

121.Liang, H.; Xu, G.-Q.; Feng, Z.-T.; Wang, Z.-Y.; Xu, P.-F. J. Org. Chem. 2019, 84, 60-72. doi:10.1021/acs.joc.8b02316

122.Zhou, Z.; Nie, X.; Harms, K.; Riedel, R.; Zhang, L.; Meggers, E. Sci. China: Chem. 2019, 62, 1512-1518. doi:10.1007/s11426-019-9584-X

123.Zhang, C.; Chen, S.; Ye, C.-X.; Harms, K.; Zhang, L.; Houk, K. N.; Meggers, E. Angew. Chem., Int. Ed. 2019, 58, 14462-14466. doi:10.1002/anie.201905647

124.Zhang, K.; Lu, L.-Q.; Jia, Y.; Wang, Y.; Lu, F.-D.; Pan, F.; Xiao, W.-J. Angew. Chem., Int. Ed. 2019, 58, 13375-13379. doi:10.1002/anie.201907478

125.Ding, W.; Lu, L.-Q.; Zhou, Q.-Q.; Wei, Y.; Chen, J.-R.; Xiao, W.-J. J. Am. Chem. Soc. 2017, 139, 63-66. doi:10.1021/jacs.6b11418

126. Liu, J.; Ding, W.; Zhou, Q.-Q.; Liu, D.; Lu, L.-Q.; Xiao, W.-J. Org. Lett. 2018, 20, 461-464. doi:10.1021/acs.orglett.7b03826

127.Li, Y.; Zhou, K.; Wen, Z.; Cao, S.; Shen, X.; Lei, M.; Gong, L. J. Am. Chem. Soc. 2018, 140, 15850-15858. doi:10.1021/jacs.8b09251

128. Han, B.; Li, Y.; Yu, Y.; Gong, L. Nat. Commun. 2019, 10, 3804. doi:10.1038/s41467-019-11688-7

129. Li, Y.; Lei, M.; Gong, L. Nat. Catal. 2019, 2, 1016-1026. doi:10.1038/s41929-019-0357-9

130.Lewis, F. D.; Howard, D. K.; Oxman, J. D. J. Am. Chem. Soc. 1983, 105, 3344-3345. doi:10.1021/ja00348a069

131.Lewis, F. D.; Barancyk, S. V. J. Am. Chem. Soc. 1989, 111, 8653-8661. doi:10.1021/ja00205a015

132. Guo, H.; Herdtweck, E.; Bach, T. Angew. Chem., Int. Ed. 2010, 49, 7782-7785. doi:10.1002/anie.201003619

133. Brimioulle, R.; Bauer, A.; Bach, T. J. Am. Chem. Soc. 2015, 137, 5170-5176. doi:10.1021/jacs.5b01740

134. Brimioulle, R.; Bach, T. Science 2013, 342, 840-843. doi:10.1126/science.1244809

135. Poplata, S.; Bach, T. J. Am. Chem. Soc. 2018, 140, 3228-3231. doi:10.1021/jacs.8b01011

136. Stegbauer, S.; Jandl, C.; Bach, T. Angew. Chem., Int. Ed. 2018, 57, 14593-14596. doi:10.1002/anie.201808919

137.Leverenz, M.; Merten, C.; Dreuw, A.; Bach, T. J. Am. Chem. Soc. 2019, 141, 20053-20057. doi:10.1021/jacs.9b12068

138.Daub, M. E.; Jung, H.; Lee, B. J.; Won, J.; Baik, M.-H.; Yoon, T. P. J. Am. Chem. Soc. 2019, 141, 9543-9547. doi:10.1021/jacs.9b04643

139.De Abreu, M.; Belmont, P.; Brachet, E. Eur. J. Org. Chem. 2020, 1327-1378. doi:10.1002/ejoc.201901146

140.Twilton, J.; Le, C.; Zhang, P.; Shaw, M. H.; Evans, R. W.; MacMillan, D. W. C. Nat. Rev. Chem. 2017, 1, 0052. doi:10.1038/s41570-017-0052

141.Gui, Y.-Y.; Sun, L.; Lu, Z.-P.; Yu, D.-G. Org. Chem. Front. 2016, 3, 522-526. doi:10.1039/c5qo00437c

142. Tellis, J. C.; Kelly, C. B.; Primer, D. N.; Jouffroy, M.; Patel, N. R.; Molander, G. A. Acc. Chem. Res. 2016, 49, 1429-1439. doi:10.1021/acs.accounts.6b00214

143.Zuo, Z.; Cong, H.; Li, W.; Choi, J.; Fu, G. C.; MacMillan, D. W. C. J. Am. Chem. Soc. 2016, 138, 1832-1835. doi:10.1021/jacs.5b13211

144.Cheng, X.; Lu, H.; Lu, Z. Nat. Commun. 2019, 10, 3549. doi:10.1038/s41467-019-11392-6
145. Pezzetta, C.; Bonifazi, D.; Davidson, R. W. M. Org. Lett. 2019, 21 , 8957-8961. doi:10.1021/acs.orglett.9b03338

146.Shen, Y.; Gu, Y.; Martin, R. J. Am. Chem. Soc. 2018, 140, 12200-12209. doi:10.1021/jacs.8b07405

147.Stache, E. E.; Rovis, T.; Doyle, A. G. Angew. Chem., Int. Ed. 2017, 56, 3679-3683. doi:10.1002/anie.201700097

148. Guan, H.; Zhang, Q.; Walsh, P. J.; Mao, J. Angew. Chem., Int. Ed. 2020, 59, 5172-5177. doi:10.1002/anie.201914175

149.Rand, A. W.; Yin, H.; Xu, L.; Giacoboni, J.; Martin-Montero, R.; Romano, C.; Montgomery, J.; Martin, R. ACS Catal. 2020, 10, 4671-4676. doi:10.1021/acscatal.0c01318

150. Esposti, S.; Dondi, D.; Fagnoni, M.; Albini, A. Angew. Chem., Int. Ed. 2007, 46, 2531-2534. doi:10.1002/anie.200604820

151.Fan, P.; Lan, Y.; Zhang, C.; Wang, C. J. Am. Chem. Soc. 2020, 142, 2180-2186. doi:10.1021/jacs.9b12554

152. Perry, I. B.; Brewer, T. F.; Sarver, P. J.; Schultz, D. M.; DiRocco, D. A.; MacMillan, D. W. C. Nature 2018, 560, 70-75. doi:10.1038/s41586-018-0366-x

153. Yuan, M.; Song, Z.; Badir, S. O.; Molander, G. A.; Gutierrez, O. J. Am. Chem. Soc. 2020, 142, 7225-7234. doi:10.1021/jacs.0c02355

154.Kainz, Q. M.; Matier, C. D.; Bartoszewicz, A.; Zultanski, S. L.; Peters, J. C.; Fu, G. C. Science 2016, 351, 681-684. doi:10.1126/science.aad8313

155.Zhang, Y.; Sun, Y.; Chen, B.; Xu, M.; Li, C.; Zhang, D.; Zhang, G. Org. Lett. 2020, 22, 1490-1494. doi:10.1021/acs.orglett.0c00071

156.Wang, D.; Zhu, N.; Chen, P.; Lin, Z.; Liu, G. J. Am. Chem. Soc. 2017, 139, 15632-15635. doi:10.1021/jacs.7b09802

157.Zhang, W.; Wang, F.; McCann, S. D.; Wang, D.; Chen, P.; Stahl, S. S.; Liu, G. Science 2016, 353, 1014-1018. doi:10.1126/science.aaf7783

158.Lu, F.-D.; Liu, D.; Zhu, L.; Lu, L.-Q.; Yang, Q.; Zhou, Q.-Q.; Wei, Y.; Lan, Y.; Xiao, W.-J. J. Am. Chem. Soc. 2019, 141, 6167-6172. doi:10.1021/jacs.9b02338

159.Chen, J.; Wang, P.-Z.; Lu, B.; Liang, D.; Yu, X.-Y.; Xiao, W.-J.; Chen, J.-R. Org. Lett. 2019, 21, 9763-9768. doi:10.1021/acs.orglett.9b03970

160.Sha, W.; Deng, L.; Ni, S.; Mei, H.; Han, J.; Pan, Y. ACS Catal. 2018, 8, 7489-7494. doi:10.1021/acscatal.8b01863

161.Guo, Q.; Wang, M.; Peng, Q.; Huo, Y.; Liu, Q.; Wang, R.; Xu, Z. ACS Catal. 2019, 9, 4470-4476. doi:10.1021/acscatal.9b00209

162.Zhang, H.-H.; Zhao, J.-J.; Yu, S. J. Am. Chem. Soc. 2018, 140, 16914-16919. doi:10.1021/jacs.8b10766

163.Zhang, H.-H.; Zhao, J.-J.; Yu, S. ACS Catal. 2020, 10, 4710-4716. doi:10.1021/acscatal.0c00871

164.Shen, D.; Saracini, C.; Lee, Y.-M.; Sun, W.; Fukuzumi, S.; Nam, W. J. Am. Chem. Soc. 2016, 138, 15857-15860. doi:10.1021/jacs.6b10836

165. Mitsunuma, H.; Tanabe, S.; Fuse, H.; Ohkubo, K.; Kanai, M. Chem. Sci. 2019, 10, 3459-3465. doi:10.1039/c8sc05677c

166. Bornscheuer, U. T.; Kazlauskas, R. J. Enzymatic Catalytic Promiscuity and the Design of New Enzyme Catalyzed Reactions. Enzyme Catalysis in Organic Synthesis; John Wiley \& Sons, 2012; pp 1693-1733. doi:10.1002/9783527639861.ch41

167. Emmanuel, M. A.; Greenberg, N. R.; Oblinsky, D. G.; Hyster, T. K. Nature 2016, 540, 414-417. doi:10.1038/nature20569

168. Biegasiewicz, K. F.; Cooper, S. J.; Gao, X.; Oblinsky, D. G.; Kim, J. H.; Garfinkle, S. E.; Joyce, L. A.; Sandoval, B. A.; Scholes, G. D.; Hyster, T. K. Science 2019, 364, 1166-1169. doi:10.1126/science.aaw1143 
169.Guo, X.; Okamoto, Y.; Schreier, M. R.; Ward, T. R.; Wenger, O. S. Chem. Sci. 2018, 9, 5052-5056. doi:10.1039/c8sc01561a

170.Litman, Z. C.; Wang, Y.; Zhao, H.; Hartwig, J. F. Nature 2018, 560 355-359. doi:10.1038/s41586-018-0413-7

171.Biegasiewicz, K. F.; Cooper, S. J.; Emmanuel, M. A.; Miller, D. C.; Hyster, T. K. Nat. Chem. 2018, 10, 770-775. doi:10.1038/s41557-018-0059-y

172. Nakano, Y.; Black, M. J.; Meichan, A. J.; Sandoval, B. A.; Chung, M. M.; Biegasiewicz, K. F.; Zhu, T.; Hyster, T. K. Angew. Chem., Int. Ed. 2020, 59, 10484-10488. doi:10.1002/anie.202003125

173.Ding, X.; Dong, C.-L.; Guan, Z.; He, Y.-H. Angew. Chem., Int. Ed. 2019, 58, 118-124. doi:10.1002/anie.201811085

174.van den Wittenboer, A.; Hilterhaus, L.; Liese, A. Industrial Applications of Enzymes in Emerging Areas. Enzyme Catalysis in Organic Synthesis; John Wiley \& Sons, 2012; pp 1837-1846. doi:10.1002/9783527639861.ch45

175.Yang, Q.; Zhao, F.; Zhang, N.; Liu, M.; Hu, H.; Zhang, J.; Zhou, S. Chem. Commun. 2018, 54, 14065-14068. doi:10.1039/c8cc07990k

176. Ener, M. E.; Lee, Y.-T.; Winkler, J. R.; Gray, H. B.; Cheruzel, L. Proc. Natl. Acad. Sci. U. S. A. 2010, 107, 18783-18786. doi:10.1073/pnas.1012381107

177.Tran, N.-H.; Nguyen, D.; Dwaraknath, S.; Mahadevan, S.; Chavez, G.; Nguyen, A.; Dao, T.; Mullen, S.; Nguyen, T.-A.; Cheruzel, L. E. J. Am. Chem. Soc. 2013, 135, 14484-14487. doi:10.1021/ja409337v

178.Sosa, V.; Melkie, M.; Sulca, C.; Li, J.; Tang, L.; Li, J.; Faris, J.; Foley, B.; Banh, T.; Kato, M.; Cheruzel, L. E. ACS Catal. 2018, 8, 2225-2229. doi:10.1021/acscatal.7b04160

\section{License and Terms}

This is an Open Access article under the terms of the Creative Commons Attribution License (https://creativecommons.org/licenses/by/4.0). Please note that the reuse, redistribution and reproduction in particular requires that the authors and source are credited.

The license is subject to the Beilstein Journal of Organic Chemistry terms and conditions:

(https://www.beilstein-journals.org/bjoc)

The definitive version of this article is the electronic one which can be found at:

$\underline{\text { https://doi.org/10.3762/bjoc.16.197 }}$ 